\title{
A review of marine geomorphometry, the quantitative study of the seafloor
}

\author{
Vincent Lecours ${ }^{1}$, Margaret F. J. Dolan ${ }^{2}$, Aaron Micallef ${ }^{3}$, and Vanessa L. Lucieer ${ }^{4}$ \\ ${ }^{1}$ Marine Geomatics Research Lab, Department of Geography, Memorial University of Newfoundland, \\ St. John's, A1B 3X9, Canada \\ ${ }^{2}$ Geological Survey of Norway, P.O. Box 6315 Sluppen, 7491 Trondheim, Norway \\ ${ }^{3}$ Marine Geology and Seafloor Surveying, Department of Geosciences, University of Malta, Msida, MSD 2080, Malta \\ ${ }^{4}$ Institute for Marine and Antarctic Studies, University of Tasmania, Hobart, 7004, Australia \\ Correspondence to: Vincent Lecours (vlecours@mun.ca)
}

Received: 12 February 2016 - Published in Hydrol. Earth Syst. Sci. Discuss.: 1 March 2016

Revised: 4 July 2016 - Accepted: 17 July 2016 - Published: 9 August 2016

\begin{abstract}
Geomorphometry, the science of quantitative terrain characterization, has traditionally focused on the investigation of terrestrial landscapes. However, the dramatic increase in the availability of digital bathymetric data and the increasing ease by which geomorphometry can be investigated using geographic information systems (GISs) and spatial analysis software has prompted interest in employing geomorphometric techniques to investigate the marine environment. Over the last decade or so, a multitude of geomorphometric techniques (e.g. terrain attributes, feature extraction, automated classification) have been applied to characterize seabed terrain from the coastal zone to the deep sea. Geomorphometric techniques are, however, not as varied, nor as extensively applied, in marine as they are in terrestrial environments. This is at least partly due to difficulties associated with capturing, classifying, and validating terrain characteristics underwater. There is, nevertheless, much common ground between terrestrial and marine geomorphometry applications and it is important that, in developing marine geomorphometry, we learn from experiences in terrestrial studies. However, not all terrestrial solutions can be adopted by marine geomorphometric studies since the dynamic, fourdimensional (4-D) nature of the marine environment causes its own issues throughout the geomorphometry workflow. For instance, issues with underwater positioning, variations in sound velocity in the water column affecting acousticbased mapping, and our inability to directly observe and measure depth and morphological features on the seafloor are all issues specific to the application of geomorphome-
\end{abstract}

try in the marine environment. Such issues fuel the need for a dedicated scientific effort in marine geomorphometry.

This review aims to highlight the relatively recent growth of marine geomorphometry as a distinct discipline, and offers the first comprehensive overview of marine geomorphometry to date. We address all the five main steps of geomorphometry, from data collection to the application of terrain attributes and features. We focus on how these steps are relevant to marine geomorphometry and also highlight differences and similarities from terrestrial geomorphometry. We conclude with recommendations and reflections on the future of marine geomorphometry. To ensure that geomorphometry is used and developed to its full potential, there is a need to increase awareness of (1) marine geomorphometry amongst scientists already engaged in terrestrial geomorphometry, and of (2) geomorphometry as a science amongst marine scientists with a wide range of backgrounds and experiences.

\section{Introduction}

\subsection{Background}

Studies of geomorphology have improved our understanding of many of the Earth's systems and surface processes (Smith et al., 2011; Bishop et al., 2012). Morphology and quantitative measures of topography are considered the most important components of geomorphology because they represent the age and origin of the landscape (Speight, 1974; Minár and 
Evans, 2008; Bishop et al., 2012). The shapes of the terrestrial landscape are important for many Earth systems across a range of scales. For instance, broadscale features such as mountains and valleys may dictate weather patterns (Dimri et al., 2013), vegetation and biodiversity patterns (Anderson and Ferree, 2010), and hydrological processes (Iordanishvili, 2000), while fine-scale features such as local slope may influence soil stability (Buscarnera and Di Prisco, 2013) or influence nest-site selection by certain bird species (Whittingham et al., 2002). Overall, topography is known to influence gradients in moisture, energy, and nutrients across the landscape (Hengl and MacMillan, 2009). Likewise, the oceans play a fundamental role in the Earth system at multiple scales. Knowledge of seafloor topography is also crucial for many subjects (Smith, 2004). For example, seafloor topography, or bathymetry, influences surface currents (Gille et al., 2004), near-bottom currents (White et al., 2007), and ocean mixing rates (Kunze and Llewellyn Smith, 2004). Lack of knowledge on factors influenced by bathymetry can affect the efficacy of model predictions, for example models of marine species distributions (McArthur et al., 2010), climate (Jayne et al., 2004), or the paths of floating objects like marine debris (Smith and Marks, 2014).

It is commonly stated that $90 \%$ of the global ocean is unexplored (e.g. Gjerde, 2006) and that more is known about the surface of Earth's Moon, Mars, Mercury, or Venus than about the ocean floor (Sandwell et al., 2002; Smith and Marks, 2014). However, such statements mean little without further specification or elaboration on their real meaning in relation to objectives, data types and spatial resolution. The entire ocean floor has been mapped to a resolution of a few kilometres using satellites, which has created an estimated surface of global bathymetry (Smith and Sandwell, 1994). However, these coarse-resolution data are often inadequate for many scientific, economic, public safety, and management purposes. Applications such as tsunami hazard assessment, submarine cable and pipeline route planning, resource exploration, habitat mapping, territorial claims, navigation, and ocean circulation and climate studies all require more reliable, fine-scale bathymetric data (i.e. finer than $5 \mathrm{~km}$ ) (Sandwell et al., 2002).

Fuelled by advancements in remote sensing and geographic information systems (GISs) (e.g. Grohmann, 2004), the field of geomorphometry has entered a new era in recent decades (Evans and Minár, 2011; Florinsky, 2012). Geomorphometry is defined as the science on which quantitative measurements of terrain morphology are based, with foundations in geosciences, mathematics, and computer sciences (Chorley et al., 1957; Mark, 1975; Pike et al., 2009). It can be divided into two sub-fields: general geomorphometry (e.g. Minár et al., 2013), and specific geomorphometry (e.g. Drăguţ and Blaschke, 2006). General geomorphometry deals with continuous surfaces in order to extract terrain attributes (e.g. slope, aspect, rugosity), while specific geomorphometry aims at characterizing or extracting discrete landforms (Evans, 1972). The science of geomorphometry, including its theories, methods, algorithms, and tools, was mainly developed and tested on artificial (e.g. Jones, 1998; Qin et al., 2013), terrestrial (e.g. Grohmann, 2015; RigolSanchez et al., 2015), and extra-terrestrial settings (e.g. Li et al., 2014; Podobnikar and Székely, 2015). These methods are relevant for underwater applications and have been increasingly used in the last decade (Lecours et al., 2015a), but differences in the nature of the input data (e.g. no need to hydrologically correct the surface model, little to no ability to validate measurements on the terrain) can sometimes produce different results than expected from land-based studies, creating the additional need for a dedicated scientific effort in marine geomorphometry. To our knowledge, no review on the state-of-the-art of marine geomorphometry has ever been written.

This contribution aims to raise awareness of the relatively recent field of marine geomorphometry by providing an overview of current practices and application areas and summarising the relevant literature to date. We first discuss the gradual rise in the application and development of marine geomorphometry (Sect. 1.2), from the first marine geophysical applications to the latest developments in marine habitat mapping and geomorphology. The paper then addresses the five main steps of geomorphometry identified by Pike et al. (2009) and adopted by the community (Bishop et al., 2012), with a focus on how these steps are relevant to marine geomorphometry and different from traditional, terrestrial geomorphometry (Fig. 1). Section 2 reviews the first step of the geomorphometry workflow, which is to sample the surface. The characteristics of bathymetric data collected from four types of remote sensing techniques are described: satellite radar altimetry, optical remote sensing, acoustic remote sensing, and lidar (light detection and ranging). Section 3, addressing the step in which we need to generate a surface model from the sampled heights, discusses elements that have implications on how the seafloor is represented as data, including the interpolation methods used to create models and the spatial scale (i.e. spatial resolution and extent) at which to generate them. Section 4 addresses the preprocessing step that corresponds to making the surface model ready for the next step, surface analysis, which is reviewed in Sect. 5. The pre-processing of the surface model involves the correction for errors, artefacts, and erroneous data in the surface model. The analysis of the surface is the core of the geomorphometric workflow and consists in deriving terrain attributes and terrain features (or objects). Finally, the last step of this workflow is the use of the derived terrain attributes or features for a particular problem or application. The main disciplines in which marine geomorphometry has been applied and developed are examined in Sect. 6, and we also suggest other fields of research and applications that could benefit from the integration of marine geomorphometry in their practices. We conclude this review with recommenda- 


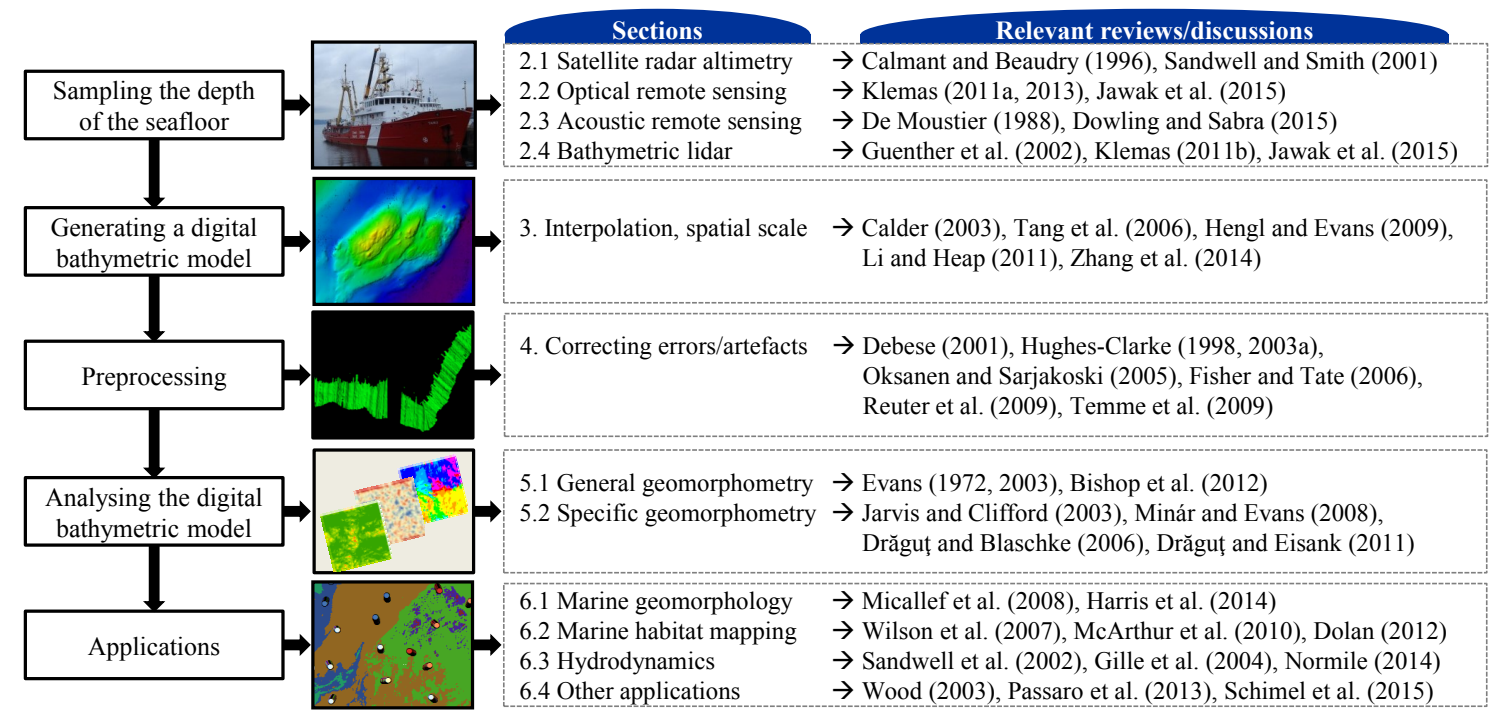

Figure 1. Geomorphometry is commonly implemented in five steps (Pike et al., 2009; Bishop et al., 2012), here adapted to the application of geomorphometry to the marine environment (left). The panels on the right describe the structure and elements addressed in Sects. 2 to 6 of this paper, and list reviews and important discussion papers on these elements.

tions and reflections on the future of marine geomorphometry.

\subsection{The rise of marine geomorphometry}

The science of geomorphometry has roots in morphography, hypsometry, cartometric, geophysics, and geomorphology (Pike et al., 2009; Evans and Minár, 2011; Evans, 2013). Following the increase in digital terrain models (DTMs) availability in the 1960s, the underlying theories and mathematical developments of modern geomorphometry (i.e. based on quantitative measurements rather than qualitative observations derived from DTMs) started to be developed in the early 1970s (e.g. Carson and Kirby, 1972; Evans, 1972; Krcho, 1973; Schabber et al., 1979). These methods and algorithms were gradually automated in the 1980s as computers became more available (e.g. Horn, 1981; Imhof, 1982; Pike, 1988). However, constraints in computing power (Burrough, 1986) delayed the rapid expansion of geomorphometry until the early 1990s (Pike et al., 2009). As mentioned in recent reviews (e.g. Gessler et al., 2009; Evans and Minár, 2011, p. 105), the field of modern geomorphometry is a "young field" that is "still forming, with many concepts, methods and applications."

In the marine environment, early geophysical research that studied the link between the shape of the seafloor and elements such as global tectonics (Parsons and Scalter, 1977; Wessel and Chandler, 2011; references therein) led the way to the more recent marine applications of modern geomorphometry. The first applications of quantitative measurements derived from marine DTMs came from the field of marine geomorphology (e.g. Czarnecki and Bergin,
1986; Shaw and Smith, 1987, 1990; Malinverno, 1990; Goff, 1992, 2001), and was sometimes referred to as mathematical morphology or geology, or simply seafloor classification (Herzfeld, 1993). Then, the realization that different characteristics of seabed morphology was often linked to species distribution and biodiversity (e.g. Burrows et al., 2003; Giannoulaki et al., 2006), combined with the increased availability of higher-resolution bathymetric data (Smith and McConnaughey, 2016), opened a wide range of possibilities for marine habitat mapping in the mid-2000s (Bakran-Petriocili et al., 2006; Lundblad et al., 2006; Wilson et al., 2007). As discussed in Sect. 6, these two applications are still leading research areas in marine geomorphometry, as new applications slowly emerge. While qualitative descriptions of terrain morphology from DTMs are common in the literature (e.g. in geophysics), the current review focuses on modern geomorphometry, i.e. the extraction of quantitative information from depth models to describe terrain characteristics.

Figure 2 compares the increase in publications in both marine and terrestrial (and potentially extra-terrestrial) geomorphometry over time. The numbers illustrate that marine applications of geomorphometry are more recent and less numerous than their terrestrial counterparts. However, we note that the lower number of published marine applications indicated in Fig. 2 may be biased by the fact that the researched terms (e.g. geomorphometry and terrain analysis) are not always used in marine studies, even where geomorphometric techniques have been employed. Consequently, Fig. 2 may be a reflection of how these terms have been adopted rather than a representation of the actual evolution of the practice. For instance, in Harris and Baker (2012a), an authoritative volume in marine habitat mapping, all of the 57 case studies used 

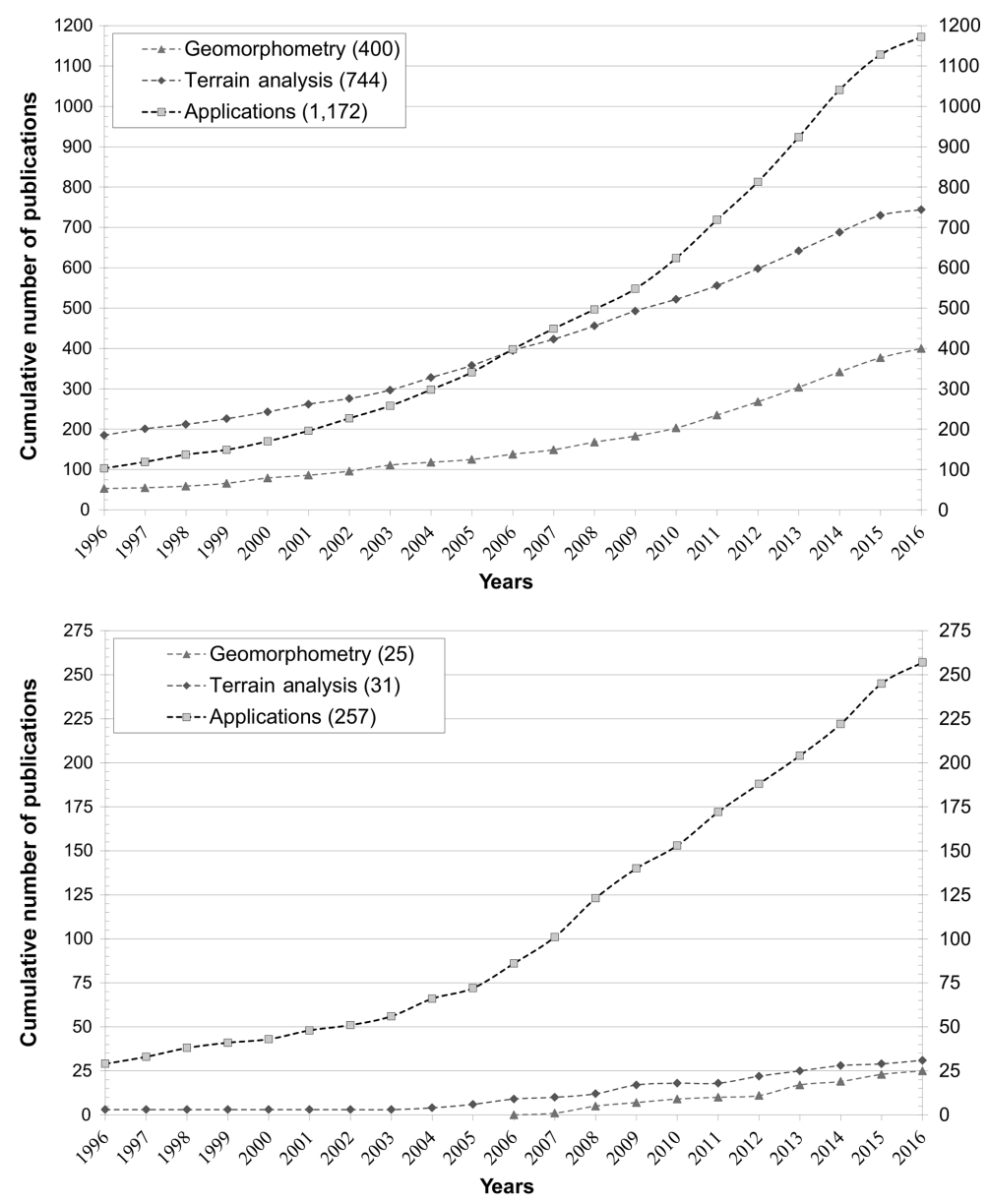

Figure 2. Cumulative number of publications (articles or reviews) listed in the Scopus database mentioning specific keywords in their title, abstract of keywords, by the end of June 2016 for land-based (top) and marine (bottom) geomorphometry publications. For the "geomorphometry" curves, the keywords "geomorphometry" and "geomorphometric" were queried. The keyword "terrain analysis" was researched for the "terrain analysis" curves. For the terrestrial applications, the following terms were used to query the database: "topographic variables", "topographic attributes", "topographic derivatives", "terrain variables", "terrain attributes", "terrain derivatives", and "terrain morphology". These terms were also used for marine applications, in addition to "bathymetric variables", "bathymetric attributes", "bathymetric derivatives", "seafloor morphology", and "seabed morphology". The queries were all performed to exclude (for land-based publications) or include (for marine publications) the terms "marine", "ocean", and "underwater". We note that some common terms in the field (e.g. surface parameters, seafloor characterization) were not included because of their parallel use and different meaning in other fields that do not involve geomorphometry.

bathymetry, 33 of them generated slope, 23 of them measured rugosity, and 14 of them calculated a topographic position index, amongst other terrain attributes (Harris and Baker, 2012b). Despite this high use of general geomorphometry techniques, the term "geomorphometry" was not once used in the 900 pages of the volume, and "terrain analysis" was only mentioned twice.

\section{Sampling the depth of the seafloor}

For centuries, the lead line was the main instrument used to determine the depth of the seafloor, until remote sensing technologies revolutionized the way we could measure bathymetry. This section introduces four types of remote sensing technology that are currently used to collect depth information and found in the geomorphometry literature: satellite radar altimetry, optical remote sensing, acoustic remote sensing, and bathymetric lidar. From an application perspective, the survey methodology or methodologies dictate the spatial scale (i.e. resolution and extent) of the final surface model. First, the fundamental technical limitations of the remote sensing technique that is used to collect bathymetric data will define the scale (resolution) of the surface model (Kenny et al., 2003; Van Rein et al., 2009). For instance, radar altimetry data limit models constructed with them to coarse, usually kilometre-scale resolution, while other methods can achieve up to centimetre-scale resolution models. 
Second, by defining the distance between the platform and the target, the characteristics of the former may also influence the scale (extent) of the final model; a remotely sensed image collected from a satellite will usually have a coarser resolution and cover a larger area than an image collected from an aircraft or an unmanned aerial vehicle. While radar altimetry and acoustic remote sensing are limited to deeper waters and optical remotely sensed and bathymetric lidar data are limited to shallower waters, there is some degree of overlap between the depths in which the various methods can be applied. In terms of effort, systematic bathymetric survey could be performed with satellite-based methods within a few years at a global scale (Sandwell et al., 2002), compared to the estimated 600 years (Carron et al., 2001) that it would take using acoustic remote sensing technologies. The different techniques are discussed in the perspective of using the information they collect to generate DTMs and perform geomorphometric analyses. DTMs using bathymetric data are hereafter referred to as digital bathymetric models (DBMs) to distinguish them from digital elevation models (DEMs), a term usually reserved for terrestrial elevation data. Other techniques can be used to measure depth but are less common in the literature (e.g. ground-penetrating radar, Feurer et al., 2008). More details on the underlying theories of these four techniques can be found in the Appendix.

\subsection{Satellite radar altimetry}

In the 1970s, satellite-based radar altimeters were developed as a method to study the oceans on a global scale (Douglas et al., 1987; see the Appendix), which was a significant improvement over the extent covered by very narrow ship tracks. Consequently, the applications of altimetry-derived bathymetric data are limited to the study of broadscale patterns, processes, and features as they only provide lowresolution estimates of bathymetry (Goff et al., 2004). Technological constraints and satellite orbits also prevent data collection close to the poles and the coastline (Sandwell et al., 2002). Some authors identified weaknesses in the method and warned that predicted depths from altimetry may not be reliable and should not be used for geodynamics studies (Smith, 1993), navigation, or hazard identification (Smith and Sandwell, 1994). The main advantages of altimetryderived bathymetry are speed of collection and uniformity of coverage (Mackenzie, 1997).

Two main altimetry-derived data sets are currently used in applications of marine geomorphometry: the General Bathymetric Chart of the Oceans (GEBCO, 2014) and the Shuttle Radar Topography Mapping 30-arcsec database (SRTM30_PLUS, Becker et al., 2009). They are both free data sets that combine together elevation and bathymetric data. The bathymetric parts were created by filling the gaps between publicly available data sets from different sources with radar altimetry (Smith and Sandwell, 1994; Becker et al., 2009). These data sets have been used for instance in habitat mapping and predictive modelling (e.g. Davies et al., 2008; Knudby et al., 2013), conservation (e.g. Ross and Howell, 2013), search and rescue operations (Smith and Marks, 2014), and geomorphology (e.g. Harris et al., 2014). Many works have found these data sets to be too coarse for their purposes (e.g. Davies et al., 2008; McNutt, 2014). For instance, Vierod et al. (2014) stated: "At present, the availability of bathymetric data at a resolution sufficient to inform reliable terrain attribute predictors is a major limitation to the ability of deep-sea species distribution models to make accurate predictions of the distributions of benthic organisms." For many applications, quality can also be just as important as resolution (cf. Sects. 4 and 6).

\subsection{Optical remote sensing}

Of the four remote sensing methods presented in this section, optical remote sensing is the least common in the marine geomorphometry literature. However, it presents a cheaper alternative to lidar data for collecting depth information in very shallow coastal areas (Su et al., 2014), as satellites can cover large areas in less time (Lafon et al., 2002; Wang and Philpot, 2007). Two main optical remote sensing groups of methods are usually used to estimate bathymetry from optical remote sensing: one based on the interactions of electromagnetic radiations with water and one based on stereoscopy (see the Appendix).

Methods based on electromagnetic radiations are limited to shallow waters because of light attenuation within the water column (Jawak et al., 2015). In theory, based on light penetration in coastal waters, depths down to $50 \mathrm{~m}$ could be retrieved (Speight and Henderson, 2010). However, the practical limit varies with local sea conditions. A maximum of $30 \mathrm{~m}$ deep is usually achieved when local conditions are exceptionally good (Collet et al., 2000; Jawak et al., 2015), and most often a depth of $15 \mathrm{~m}$ is reported as being the performance limit of optical remote sensing for bathymetry retrieval (e.g. Stumpf et al., 2003). Optical methods are sensitive to errors caused by waves, turbidity, sunglint from specular reflection, heterogeneous and complex seafloors, and the presence of shadow that artificially increases depth estimates (Lafon et al., 2002; Louchard et al., 2003; Holman and Haller, 2013; Eugenio et al., 2015). Some of these elements can be corrected or accounted for. For instance, Knudby et al. (2010) applied "deglinting" (Hedley et al., 2005; Kay et al., 2009) and water column corrections (Lyzenga, 1978), in addition to the common geometric and atmospheric corrections, to IKONOS satellite images to create a $4 \mathrm{~m}$ resolution DBM from which was derived measures of seafloor rugosity. The authors indicated, however, that noise prevented the use of bathymetry at depths deeper than $15 \mathrm{~m}$ as rugosity values were artificially increased.

For stereoscopy-based methods, photogrammetry applied to pairs of stereo images can be used to build DBMs in a similar way as it is done on land. Although possible (e.g. Stojic et 
al., 1998), through-water photogrammetry is challenging due to the need to correct for the air-water interface (Feurer et al., 2008). However, underwater photogrammetry (i.e. active remote sensing) has been successfully applied at a fine scale to reconstruct the digital terrain (e.g. Johnson-Roberson et al., 2010; Kwasnitschka et al., 2013). The work by Friedman et al. (2012) is noteworthy as they derived multi-scale measures of rugosity, slope, and aspect from underwater stereo image reconstructions.

\subsection{Acoustic remote sensing}

The development of acoustic technologies has fuelled marine exploration probably more than any other method, by providing reliable swath coverage and relatively high-density data at ever-decreasing price per line kilometre (see Lurton, 2010 for review). Three types of active sonars (Sound Navigation and Ranging) can be used to collect depth estimates and/or backscatter information using sound waves (see the Appendix): side-scan sonars (SSSs; reviewed in Blondel and Murton, 1997), single-beam echo sounders (SBESs), and multibeam echo sounders (MBESs; reviewed in de Moustier, 1988). Backscatter data are effective in providing information on seafloor properties (e.g. sediment composition). These tools can be pole-mounted on the side of vessels, or mounted on the hull of vessels, on remotely operated vehicles (ROVs), on autonomous underwater vehicles (AUVs), or on a towed platform.

SSSs provide an acoustic image of the seafloor from backscatter measurements that can inform on topographic roughness. They can only provide bathymetric measurements when data from two receiving antennas are combined and principles from interferometry are applied. SSSs are a commonly used seafloor technology because they are easy to deploy and cheaper than other acoustic technologies (Harris and Baker, 2012c). The acoustic image quality of SSS images are very high resolution, and characteristics (e.g. length and shape) of the acoustic shadows, which are the areas on a SSS image that have null intensity values because the sound was blocked by an object of feature higher than its surroundings, enable the estimation of the height and size of these objects or features (Blondel and Murton, 1997). Collier and Humber (2012) provided an example of the use of side-scanderived bathymetry to identify geomorphic features on the seafloor. Some techniques from specific geomorphometry are used on backscatter data to identify specific bedforms or depositional units on the seafloor based on their unique acoustic signature (Greene et al., 1999; Huvenne et al., 2005; Martorelli et al., 2012) and to detect differences in reflectivity and texture patterns on the seafloor (van Lancker et al., 2012). We also recognize the potential to generate higher-resolution (centimetre-scale) bathymetric data using modern synthetic aperture sonar systems such as the HISAS 1030 (Kongsberg Maritime, 2015) from a stable AUV platform (e.g. Ludvigsen et al., 2014). There are many potential benefits to this ap- proach although, at present, the processing of bathymetric data is very computationally demanding and therefore best suited to mapping of small areas.

SBESs, or fathometers, collect both depth and backscatter data by transmitting a single sound beam at nadir. The mapped extent is thus limited to a single track directly below the supporting platform. Although they remain standard for ships navigation, SBESs are less and less used for mapping purposes since MBESs became more affordable. However, recent applications can still be found, particularly where compiled SBES data are available; a SBES bathymetric data set of the English Channel was used by Coggan and Diesing (2012) for the broadscale analysis of an exposed rock ridge system, by Elvenes et al. (2014) for surficial sediment and habitat mapping, and by James et al. (2012) to identify geomorphic features in a palaeo-valley.

MBESs provide a relatively fast, high-resolution, and wide coverage measurement of the seafloor. They sweep a large swath of the seafloor by emitting a fan of narrow sound beams, and are currently the most efficient and accurate tool available to collect bathymetric and backscatter data (Costa et al., 2009; Schimel et al., 2010a, b). In recent years, advancement in MBES technology has further enhanced a valuable source of seafloor data. These advances have come out of traditional user groups extending the application of the data to meet new requirements and from the motivation of new user groups wanting to employ the technology. This wide-ranging and ever growing community of MBES users are adapting and extending the potential of MBES data to address unique applications. MBES users have traditionally included hydrographers, navigators, engineers, marine geologists, and military planners, but now we see the extension of the technology to meet the needs of maritime explorers, archaeologists, fisheries biologists, geomorphologists, and ecosystem modellers, to name a few. MBESs are currently the main source of bathymetric data for applications of marine geomorphometry, although these data are limited in terms of coverage: "Multibeam soundings are the gold standards, but such mapping has been concentrated in coastal zones, along shipping lanes, and in regions harbouring hydrocarbon or mineral deposits" (Normile, 2014, p. 964).

\subsection{Bathymetric lidar}

Bathymetric lidar is an adaptation of the more traditional airborne topographic lidar (Guenther et al., 2002; see the Appendix) and has become increasingly common in the literature in the last 2 decades (Brock and Purkis, 2009). Recently, they have been combined into topo-bathymetric lidar, which are multispectral systems that enable data collection both above land and water; when flying over the water, a green laser - characteristic of bathymetric lidar - penetrates the sea surface and collects information on the water column and the seafloor, while the red/infrared laser - characteristic of topographic lidar - collects information on the sea surface. Lidar 
can also collect intensity values that, like acoustic backscatter, provide information on the characteristics of the seafloor (Costa et al., 2009; Kashani et al., 2015).

Bathymetric lidar is the only technique that can collect high-resolution data in very shallow waters, which makes it especially relevant for coastal applications requiring finescale data ( $<1 \mathrm{~m}$ resolution) (Brock and Purkis, 2009). The efficiency of bathymetric lidar systems is greatly limited by turbidity, wave action, depth (up to 50-70 $\mathrm{m}$ in exceptionally good conditions), steep slopes, and rocky substrate (Costa et al., 2009; Chust et al., 2010; Jalali et al., 2015). Current geomorphometric applications on bathymetric lidar data are mainly related to the exploration of coastal ecosystems (e.g. Wedding et al., 2008; Zavalas et al., 2014) and geomorphology (e.g. Arifin and Kennedy, 2011; Kennedy et al., 2014), but are likely to extend to other applications such as marine archaeology and natural hazards assessment (e.g. Solsten and Aitken, 2006). In 2015, lidar data represented $4.5 \%$ of the coastal data collected for the Continually Updated Shoreline Product (CUSP) compiled by the National Oceanic and Atmospheric Administration (NOAA) and the National Geodetic Survey (NGS) of the United States (Graham et al., 2015).

\section{Generating a surface model from sampled depths}

A detailed account of the various approaches to processing (i.e. georeferencing and applying system and environmentrelated corrections) and cleaning of data (i.e. removal of spurious depth soundings) are beyond the scope of this paper and are specific to the sensors used for data acquisition as well as industry and application-related standard practices. In this section, we focus on the interpolation of data and only touch briefly on data cleaning when we present a method where uncertainty algorithms are used to aid data cleaning, and where the interpolation of data is intrinsically linked to the calculation of uncertainty of the bathymetric surface.

By nature, geomorphometric analyses necessitate spatially continuous data, but no remote sensing techniques used to collect depth samples create truly continuous surfaces. Hengl and Evans (2009) identified several techniques used to generate gridded DTMs from height samples for geomorphometric purposes, including inverse distance weighting (IDW), minimum curvature, spline, kriging, polynomial regression, moving average, and many others. The same methods can all be used to generate DBMs from depth samples. For instance, Ezhova et al. (2012) created a DBM from SBES data using the natural neighbour interpolation method, and Ramillien and Cazenave (1997) combined altimetry and shipbased data into a single DBM using bilinear interpolation. More rarely, triangulated irregular networks (TINs) are created from depth samples; for example, Heyman and Kobara (2012) generated a TIN from SBES data, and Foster et al. (2009) computed TINs from SBES and bathymetric lidar from which volumetric attributes were computed. The choice of interpolator varies depending on the type of data and the spatial arrangement of the depth samples. For instance, MBESs or lidar data can collect very dense point clouds that require little interpolation between points, resulting in limited interpolator influence in the final DBM. On the other hand, creating a DBM for a big area from SBES data requires more interpolation as SBESs only sample very narrow tracks and have a high density of points along the survey line but no data between the survey lines. This has implications for geomorphometry as the interpolated DBM may miss important geomorphological features (depending on the distance between the survey lines), similarly to what happens with the interpolation of contour lines (Wise, 1998). Also, some methods (e.g. IDW) do not extrapolate and are hence less accurate in cases of sparse sampling. The choice of an appropriate interpolator to generate a surface model is critical as some interpolators may produce erroneous depth values that do not adequately represent the real bathymetry (Smith and Wessel, 1990).

There are no optimal interpolation methods ( $\mathrm{Li}$ et al., 2005), and it is well known that each technique has different sensitivity to errors and sample distribution and that the quality of DTMs can be improved when making the appropriate choice of interpolator (Carrara et al., 1997; Hengl and Evans, 2009). For instance, some techniques will consider all samples while others will ignore outliers or smooth out their effect. By being different in nature, sampled depths may not require the same characteristics from an interpolator than sampled elevations; for instance, DBMs do not need to be hydrologically corrected as drainage analyses are futile underwater. This is why techniques were developed in recent years to address the particular characteristics of depth sampling. Here we examine such techniques, the CUBE (Combined Uncertainty and Bathymetric Estimator) algorithm (Calder, 2003), which accounts for different errors specific to acoustic remote sensing (e.g. geometric and acoustic) and is incorporated in several of the most widely used bathymetric processing software used by the hydrographic survey industry and scientific community. Although not yet universally accepted as data cleaning method by the hydrographic survey industry and hydrographic agencies, who have a particular need to preserve shoal soundings and comply with strict quality control procedures to ensure safety of navigation, CUBE is widely used and of special interest to more applied bathymetric data users and the related scientific community. According to Schimel et al. (2010b), CUBE could be more appropriate than traditional gridding methods to compute precise bathymetry and associated terrain attributes. CUBE is based on the spatially explicit quantification of the total propagated uncertainty (TPU) for each data point (Calder and Mayer, 2003), enabling the rejection of samples that are outside a certain uncertainty confidence level (e.g. $95 \%$ for Calvert et al., 2015). When creating the DBM, the algorithm provides vertical error estimates and statistically assigns, to each pixel, the most likely depth value based on the uncertainty of each sounding within the pixel (see Dolan and Lucieer, 

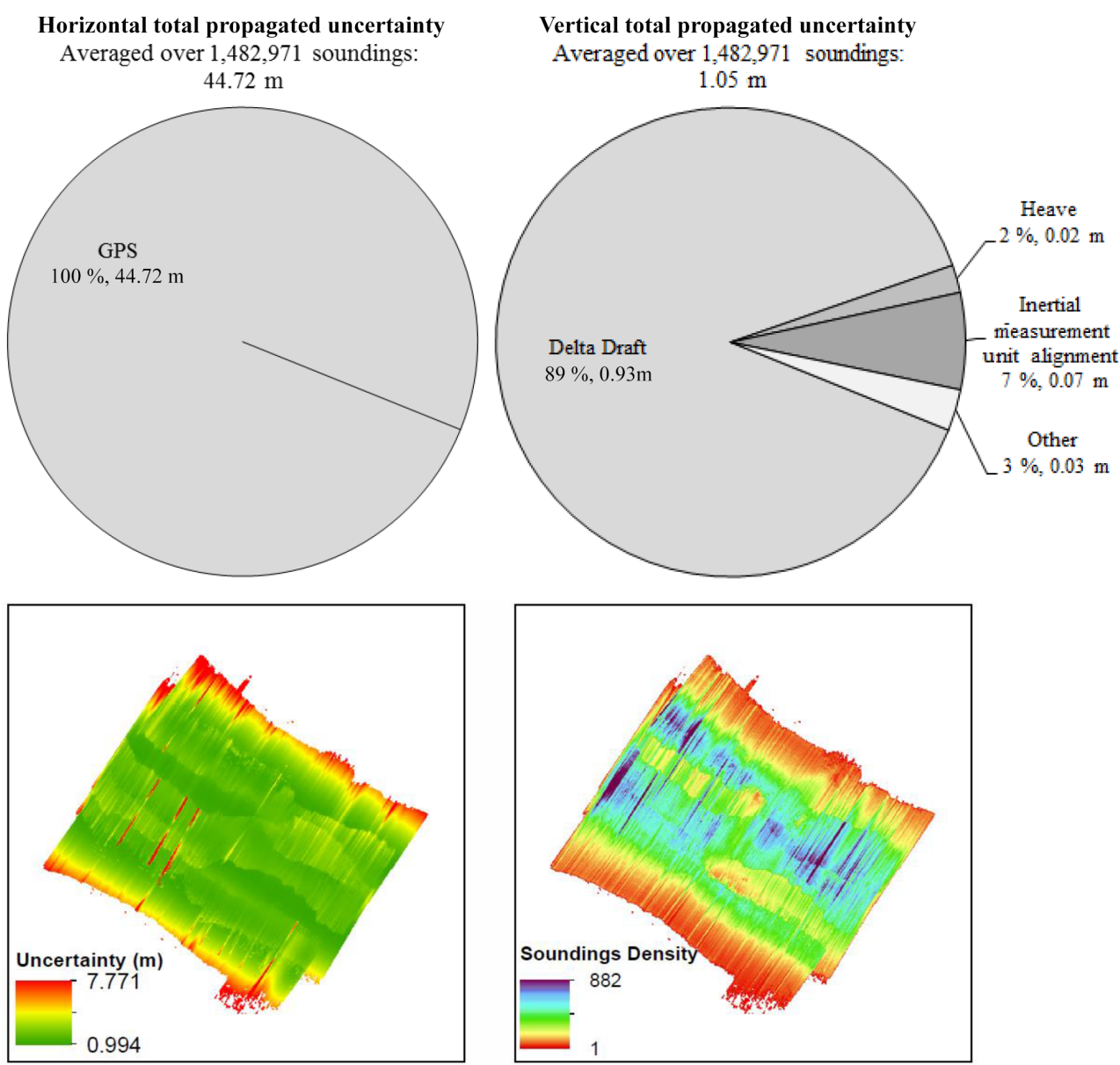

Figure 3. Example of elements that can be extracted and visualized when using the CUBE algorithm, using the ROV-based data set from Fig. 4 (source: Lecours and Devillers, 2015). In the top panel, the components contributing to the horizontal and vertical TPUs can be studied. Other marginal contributions to the vertical TPU included the roll and pitch of the platform, timing of the inertial measurement unit, and uncertainty associated with the sonar system (range and angle). The combination of the GPS and delta draft provides the three-dimensional position of the soundings $(x, y, z)$; in ROV-based research, the positional accuracy decreases with depth (Lecours and Devillers, 2015). In the bottom panel, it is possible to visualize how the uncertainty and the density of soundings vary spatially.

2014). In several bathymetric processing software offering CUBE, users can visualize not only the most probable depth for each pixel, but also the subsequent most probable depths (e.g. second or third most likely) and select the one they think is the most appropriate based on their knowledge of an area. For example, this can allow correction for occurrences when the sonar detects fish close to the seafloor instead of the seafloor itself and data cleaning did not appropriately remove these soundings. Figure 3 shows some of the information that can be extracted and visualized from the application of the CUBE algorithm. When interpolating the soundings to create a DBM, the bathymetry, and the horizontal and vertical components of uncertainty can be stored in a BASE (Bathymetry Associated with Statistical Error) surface. The BASE format allows multi-attributes surface models. CUBE's main inconvenience is that it requires a lot of ancillary data to be collected in order to compute TPU, but it is very reliable in defining the spatial pattern of errors, their importance, and helping to identify their sources (Passalacqua et al., 2015). In addition to the bathymetry, a map of uncertainty can be computed, which can become very important when making decisions using the bathymetry and for onward geomorphometric analysis.

Spatial scale is an important component of the interpolation of depth data to generate DBMs, and differences in sampling characteristics have an impact on the spatial scale of the resulting surface model. Unlike systems used in optical remote sensing, radar altimetry, and bathymetric lidar, acoustic systems do not sample the seafloor uniformly, which influences the spatial scale of the resulting DBM. The sampling density of these systems is directly dependent on depth, or more specifically on the sensor-to-seafloor distance (Lecours and Devillers, 2015). For instance, as the distance between a MBES and the seafloor increases, it takes longer for the 

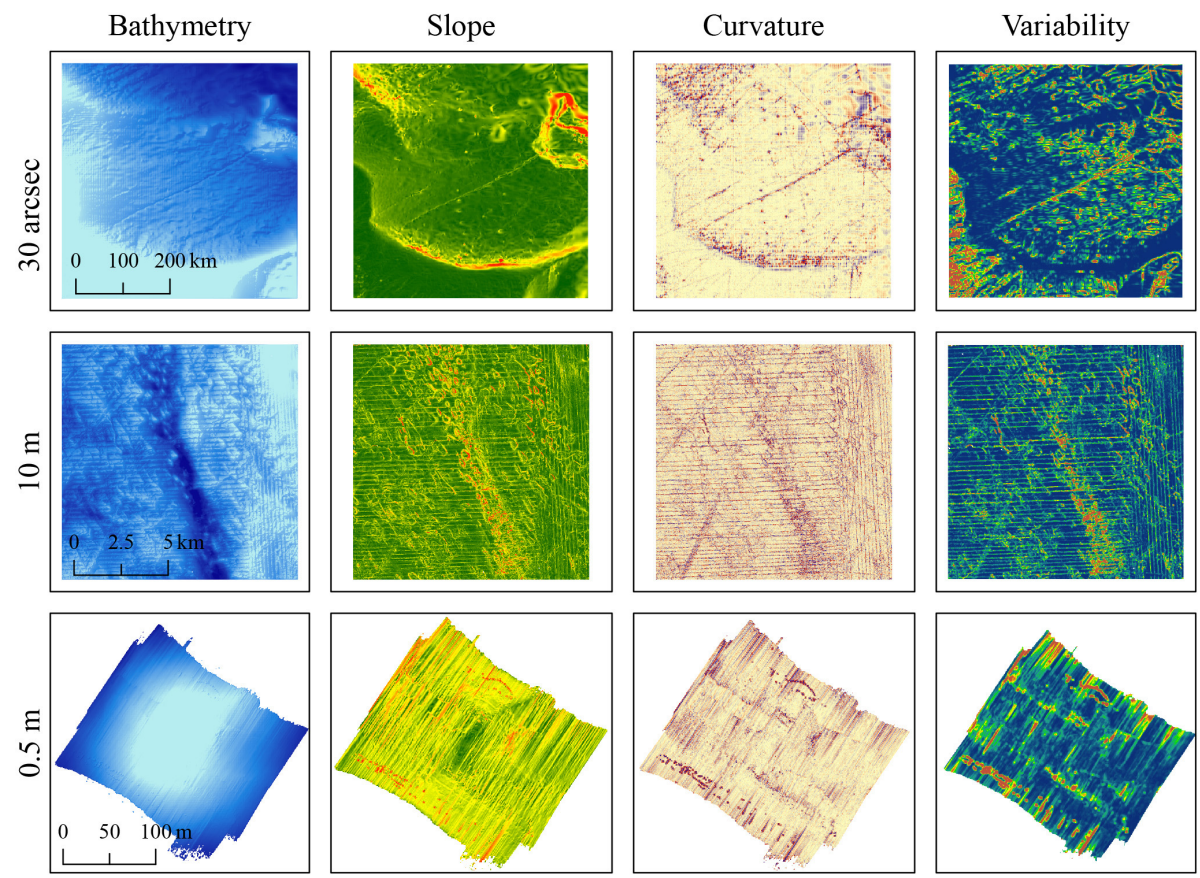

Figure 4. Examples of errors and artefacts found in different data sets and their impact on derived terrain attributes. The top panels represent data from GEBCO (2014), which uses radar altimetry to fill in the gaps between higher-resolution, freely available bathymetric data. The main artefacts that can be observed are caused by the interpolation method that was used to combine the different data sets. For instance, a linear artefact following a southwest to northeast axis can be observed as a result of the combination of one SBES acoustic survey line with radar altimetry data. Similarly, some "spots" can be seen in the middle of the panels (south to north direction). These artefacts, especially apparent in the curvature, are caused by the merging of punctual lead line measurements with the radar altimetry data. Finally, a slight gridding artefact can be observed in the curvature (i.e. thin vertical and horizontal linear features). The middle panels show ship-based MBES data (Brown et al., 2012). The obvious artefacts follow the surveying pattern of the vessel, and are mainly caused by vessel motion that was not compensated properly by the motion sensor. Finally, the bottom row of panels corresponds to ROV-based MBES collected from $20 \mathrm{~m}$ above the seafloor in the deep sea (Lecours et al., 2013). In this case, the artefacts are caused by a combination of heave and other platform motions; the ancillary data collected to account for this motion are too uncertain at this depth to appropriately correct for the errors (Lecours and Devillers, 2015). The "spots" observed in the bottom and top of the derived terrain attributes are spurious soundings that can be removed in bathymetric software during post-processing of the data. Note differences in spatial resolutions (left axis) and cartographic scales. Depth values of the top left panel range from 60 to $4275 \mathrm{~m}$ deep, those of the middle left panel range from 20 to $105 \mathrm{~m}$ deep, and those of the bottom left panel range from 2345 to $2425 \mathrm{~m}$ deep. Lighter blue is shallower.

sound to reach the seafloor, the system's footprint and related beam widths increase, leading to a lower sampling density for a greater area sampled at a coarser resolution. Since the seafloor is rarely perfectly flat and at a constant depth, the sampling density is almost never uniform across survey areas, which can make it challenging to determine the appropriate spatial resolution of DBMs for interpolation. Ultimately, the spatial scale of a DBM will be dictated by its intended use (see Sect. 6), which then influences the choice of the data collection method, typically following hydrographic standards (IHO, 2008) that ensure the appropriate data are acquired to ensure safety of navigation. Besides DBMs created directly from one source of survey data, we are increasingly seeing DBMs generated or pooled together from several surveys and/or sensor technologies (e.g. EMODnet, 2015). These data sets can be a valuable resource but impose additional challenges for DBM creation and geomorphometric analysis (e.g. Sect. 6.4.3).

\section{Correcting errors and artefacts in digital bathymetric models}

In terrestrial applications, it is well known that all DEMs, regardless of the techniques used to collect and generate data, are influenced by uncertainty and errors (Fisher and Tate, 2006; Gessler et al., 2009). This is also true for marine applications, but the properties and dynamic nature of the ocean makes DBMs more prone to errors and artefacts than DEMs (Hughes-Clarke et al., 1996). As illustrated in Fig. 4, this has significant implications for marine geomorphometry, which shows as widely recognized in the terrestrial literature (Florinsky, 1998; Zhou and Liu, 2004; Oksa- 
nen and Sarjakoski, 2005) that errors and artefacts in a DTM propagate to and may be amplified in terrain attributes.

As with DEMs (Harrison et al., 2009; Sofia et al., 2013), errors and artefacts in DBMs can be caused by the interpolation method (Erikstad et al., 2013), movement and positioning of the supporting platform (Hughes-Clarke et al., 1996), and a temporal (Lecours and Devillers, 2015) or spatial (Hughes-Clarke, 2003a, b) misalignment between the different elements of the surveying system. Data from radar altimetry are the least sensitive to platform motion (Smith and Sandwell, 1994). However, large artefacts resulting from fine-scale noise in the gravity field (Goff et al., 2004) and the algorithms used to convert gravity data into bathymetric estimates (Dixon et al., 1983; Calmant and Beaudry, 1996) are often characteristic of these data. Similar large linear artefacts can sometimes be found in satellite images (e.g. Klemas, 2011a). The level of error in bathymetric data from optical remote sensing is known to directly depend on water depth as a result of light attenuation in the water column (e.g. Liceaga-Correa and Euan-Avila, 2002). Recent studies (Leon et al., 2013; Hamylton et al., 2015) have demonstrated that the integration of the spatial structure of errors improves bathymetric estimates derived from satellite images. Data collected with acoustic methods are the most susceptible to artefacts for several reasons. First, they are collected from surface vessels/platforms or underwater vehicles that can be strongly affected by environmental conditions such as waves and wind. Furthermore, acoustic waves need to be corrected for sound velocity. Without this correction the data will exhibit artefacts broadly similar to those caused by an inappropriate correction of the atmospheric conditions in optical remote sensing ( $\mathrm{Li}$ and Goldstein, 1990). Sound velocity varies with temperature, salinity and pressure and the failure to correct for these variations can induce refraction artefacts in the DBM (Yang et al., 2007). This is particularly challenging as water column properties vary both spatially and temporally, especially in the coastal zone where there is the additional complication of freshwater input from rivers, and are less predictable than atmospheric conditions (CushmanRoisin and Beckers, 2011). Tidal corrections are generally applied using data from locally installed tide gauges, or modelled tides, depending on the accuracy required. Finally, since the surveying system is underwater, direct positioning using the Global Positioning System (GPS) is not possible (Roman and Singh, 2006). The level of error in the data is thus strongly influenced by the accuracy of the different instruments that provide ancillary data to estimate the position of the system's underwater components (Rattray et al., 2014; Lecours and Devillers, 2015).

Figure 4 illustrates different types of errors and artefacts that can be found in bathymetric data of different types and at different scales, and their propagation to derived terrain attributes. Artefacts commonly found in bathymetric data and that often cannot be corrected using existing methods include gridding and interpolation artefacts (e.g. in the top panels), motion artefacts (e.g. middle and bottom panels), refraction artefacts, and artefacts caused by the temporal or spatial uncertainty associated with ancillary data (e.g. bottom panels). Common errors include spurious soundings (e.g. bottom panels). Artefacts in DBMs are difficult to handle properly as depth generally cannot be ground-truthed, thus preventing verification of whether or not a feature is natural or the result of an artefact ( $\mathrm{Li}$ and $\mathrm{Wu}, 2006)$. Most marine environments are not easy to access and the collection of groundtruth data is often limited by technological and logistical constraints (Solan et al., 2003; Robinson et al., 2011). Consequently, ground-truthing of DBMs is not standard practice. We note however that ground-truthing is often performed for backscatter data to attempt matching sediment types with acoustic reflectivity characteristics. As illustrated in Fig. 4, artefacts in DBMs may be present at all scales and persist, or are sometimes amplified in derived terrain attributes. For instance, artefacts in the GEBCO data set are common (Lecours et al., 2013; GEBCO, 2014; Fig. 4), arising mostly from the merging of data sets of different quality. When the artefacts are large they dominate the surface and cannot be removed with traditional filtering methods (e.g. Gaussian filtering) as this considerably affects the overall quality of the surface (Passalacqua et al., 2015), and the artefacts are also difficult to overcome when deriving terrain attributes even by using multi-scale methods (Sect. 5.1). At a finer scale, Yang et al. (2007) developed an algorithm to correct refraction artefacts, although this was only partially successful. When the artefacts are smaller, it can be difficult to distinguish them from real fine-scale features such as sandwaves or iceberg scourings (Hughes-Clarke et al., 1996), especially when no underwater video data are available to confirm the geomorphology of an area. This is particularly challenging for marine geomorphometry as analyses are likely to capture both the real features and the artefacts (Wilson et al., 2007). Currently, the main ways to address artefacts in DBMs are to apply filtering techniques, resample the data to coarser resolutions, manually correct the data based on visual interpretation, and to use algorithms like CUBE that account for errors and uncertainty. Most marine geomorphometry applications simply disregard the presence of the remaining artefacts, excluding them for practical purposes by expert judgement.

\section{Deriving terrain attributes and terrain features}

Bathymetric data, particularly full coverage multibeam, or lidar data, are well suited for the generation of quantitative terrain attributes and terrain features. These attributes and feature classifications can be very useful in describing, interpreting, and classifying geomorphology in the marine environment, just as their terrestrial equivalents are on land. These derived data sets can also be of further use in many applications (cf. Sect. 6). With bathymetric data now available in many areas at comparable resolutions to terrestrial DEMs, depending on the survey equipment used (cf. Sect. 2), 


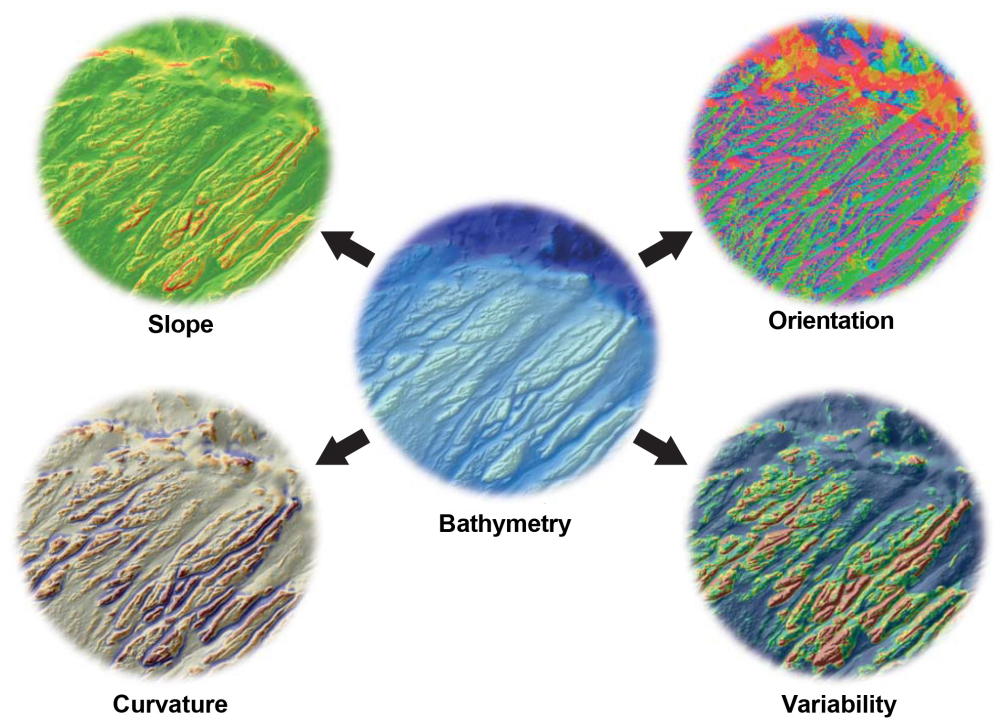

Figure 5. Illustration of the main types of terrain attributes that can be derived from bathymetry data. Modified after Wilson et al. (2007).

we can extract a similar level of information to that obtainable from terrestrial DEMs. Elsewhere, global (e.g. GEBCO, 2014) and regional (e.g. IBCAO (Jakobsson et al., 2012); EMODnet, 2015) bathymetric data sets combining information from many sources have become an impressive resource and are being used routinely for many marine science applications, not least those including high seas areas which, as yet, have little detailed coverage. This section reviews both the use of general (i.e. terrain attributes) and specific (i.e. terrain features) marine geomorphometry.

\subsection{General geomorphometry (terrain attributes)}

The calculation of terrain attributes (synonymous with terrain/topographic variables) first requires some method for mathematically representing the bathymetric surface. This surface representation is then used to calculate the required terrain attribute, and is typically achieved by either using neighbourhood analysis of raster pixels, or by fitting a polynomial expression to describe the surface. The computations performed on DBMs, and the range of applications that these derived terrain attributes are used for, are common to many of those performed on DEMs for terrestrial applications. Differences in analysis of bathymetric DBMs vs. DEMs are often more related to the meaning or application of the information from the analysis. For instance, deriving a watershed network underwater may be useful, e.g., for delineating potential sediment pathways on the continental slope, but is a deviation from the original intended purpose. A review of terrain attributes was provided by Wilson et al. (2007) in the context of marine benthic habitat mapping and updated by Dolan et al. (2012). In addition, Brown et al. (2011) offer a useful summary of the extent to which many of these various terrain attributes have been employed within published habitat mapping studies in the period 2000 to 2011. Habitat mapping is currently one of the largest application areas for these techniques. To our knowledge no equivalent reviews on the use of general geomorphometry exist for marine geomorphology or other application areas.

Terrain variables can be grouped into four main types describing different properties of the terrain - slope, orientation, curvature/relative position, and terrain variability (Fig. 5). It is beyond the scope of this paper to provide details on all the various options for computation; however, we provide an overview of some of the most commonly used terrain attributes in marine-based studies, as well as an indication of some common calculation approaches (Table 1). Here we note the geomorphological relevance and ecological relevance of the various types of terrain attributes in the context of seabed mapping. Whilst the effects on geomorphology are more direct, the popularity of terrain attributes in benthic habitat mapping is, to a large extent, due to their function as a surrogate (or proxy) in explaining the distribution of benthic fauna. In the absence of better, or alternate information (e.g. gained from high-resolution oceanographic data), proxy information such as whether a given location is sheltered or exposed to dominant currents as indicated by its position relative to neighbouring terrain, can be useful in determining suitable habitat for a given species or community. An elevated position for example may be advantageous for suspension feeding organisms and act as a surrogate for the direct need for food supply. Other terrain attributes may capture a proxy for shelter or other ecological advantage. This topic is discussed further by Lecours et al. (2015b) including the all-important effect of scale, which is linked both to data resolution and the scale at which geomorphometric analysis is conducted. 
Table 1. Summary of the most commonly used terrain attributes in marine-based studies, as well as an indication of some common calculation approaches. Modified after Dolan et al. (2012). The term "multiple scale" refers to terrain attributes derived in turn using analysis windows of different sizes. "Multiscale" refers to indices derived simultaneously over a range of window sizes. The more general term "multi-scale" is used in this paper to refer to both types of analysis as well as geomorphometric analysis using data of different resolutions.

\begin{tabular}{|c|c|c|c|c|}
\hline & Slope & Orientation & Curvature & Terrain variability \\
\hline $\begin{array}{l}\text { Ecological } \\
\text { relevance }\end{array}$ & $\begin{array}{l}\text { Stability of sediments } \\
\text { (ability to live in/on } \\
\text { sediments); } \\
\text { local acceleration of } \\
\text { currents (food supply, } \\
\text { exposure, etc.) }\end{array}$ & $\begin{array}{l}\text { Degree of exposure to } \\
\text { dominant and/or local } \\
\text { currents from a particu- } \\
\text { lar direction (food sup- } \\
\text { ply, sedimentation, lar- } \\
\text { val dispersion, etc.) }\end{array}$ & $\begin{array}{l}\text { Index of exposure/ } \\
\text { shelter, e.g., on a peak or } \\
\text { in a hollow (food } \\
\text { supply, sedimentation, } \\
\text { predators, etc.) }\end{array}$ & $\begin{array}{l}\text { Index of degree of habitat } \\
\text { structure; } \\
\text { shelter from expo- } \\
\text { sure/predators (link to life } \\
\text { stages); } \\
\text { structural diversity } \\
\text { linked to biodiversity }\end{array}$ \\
\hline $\begin{array}{l}\text { Geomorphological } \\
\text { relevance }\end{array}$ & $\begin{array}{l}\text { Stability of sediments } \\
\text { (grain size); } \\
\text { local acceleration } \\
\text { of currents (erosion, } \\
\text { movement of sediments, } \\
\text { creation } \\
\text { of bedforms) }\end{array}$ & $\begin{array}{l}\text { Relation to direction } \\
\text { of dominant geomor- } \\
\text { phic processes }\end{array}$ & $\begin{array}{l}\text { Flow, channelling } \\
\text { of sediments/currents, } \\
\text { hydrological, and } \\
\text { glacial processes; } \\
\text { useful in the classifica- } \\
\text { tion of landforms }\end{array}$ & $\begin{array}{lr}\text { Terrain variability and } \\
\text { structures } \\
\text { dominant gresent reflect } \\
\text { processes }\end{array}$ \\
\hline $\begin{array}{l}\text { Commonly com- } \\
\text { puted terrain at- } \\
\text { tribute and exam- } \\
\text { ple marine-based } \\
\text { reference }\end{array}$ & $\begin{array}{l}\text { Slope (Lundblad et al., } \\
\text { 2006; Lanier et al., 2007; } \\
\text { Micallef et al., 2012a; } \\
\text { Dolan and Lucieer, 2014) }\end{array}$ & $\begin{array}{l}\text { Aspect (Galparsoro } \\
\text { et al., 2009), north- } \\
\text { ness/northerness and } \\
\text { eastness/easterness } \\
\text { (Monk et al., 2011) }\end{array}$ & $\begin{array}{l}\text { Mean curvature (Dolan } \\
\text { et al., 2008); } \\
\text { profile curvature } \\
\text { (Guinan et al., 2009); } \\
\text { plan/planimetric curva- } \\
\text { ture (Ross et al., 2015); } \\
\text { Bathymetric Position } \\
\text { Index (BPI) (Monk et al., } \\
\text { 2010; Pirtle et al., 2015) }\end{array}$ & $\begin{array}{l}\text { Rugosity (Dunn and } \\
\text { Halpin, 2009); } \\
\text { vector ruggedness } \\
\text { measure (VRM) } \\
\text { (Tempera et al., 2012); } \\
\text { relative relief } \\
\text { (Elvenes, 2013); } \\
\text { fractal dimension } \\
\text { (Wilson et al., 2007) }\end{array}$ \\
\hline \multirow[t]{2}{*}{$\begin{array}{l}\text { Commonly used } \\
\text { terrain attribute } \\
\text { and software } \\
\text { (algorithm refer- } \\
\text { ence) }\end{array}$} & $\begin{array}{l}\text { Single scale: } \\
\text { slope: ArcGIS Spatial } \\
\text { Analyst (Horn, 1981) }\end{array}$ & $\begin{array}{l}\text { Single scale: } \\
\text { aspect: ArcGIS Spatial } \\
\text { Analyst (Horn, 1981); } \\
\text { statistical aspect } \\
\text { (northness/eastness); } \\
\text { BTM toolbox (Wright } \\
\text { et al., 2012) }\end{array}$ & $\begin{array}{l}\text { Single scale: } \\
\text { mean, profile, and plan } \\
\text { curvature ArcGIS Spa- } \\
\text { tial Analyst (Zevenber- } \\
\text { gen and Thorne, 1987) }\end{array}$ & $\begin{array}{l}\text { Single scale: } \\
\text { rugosity (surface } \\
\text { area/planar area ratio) } \\
\text { (Jenness, 2004) }\end{array}$ \\
\hline & $\begin{array}{l}\text { Multi-scale: } \\
\text { Multiple scale slope: } \\
\text { r.param.scale, Landserf } \\
\text { (Wood, 1996); } \\
\text { Multiscale slope: Land- } \\
\text { serf (Wood, 1996) }\end{array}$ & $\begin{array}{l}\text { Multi-scale: } \\
\text { Multiple scale aspect: } \\
\text { r.param.scale, Landserf } \\
\text { (Wood, 1996); } \\
\text { Multiscale aspect: } \\
\text { Landserf (Wood, 1996) }\end{array}$ & $\begin{array}{l}\text { Multi-scale: } \\
\text { Several measures of } \\
\text { multiple scale curvature: } \\
\text { r.param.scale, } \\
\text { Landserf (Wood, 1996); } \\
\text { Multiple scale BPI } \\
\text { (Lundblad et al., 2006); } \\
\text { Multiscale curvature } \\
\text { Landserf (Wood, 1996) }\end{array}$ & $\begin{array}{l}\text { Multi-scale: } \\
\text { Multiple scale VRM } \\
\text { (Sappington et al., } \\
\text { 2007); } \\
\text { Multiple scale relative re- } \\
\text { lief (Erikstad et al., 2013, } \\
\text { and references } \\
\text { therein); } \\
\text { Multiple and multiscale } \\
\text { fractal dimension - Land- } \\
\text { serf (Wood, 1996) }\end{array}$ \\
\hline
\end{tabular}

For GIS-based calculation of terrain attributes, extending the analysis window beyond the basic $3 \times 3$ neighbourhood is particularly useful in marine geomorphometry as it facilitates the identification of spatial scales that are relevant to benthic communities (Lecours et al., 2015b) or to geomorphological interpretation (Shaw, 1992) and may also help to overcome artefacts in the DBM (Wilson et al., 2007). The multi-scale analysis methods developed by Wood (1996), which built on the work of Evans (1972, 1980), have been fundamental in establishing an appreciation of scale in marine and terrestrial geomorphometry alike. The associated software package Landserf (Wood, 2009) puts multi-scale 
analysis within easy reach of marine scientists and the use of Landserf for DBM analysis took off following the early applications of the software to bathymetric data (e.g. Wilson et al., 2007). Although Landserf 2.3 is still used by many scientists requiring a stand-alone programme for geomorphometric analysis, Wood's algorithms are now perhaps more widely used among the marine community through the GRASS module r.param.scale. The newly released ArcGeomorphometry toolbox (Rigol-Sanchez et al., 2015) offers a means to access the Wood-Evans (and other) algorithms for geomophometric analysis, and has the potential to provide a long-awaited, convenient multi-scale analysis option for ArcGIS users.

One terrain attribute that is specifically tailored to analysis of bathymetric data is the bathymetric position index (BPI) (Lundblad et al., 2006), which is an adaptation of the topographic position index (TPI) by Weiss (2001) and a useful measure of relative position that is simple to calculate over different neighbourhood sizes. Although a relatively simple algorithm to implement (Lunblad's BPI indices can be performed through the raster calculator (e.g. Wilson et al., 2007) or scripting), many marine scientists make use of the Benthic Terrain Modeler (BTM) Toolbox, which was first developed following the study by Lundblad (2006). The current version of BTM (Wright et al., 2012) for ArcGIS 10.1 and later has seen around 4000 downloads in the period 2012-2015, a figure that gives a conservative estimate of how many scientists are actually using the tool (S. Walbridge, ESRI, personal communication, 2015). The BTM toolbox relies on ArcGIS Spatial Analyst and includes tools for calculating slope, aspect, and terrain variability (rugosity, vector ruggedness measure - VRM) as well as methods for combining these into geomorphic zones. It was launched for the scientific community at a time when multibeam data were becoming widely available and modern marine geomorphometry was becoming established. The BTM toolbox quickly became popular as a one-stop shop for terrain analysis and classification of bathymetric data, offering a slightly more tailored solution, and the ability to handle larger data sets than Landserf, with at least the BPI index being computable at different scales since the first release (now joined by VRM). The utility of the BTM tool has been augmented in recent years through updating of the terrain variability and aspect indices, and by providing the tools as both an AddIn and as a stand-alone ArcToolbox, providing greater flexibility to users who may wish to benefit from all, or just part of, the functionality.

Several bathymetric data processing software (e.g. CARIS HIPS and SIPS, QPS-Fledermaus) also have built in tools for calculation of basic indices such as slope and rugosity, bringing the functions directly to the bathymetric data user and removing the need to search for and select from the vast array of available methods. This has advantages of convenience for some bathymetric data users, but in most applied projects the computation of terrain attributes and further analysis will be conducted in some generic GIS software. Although many of the commercial software are currently limited to single-scale analysis $(3 \times 3$ rectangular neighbourhood $)$ it has become easier to find tools for multi-scale analysis, either directly in open-source software (e.g. GRASS), through additional toolboxes (e.g. SEXTANTE for QGIS), or via scripting. Many of these also give alternative choices for computation algorithms, the effects of which are investigated by Dolan and Lucieer (2014) using slope as an example.

Terrain variability has been a particularly popular terrain attribute in relation to benthic habitat mapping. This is largely due to the generally accepted link of terrain variability with biodiversity, which has, however, not yet been fully established with regard to spatial scale (Lecours et al., 2015b). Several measures of terrain variability have been applied to DBMs (Table 1) with some proving suitable for multi-scale analysis and others becoming problematic at larger analysis scales (Wilson, 2006). A rugosity index, which is the ratio of surface area to planar area (Jenness, 2004), remains perhaps the most widely applied method in marine studies and this was implemented in early releases of BTM. Both the VRM (Sappington et al. 2007) now incorporated in BTM, and the more recent Arc_Chord Rugosity measure (Du Preez et al., 2014) offer alternatives that are better decoupled from slope. Where slope and a terrain variability measures are to be used in further analysis, e.g., as predictor variables for habitat modelling, it is particularly important that the user is aware of any autocorrelation or covariation between these attributes, so they can be handled appropriately. Du Preez et al. (2014) listed several marine studies among those who have ignored the need for decoupling. However, with methods like VRM and Arc-Chord rugosity, or toolboxes like BTM and TASSE (Lecours, 2015) now readily available, we trust that future studies will make a conscious choice of the best geomorphometric analysis to use for their particular application.

\subsection{Specific geomorphometry (terrain features/objects)}

Compared to general geomorphometry and the use of terrain attributes, applications of computer-based specific geomorphometry are still relatively rare in the marine environment. Calculation of terrain features generally relies on the combined properties of several terrain attributes. For instance, Lecours et al. (2013) used Troeh's landform classification (Shary et al., 2005), which uses different types of curvatures to identify zones of relative deflection or accumulation and transit zones, on bathymetric data. The authors also adapted the landform classification by Weiss (2001), which combines slope with TPI measures at different scales to identify up to 16 landform classes, for application within the marine environment using BPI measures.

Terrain features such as crests and troughs can be extracted through the use of pixel-based analysis (e.g. Blaszczynski, 1997; Wood and Dragicevic, 2007), but object-oriented methods for landform classification have recently become in- 
creasingly popular and are beginning to make their mark on marine studies (e.g. Lawrence et al., 2015) driven by an opportunity to analyse the DBM in conjunction with acoustic backscatter data (an indicator of seabed sediment type) rather than analysing the DBM alone, which offers several advantages for seabed classification. Geographic Object-Based Image Analysis (GeOBIA, OBIA) has been gaining some traction in the seabed mapping community as the spatial resolution of acoustic backscatter data improves (Diesing et al., 2014). The basic processing units in object-based image analysis are objects which are represented by textural changes in the acoustic backscatter image and are constrained by derived topographic variables (Benz et al., 2004). GeOBIA allows for the quantitative extraction of image textures and features to be identified in the backscatter data and the ability to relate these spatially to topographic variability (Costa and Battista, 2013). Multi-resolution segmentation is one of the most popular segmentation algorithms to delineate homogeneous seabed segments (Lucieer, 2008; Lucieer and Lamarche, 2011; Hasan, 2012; Eisank et al., 2014) and in the terrestrial literature stands out as the most successful method to delineate homogeneous terrain segments rather than landforms per se (e.g. Drăguţ and Blaschke, 2006; Drăguţ et al., 2011; Blaschke et al., 2014). This has been successfully demonstrated by Ismail et al. (2015) to identify and classify submarine canyons. By combining both the spatial derivatives of the DBM with GeOBIA variables, the authors were able to perform an automated multiple-scale terrain analysis to discriminate local and broadscale geomorphic features in the marine landscape. This information was used not only to delineate geomorphic seafloor features but also to identify properties that might influence biodiversity in a complex terrain. Specific geomorphometry is currently not used to its full potential in the marine environment.

\section{Applications of marine geomorphometry}

Pike et al. (2009) listed current and potential applications of marine geomorphometry, including oceanography, coastal geomorphology, geophysical analysis of global tectonics, ocean currents, mineral exploration, fisheries managements, navigation, and concealment of nuclear submarines. While performing the meta-analysis that enabled the making of Fig. 2, we were able to classify marine geomorphometry articles into four main research areas: geomorphology, geophysics, and geohazards; habitat mapping, biogeography, and ecology; hydrodynamics and modelling; and others. This section thus introduces the most common applications of geomorphometry in the marine environment, and discusses in Sect. 6.4 the least common uses in addition to potential future applications of marine geomorphometry. A selection of published works that have utilized geomorphometric techniques in their study of seafloor morphology is provided in Table 2 .

\subsection{Marine geomorphology, geophysics, and geohazards}

Early geomorphometric studies of seafloor morphology in the 1960 s were limited by the one-dimensionality and the low resolution of the bathymetric data that were available at the time (e.g. Krause and Menard, 1965; Neidell, 1966). In the last 3 decades, improvements in seafloor surveying technologies have resulted in a renewed interest in employing geomorphometric techniques to study seafloor geomorphology. Similar techniques have also been utilized in the interpretation of side-scan sonar data (e.g. Blondel et al., 1998; Carmichael et al., 1996; Huvenne et al., 2002; Mitchell and Somers, 1989).

Geomorphometric techniques have generally performed well in submarine environments. The use of specific geomorphometric techniques, where features of interest are identified prior to analysis, has involved examining how different morphological parameters change spatially and with each other. They have been amongst the most successful techniques, particularly with regard to the study of submarine mass movements, canyons and volcanoes. In the study of submarine mass movements, the general approach has been the prior identification of the boundaries of the landslides, the measurements of a series of morphometric parameters and their spatial and statistical analyses. This kind of approach has been applied to slope instability offshore Norway (Haflidason et al., 2005; Issler et al., 2005; Micallef et al., 2008), demonstrating the fractal characteristics of submarine mass movement morphology and statistics, which has important implications for submarine landslide modelling and hazard assessment. It has also been employed on a finer scale (Casalbore et al., 2011; Rovere et al., 2014) and a broader scale (Hühnerbach et al., 2004; McAdoo et al., 2000; Moernaut and De Batist, 2011) to identify tsunamigenic landslides and to provide interesting insights into failure frequency, preconditioning factors, triggers and controls of submarine mass movements in a wide range of environments, including lakes. In submarine canyons, specific geomorphometric analyses of submarine landslides has shown that landslides can be the most efficient process removing material from canyons and that their influence becomes more significant as the canyon matures (Green and Uken, 2008; Micallef et al., 2012b). Geomorphometric investigations of submarine canyon form have generally focused on using morphological data to propose model of canyon erosion by turbidity currents (Mitchell, 2004, 2005; Vachtman et al., 2013). More recently, specific geomorphometric techniques have been used to demonstrate how canyons in passive, progradational margins develop into geometrically self-similar systems that approach steady state and higher drainage efficiency (Micallef et al., 2014b), and how canyons in active margins fail to reach steady state because of continuous adjustment to perturbations associated with tectonic displacements and base-level change (Micallef et al., 2014a). The geomorphometric study of volcanoes has 
Table 2. Selection of studies published in the last 3 decades that applied geomorphometric techniques to the marine environment. A particular focus is given to marine geomorphology studies, as a few other documents (e.g. McArthur et al., 2010; Brown et al., 2011; Harris and Baker, 2012; Rengstorf et al., 2012; Lecours et al., 2015b) already summarized the extent to which many of these techniques have been employed in habitat mapping studies, and many of these techniques have yet to be employed in other contexts.

\begin{tabular}{|c|c|c|c|}
\hline Technique & Reference & Spatial domain & Broad theme \\
\hline \multicolumn{4}{|l|}{ General geomorphometry } \\
\hline \multirow{7}{*}{$\begin{array}{l}\text { Morphometric attributes } \\
\text { Basic geometrical analysis }\end{array}$} & Adams and Schlager (2000) & Continental slope & \multirow{3}{*}{$\begin{array}{l}\text { Geomorphology and } \\
\text { geohazards }\end{array}$} \\
\hline & De Moustier and Matsumoto (1993) & General & \\
\hline & Teide Group (1997) & Volcanic islands & \\
\hline & Coggan and Diesing (2012) & Continental shelf & \multirow{2}{*}{$\begin{array}{l}\text { Habitat mapping and } \\
\text { ecology }\end{array}$} \\
\hline & Ezhova et al. (2012) & Coastal and continental shelf & \\
\hline & Mofield et al. (2004) & Continental slope and rise, abyssal hills & Hydrodynamics \\
\hline & Passaro et al. (2013) & Coastal & Others \\
\hline \multirow{23}{*}{$\begin{array}{l}\text { Morphometric attributes } \\
\text { and their statistical } \\
\text { analyses }\end{array}$} & Berkson and Matthews (1984) & General & \multirow{11}{*}{$\begin{array}{l}\text { Geomorphology and } \\
\text { geohazards }\end{array}$} \\
\hline & Booth and O'Leary (1991) & Continental slope and upper rise & \\
\hline & Chakraborty et al. (2001) & Mid-ocean ridge, abyssal plain, seamounts & \\
\hline & Goff and Jordan (1988) & General & \\
\hline & Kukowski et al. (2008) & Continental slope & \\
\hline & Micallef et al. (2007a) & Continental slope & \\
\hline & Mitchell et al. (2000) & Mid-ocean ridge & \\
\hline & Moskalik et al. (2014a) & Coastal and inner shelf & \\
\hline & Passaro et al. (2010) & Seamount & \\
\hline & Passaro et al. (2011) & Seamount, volcanic island & \\
\hline & Smith and Shaw (1989) & Abyssal hills & \\
\hline & Lucieer et al. (2013) & Coastal to inner shelf & \multirow{8}{*}{$\begin{array}{l}\text { Habitat mapping and } \\
\text { ecology }\end{array}$} \\
\hline & Hill et al. (2014) & Coastal to inner shelf & \\
\hline & Rengstorf et al. (2012) & Continental slope & \\
\hline & Tong et al. (2013) & Outer shelf & \\
\hline & Micallef et al. (2012a) & Coastal to inner shelf & \\
\hline & Tempera et al. (2012) & Seamounts & \\
\hline & Rengstorf et al. (2013) & Shelf to abyssal plain & \\
\hline & Rengstorf et al. (2014) & Continental slope & \\
\hline & Mohn et al. (2014) & Continental slope & \multirow[t]{2}{*}{ Hydrodynamics } \\
\hline & Tong et al. (2013) & Outer shelf & \\
\hline & Solsten and Aitken (2006) & Coastal & \multirow[t]{2}{*}{ Others } \\
\hline & Stieglitz (2012) & Coastal & \\
\hline \multirow[t]{5}{*}{ Spectral analysis } & Fox and Hayes (1985) & General & \multirow{5}{*}{$\begin{array}{l}\text { Geomorphology and } \\
\text { geohazards }\end{array}$} \\
\hline & Fox $(1996)$ & Mid-ocean ridge & \\
\hline & Gilbert and Malinverno (1988) & General & \\
\hline & Goff and Tucholke (1997) & Mid-ocean ridge & \\
\hline & Moskalik et al. (2014b) & Coastal and inner shelf & \\
\hline \multirow[t]{5}{*}{ Geostatistical methods } & Herzfeld (1989) & Continental slope & \multirow{3}{*}{$\begin{array}{l}\text { Geomorphology and } \\
\text { geohazards }\end{array}$} \\
\hline & Herzfeld and Higginson (1996) & Mid-ocean ridge & \\
\hline & Ismail et al. (2015) & Continental slope & \\
\hline & Diesing et al. (2014) & Coastal to inner shelf & $\begin{array}{l}\text { Habitat mapping and } \\
\text { ecology }\end{array}$ \\
\hline & Hillman et al. (2015) & Continental slope & Hydrodynamics \\
\hline \multirow{7}{*}{$\begin{array}{l}\text { Feature-based } \\
\text { quantitative representation }\end{array}$} & Harrison et al. (2011) & Outer shelf & \multirow{5}{*}{$\begin{array}{l}\text { Geomorphology and } \\
\text { geohazards }\end{array}$} \\
\hline & Micallef et al. (2007a) & Continental slope & \\
\hline & Micallef et al. (2007b) & Continental slope & \\
\hline & Mitchell and Clarke (1994) & Continental shelf & \\
\hline & Pratson and Ryan (1996) & Continental slope & \\
\hline & Calvert et al. (2015) & Coastal & $\begin{array}{l}\text { Habitat mapping and } \\
\text { ecology }\end{array}$ \\
\hline & Bøe et al. (2015) & Continental slope & Others \\
\hline
\end{tabular}


Table 2. Continued.

\begin{tabular}{|c|c|c|c|}
\hline Technique & Reference & Spatial domain & Broad theme \\
\hline \multirow[t]{2}{*}{ Neural networks } & Jiang et al. (1993) & Mid-ocean ridge & $\begin{array}{l}\text { Geomorphology and } \\
\text { geohazards }\end{array}$ \\
\hline & Marsh and Brown (2009) & Continental shelf & $\begin{array}{l}\text { Habitat mapping and } \\
\text { ecology }\end{array}$ \\
\hline Other techniques & $\begin{array}{l}\text { Mountjoy et al. (2009) } \\
\text { Preston et al. (2001) }\end{array}$ & $\begin{array}{l}\text { Continental slope } \\
\text { Coastal to inner shelf }\end{array}$ & $\begin{array}{l}\text { Geomorphology and } \\
\text { geohazards }\end{array}$ \\
\hline \multirow[t]{2}{*}{ Specific geomorphometry } & $\begin{array}{l}\text { Casalbore et al. (2011) } \\
\text { Gee et al. (2001) } \\
\text { Green and Uken (2008) } \\
\text { Haflidason et al. (2005) } \\
\text { Hühnerbach et al. (2004) } \\
\text { Issler et al. (2005) } \\
\text { McAdoo et al. (2000) } \\
\text { Micallef et al. (2008) } \\
\text { Micallef and Mountjoy (2011) } \\
\text { Micallef et al. (2012b) } \\
\text { Micallef et al. (2014b) } \\
\text { Micallef et al. (2014a) } \\
\text { Mitchell and Searle (1998) } \\
\text { Mitchell et al. (2002) } \\
\text { Mitchell et al. (2003) } \\
\text { Mitchell (2003) } \\
\text { Mitchell (2004) } \\
\text { Mitchell (2005) } \\
\text { Rovere et al. (2014) } \\
\text { Roy et al. (2015) } \\
\text { Stretch et al. (2006) } \\
\text { Vachtman et al. (2013) }\end{array}$ & $\begin{array}{l}\text { Volcanic island } \\
\text { Volcanic island } \\
\text { Continental slope } \\
\text { Continental slope } \\
\text { Continental slope and volcanic islands } \\
\text { Continental slope } \\
\text { Continental slope } \\
\text { Continental slope } \\
\text { Continental slope } \\
\text { Continental slope } \\
\text { Continental slope } \\
\text { Continental slope } \\
\text { Mid-ocean ridge } \\
\text { Volcanic island } \\
\text { Volcanic island } \\
\text { Volcanic island } \\
\text { Continental slope } \\
\text { Continental slope } \\
\text { Continental slope } \\
\text { Coastal to inner shelf } \\
\text { Volcanic island } \\
\text { Continental slope }\end{array}$ & $\begin{array}{l}\text { Geomorphology and } \\
\text { geohazards }\end{array}$ \\
\hline & $\begin{array}{l}\text { Costa and Battista (2013) } \\
\text { Diesing et al. (2014) }\end{array}$ & $\begin{array}{l}\text { Coastal } \\
\text { Coastal to inner shelf }\end{array}$ & $\begin{array}{l}\text { Habitat mapping and } \\
\text { ecology }\end{array}$ \\
\hline
\end{tabular}

been useful in determining the key processes constructing and modifying volcano flanks and specifying the conditions that lead to slope instability (Mitchell, 2003; Mitchell et al., 2002; Stretch et al., 2006).

Initially, the techniques of general geomorphometry used in the study of submarine landscapes were less numerous and varied than those used in the study of subaerial landscapes. The majority of studies where geomorphometry was applied to the study of submarine landscapes have involved either spectral analyses of the bathymetric data or the statistical analysis of morphometric attributes (see Table 2 for examples). More recently, general geomorphometric studies have made wider use of morphometric attributes and their statistical analyses and feature-based quantitative representation, most of which were specifically developed for submarine landscapes. Micallef et al. (2007a), for example, developed a methodology for the quantitative analysis of seafloor data, which was shown to exploit the full potential of these data sets and significantly improve the mapping and characterization of submarine landslides. This methodology was applied to the submarine mass movements offshore Norway to elucidate the evolution dynamics of a multi-phase submarine landslide (Fig. 7), while emphasising the potential role of gas hydrate dissociation and contourite deposition in controlling the location and extent of submarine slope failure (Micallef et al., 2009), and to improve understanding of the mechanics and triggers of spreading, also while using limit-equilibrium and mechanical modelling (Micallef et al., 2007b). The automated and objective mapping of submarine landscapes is indeed an important application of general geomorphometry, and specific techniques have been developed for the characterization of pockmarks (Harrison et al., 2011; Gafeira et al., 2012), terraces (Passaro et al., 2011), and canyons (Ismail et al., 2015). Others have used general geomorphometric techniques to classify submarine landscapes (e.g. fjords (Moskalik et al., 2014a; Moskalik et al., 2014b), continental shelf and slope (Elvenes, 2013), and global (Harris et al., 2014); identify the various styles and scales of deformation across submarine landslides (Mountjoy et al., 2009); and infer the evolution of seamounts (Passaro et al., 2010), midocean ridge scarps (Mitchell et al., 2000), and faults in active continental margins (Kukowski et al., 2008). 


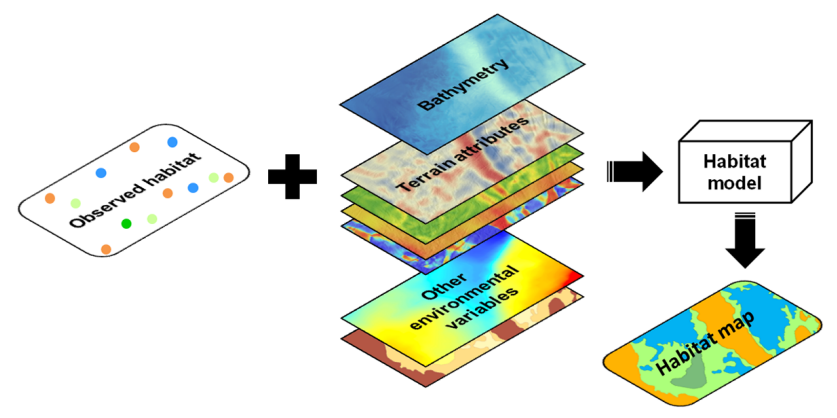

Figure 6. Indicative workflow showing the use of terrain attributes in habitat mapping. Generally following some pre-selection of variables the observed habitat points (response variable) are combined with full coverage predictor variables selected from bathymetry, terrain attributes, and other environmental variables as available to form the input to a habitat model, which will be used to predict a full-coverage habitat map. The choice of habitat model will depend on the study in question but is typically either a statistical (e.g. generalised linear models) or machine-learning-based models (e.g. random forest). Observed habitat points are classified from visual or physical samples of the seabed. Terrain attributes are typically multi-scale and may include general and/or specific geomorphometry. Other environmental variables may include, for example, oceanographic data (temperature, salinity, current speed, etc.) and geological data (e.g. grain size). A similar workflow applies to modelling of single species or communities, where the output will be a continuous map indicating the probability of occurrence within the study area, rather than a categorical map as shown here.

\subsection{Marine habitat mapping, biogeography, and ecology}

Benthic habitat mapping is one of the major applications areas where the use of marine geomorphometry has grown in recent years. Linked to the rise in the use of multibeam data for benthic habitat mapping (Brown et al., 2011; Smith and McConnaughey, 2016) the vast majority of habitat mapping studies with access to good bathymetry data are now using, or at least testing, some form of terrain attribute or feature classification in their habitat mapping activities, even though we note that many of these are not yet reflected in the peerreviewed literature. Among the habitat mapping community several approaches to habitat mapping are common, many of which directly incorporate biological data, such as modelling species (e.g. Davies et al., 2008) or biotope distributions (e.g. Elvenes et al., 2014) and others which are primarily based on physical attributes deemed relevant for the distribution of benthic fauna (e.g. Micallef et al., 2012a; Ismail et al., 2015). Geomorphometry is equally useful for both these approaches and those that combine both aspects (e.g. Tempera et al., 2012) and this discussion is relevant to an all-encompassing definition of habitat mapping (Lecours et al., 2015b). Figure 6 illustrates how terrain attributes are typically used in the production of predictive seabed habitat maps, providing an invaluable suite of full coverage predictor variables, which are used together with point samples of observed habitat as the input data to modelling.

Harris and Baker (2012b) provide a summary of surrogate variables used for habitat mapping studies, including many terrain attributes that have been applied across a multitude of approaches to habitat mapping worldwide. The issue of surrogacy is also discussed in this volume as well as by Lecours et al. (2015b) and McArthur et al. (2010). The case studies presented in the GeoHAB Atlas, and other published studies, vary in the degree to which they have established the ecological relevance of the terrain attributes and/or feature classifications used. For geomorphological variables to really be useful predictors of seafloor habitat, the relationship between habitat and specific variables first needs to be established. Apart from depth, which all of the geomorphological variables are derived from, different shapes or attributes of the seafloor will be relevant to different species at different scales over different bathymetric and biogeographic zones. Bathymetry is known to have a first-order influence on species distribution, largely because many properties that directly affect benthic habitat vary with depth (e.g. light, temperature). A number of recent papers describe the potential of terrain attributes to act as surrogates of species distribution (Lucieer et al., 2013; Hill et al., 2014). The relationships are validated using several different statistical methods that either test terrain attributes against biological or ecological data, or combine terrain attributes with other environmental data and perform classifications to differentiate between the different habitats (Thiers et al., 2014).

In an example by Rengstorf et al. (2013), habitat suitability models for the cold-water coral Lophelia pertusa were developed based on full coverage multibeam bathymetry on the Irish continental margin. Maximum entropy modelling was used to predict $L$. pertusa reef distribution at a spatial resolution of $0.002^{\circ}(250 \mathrm{~m})$. Coral occurrences were assembled from public databases, publications, and video footage, and filtered for quality. Environmental predictor variables were produced by re-sampling of global oceanographic data sets and a regional ocean circulation model. Multi-scale terrain parameters were computed from multibeam bathymetry at $50 \mathrm{~m}$ resolution. In a related study, Rengstorf et al. (2012) examined the effect of bathymetric data resolution on terrain attributes used to predict coral distribution, resampling the original $50 \mathrm{~m}$ resolution bathymetry from the Irish National Seabed Survey at successively coarser intervals up to $1 \mathrm{~km}$. They concluded that terrain attributes derived from higherresolution bathymetry are required to adequately detect the topographic features relevant to corals. In a further related study, Rengstorf et al. (2014) examined the relative importance of terrain attributes and hydrodynamic variables (e.g. current speed, vertical flow, temperature) on models of coldwater coral distribution, concluding that combining the environmental information from these two sources leads to improved predictions over the spatial scales in question. 

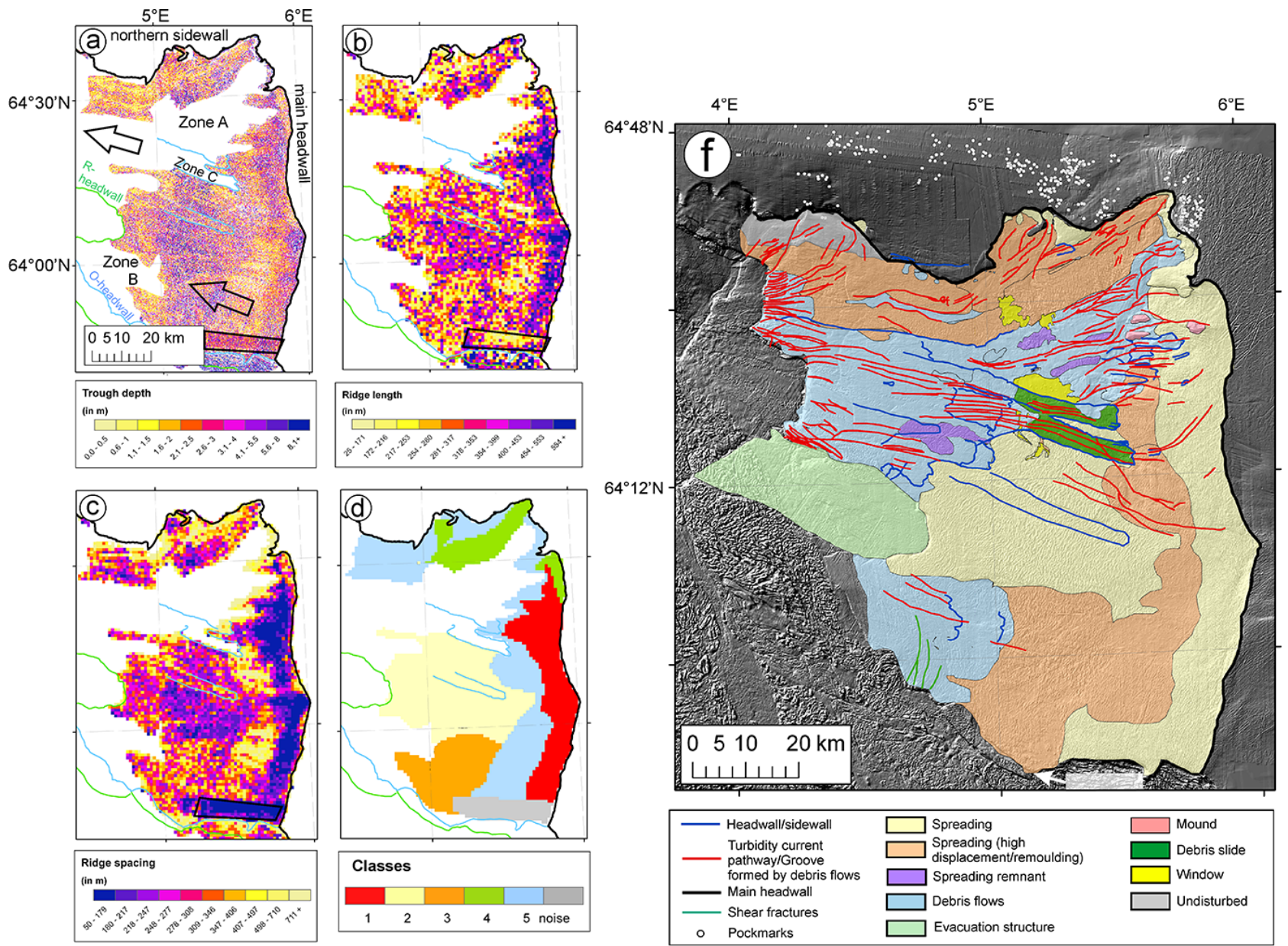

Figure 7. Example of the use of marine geomorphometry to semi-automatically map the components of mega-scale submarine landslide offshore Norway (adapted from Micallef et al., 2009). (a-c) show the trough depth, ridge length, and ridge spacing extracted from a MBES map of the north-eastern Storegga Slide using ridge characterization techniques (Micallef et al., 2007b). Figure d is a classification map generated by using these ridge characteristic maps as input layers in an unsupervised clustering algorithm (ISODATA). (e) is an interpretative map of the range of spreading events based on (a-d). Other mass movements and geological processes and structures have been interpreted using geomorphometric mapping (Micallef et al., 2007a).

At a much finer-resolution $(\sim 1 \mathrm{~m})$ species-habitat relationships were examined across a marine reserve on the south-eastern coast of Tasmania using boosted regression tree analyses (Cameron et al., 2014). The most important explanatory variables of community diversity were those describing the degree of reef aspect deviation from east and south (seemingly as a proxy for swell exposure), reef bathymetry (depth), low rugosity, and slope. These models could account for up to $30 \%$ of the spatial variability in measures of species diversity. As biological data at scales relevant to acoustic or remote sensing data, such as that from AUVs, ROVs, and diver surveys, become available on national or international databases, such as the Census for Marine Life and the Ocean Biogeographic Information System (OBIS), the ability to extend species distribution models into the wider ocean at finer scales will enhance the utility and value of marine geomorphometry variables for marine biodiversity assessment.

\subsection{Hydrodynamics and modelling}

The interaction of bottom currents with seafloor sediments results in a wide range of erosional and depositional morphologies - e.g. scours, furrows, ripples, dunes, lineations, contouritic drifts - the morphology and dimensions of which depend on flow velocity and sediment grain size (Stow et al., 2009). Detecting change in bedform morphology is of great interest to geologists, physical oceanographers, and climatologists, and many others with the applied interest in such features. Bedforms determine basic flow patterns of ocean circulation at coarse and fine scales; even small perturbations in seafloor topography can influence the pathway and velocity of major shallow and deep current flows, heat transport, and 
ultimately climate (Gille et al., 2004; Kunze and Llewellyn Smith, 2004; Metzger and Hurlburt, 2001; Palomino et al., 2011). In turn, bedforms are also excellent archives of current and past bottom flow patterns (Sandwell et al., 2002). Port managers are also interested in bedforms and their evolution, particularly where they constitute a hazard to navigation in coastal waters. Detecting change in bathymetry and its impact on oceanography is therefore important, and local geomorphometric attributes, such as aspect, curvature, and rugosity, have been used to develop hydrodynamic models or as proxies for local and regional currents (Lecours et al., 2015a). Seafloor topographic proxies are also fundamental in the predictive mapping of suspension-feeders (Lucieer et al., 2013; Hill et al., 2014), such as cold-water corals (Rengstorf et al., 2012; Tong et al., 2013), because their distribution is inextricably linked to current flow strengths and patterns (Mohn et al., 2014). More recently, understanding the link between seafloor morphometry and currents has been shown to be essential in forecasting the path of floating debris from tsunamis and air disasters and assist in search and rescue operations (Mofield et al., 2004; Normile, 2014; Smith and Marks, 2014).

\subsection{Emerging and future applications}

Other applications of marine geomorphometry can also be found in the literature. We anticipate that the number of application areas will grow substantially over the next few years as awareness of data and analysis techniques expands, and high-resolution data become more widely available.

\subsubsection{Change detection}

A number of studies have described temporal morphological dynamics of the seafloor using acoustic bathymetry (e.g. Duffy and Hughes-Clarke, 2005; Smith et al., 2007). However, assessments of biological change beyond the range of optical sensors have been based primarily on ground sampling methods. Rattray et al. (2013) investigated approaches to quantify temporal change in benthic habitats from a spatially explicit perspective using acoustic techniques. Their methods (1) quantified change in terms of gains and losses in the extent of habitat at a site on the temperate southeast Australian continental shelf, (2) they could distinguish between systematic and random patterns of habitat change, and (3) were able to assess the applicability of supervised acoustic remote sensing methods for broadscale habitat change assessment. Change detection in temperate bedrock reefs were identified through morphological characterization by Storlazzi et al. (2013). They delineated the classes using a multivariate classification routine (Dartnell and Gardner, 2004) based on acoustic backscatter and rugosity (surface-planar area ratio).

There have also been several examples in the literature of repeat multibeam surveys being used to detect change, many of which are summarized by Schimel et al. (2015). Analysis is generally focused on differences in depth values detected and often aided by a visual assessment of the changes in morphology. There are fewer studies that have explicitly used terrain attributes or features in their assessments, but we recognise the potential for gemorphometric techniques to be more widely applied in this type of study. For example, Bøe et al. (2015) used geomorphic feature detection (Wood, 1996) to identify crests and ridges in a sandwave field on the continental slope, and assess movement between surveys based on the change in position of these features. We note also that Schimel et al. (2015) incorporate measures of bathymetric uncertainty in their assessment of volume change and also recommend guidelines on thresholds, which can help to improve the confidence of such assessments.

\subsubsection{Seismic geomorphometry}

Seismic geomorphology is a rapidly evolving discipline. It comprises the application of geomorphological principles and analytical techniques to study palaeo-landscapes as imaged by three-dimensional (3-D) seismic reflection data (Carter, 2003; Posamentier and Kolla, 2003; Posamentier, 2003). More recently, 3-D seismic reflection data have also provided a good alternative source of bathymetric data when the latter are absent (e.g. broadscale geomorphic mapping in the MAREANO project - http://www.mareano.no/). The development of seismic geomorphometry is a natural consequence of increasing computer power, which enables the rapid manipulation, visualization, and interpretation of 3 D seismic reflection data, and the enormous investment in this technology by the oil and gas industry, with academics and government researchers benefitting from access to these data. The integration of seismic geomorphology with seismic stratigraphy currently represents the state-of-the-art approach to extracting geological information from 3-D seismic reflection data to understand large-scale basin evolution. Seismic geomorphological studies have addressed a broad range of geological problems, ranging from sedimentary to igneous geology, from lithology distribution to large-scale tectonic analysis (e.g. Fachmi and Wood, 2003; Miall, 2003; Wood, 2003).

Up to the present, most studies have focused on the qualitative recognition of broadscale features (e.g. Posamentier et al., 1996; 2000; Peyton and Boettcher, 2000; Posamentier, 2003; Zeng and Hentz, 2004). Quantitative seismic geomorphology, or seismic geomorphometry, is the most recent development of seismic geomorphology (Carter, 2003; Posamentier, 2003; Posamentier and Kolla, 2003). Seismic geomorphometry has been defined as the "quantitative analysis of the landforms, imaged in 3-D seismic data, for the purposes of understanding the history, processes and fill architecture of a basin" (Wood, 2003). Seismic geomorphometry encompasses techniques that use 3-D seismic data to investi- 
gate the nature and architecture of reservoirs through extraction and analysis of quantitative morphometric information.

Great opportunities exist for applying a more quantitative approach in seismic geomorphology. Seismic geomorphometric techniques provide statistical and mathematical insight into the morphological and dimensional characteristics of geologic systems that are difficult to derive through qualitative investigations of outcrop exposures and 2-D seismic reflection data. Seismic geomorphometric studies provide a deep and spatially extensive understanding of how morphology develops through time, providing insight into the historical evolution of a basin and the possibility of developing predictive models. Quantitative relationships derived from seismic geomorphological studies can decrease our uncertainty in predicting the nature and location of reservoirs in deepwater settings by testing cause-and-effect relationships in a variety of settings. Computer-assisted seismic geomorphometry, in particular planform pattern recognition, is a powerful addition to the seismic geomorphological approach. It allows the interpreter to identify geologically significant features in plan view automatically. The ability to exploit the full potential of large seismic data sets is currently hindered by the lack of tools in existing software packages, coupled with the limited knowledge of how morphometrics can be used in the analytical process. It is the development of such tools that should be a main focus for researchers of marine geomorphometry in the near future.

\subsubsection{Broadscale coastal geomorphometry}

This paper has shown how geomorphometric techniques developed mostly in terrestrial settings can be applied to the marine environment or adapted to enable quantification of the seafloor terrain. For a long time, however, the boundary between the land and the sea was not easily mapped or delineated and represented a challenge for both marine and terrestrial scientists (Klemas, 2011a). This was due to the inability of satellite remote sensing to collect data in deep waters and the limitations of acoustic systems to collect data in shallow waters, which often creates a gap in terrain data where land meets sea. This littoral gap, sometimes referred to as "the white zone" because the lack of data in this area between available DBM and DEM data appear white on maps, often complicates the study of nearshore environments and can have important implications for applications such as navigation and geohazard assessment. For instance, in their attempt to assess the effectiveness of a marine protected area in a Canadian subarctic fjord with habitat maps generated from a combination of terrain attributes and other data, Copeland et al. (2013) were only able to map $32 \mathrm{~km}^{2}$ of the total $82 \mathrm{~km}^{2}$ of the area. They highlighted the laborious nature of a shallow water survey (i.e. time- and cost-consuming MBES surveys), the need for a continuous coverage because of the large littoral gap, and indicated that interpolation and extrapolation of results in the littoral gap were inappropriate because of the heterogeneous nature of coastal fjord environments (Copeland et al., 2013).

In the last 15 years, developments in lidar surveying methods (e.g. Hardin et al., 2014) and bathymetric lidar systems (cf. Sect. 2.4) slowly helped fill the littoral gap. Consequently, efforts to map the littoral using bathymetric lidar have spread across the globe (e.g. the National Coastal Mapping Program of the Joint Airborne Lidar Bathymetry Technical Center of Expertise in the United States), and several examples of investigations of the coastal environment using geomorphometry can now be found in the literature (e.g. Purkis et al., 2008; Pittman et al., 2009). This body of literature used to be mostly characterized by the study of small areas either above the water (e.g. dunes or emergent features) or submerged (e.g. coral reefs) (Brock and Purkis, 2009), but there are now more and more efforts targeting the collection of topo-bathymetric data that span the coastal environment (e.g. Dunkin et al., 2011; Dunkin and McCormick, 2011). Several fields can benefit from seamless coastal geomorphometric analysis. For instance, inter-tidal rocky shores are known to shelter a lot of biodiversity (Kostylev et al., 2005) and linking quantitative terrain attributes to measures of biodiversity could improve scientific understanding of ecological patterns and processes in these important areas of the land-sea boundary (e.g. Collin et al., 2012). So far, limitations of lidar systems (e.g. inability to collect data in deeper waters, costs associated with airborne surveys), however, restricted these efforts to local and sometimes regional scales. To our knowledge, there are no geomorphometric applications that span the terrestrial and underwater landscapes in a continuous way over very large areas, which would require the integration or fusion of data sets from different sources (e.g. lidar, terrestrial DTMs, and acoustic surveys).

At a broader scale, a seamless analysis of terrestrial and marine environments requires the combination of terrestrial DTMs, bathymetric data from acoustic systems, and bathymetric lidar or optical remotely sensed data to fill the littoral gap and create what has been called in the literature a coastal terrain model (CTM) (Hogrefe et al., 2008; Leon et al., 2013). The challenges encountered with merging data sets from different sources makes such an approach still nascent in the general literature (Macon et al., 2008; Quadros et al., 2008; Collin et al., 2012), and very rare, if not fully absent, in the marine geomorphometry literature. Data fusion is the process of acquiring, processing, and synergistically combining multi-source data sets both geometrically (i.e. in space) and topologically (i.e. in terms of their attributes or information content) (Usery et al., 1995; Samadzadeghan, 2004; Mohammadi et al., 2011). Despite constant developments in data fusion (Pohl and van Genderen, 1998; Dong et al., 2009; Zhang, 2010), it presents particular challenges for geomorphometry. First, despite improvements in edge matching algorithms, artefacts from merging and surveying can appear when deriving terrain attributes from the fused data set (Stoker et al., 2009). Data fusion often requires the different 
data sets to overlap slightly in order to be combined. In theory, the overlapping areas should yield very similar values, within their uncertainty and error ranges. However, important inconsistencies (up to $6.5 \mathrm{~m}$ ) have been reported between depth measurements of the same areas using bathymetric lidar and MBESs (Quadros et al., 2008; Costa et al., 2009; Chust et al., 2010; Shih et al., 2014). This has implications for geomorphometry since terrain attributes will capture and classify these mismatches as features, especially as the differences usually occur locally (Chust et al., 2010). Also, coastal environments can be very dynamic; artefacts could appear in the DTM if the multi-source data are not collected at the same time and changes occurred between the data collections. Another issue concerns vertical datums (Hogrefe et al., 2008); terrestrial surveys are usually referenced to a local geoid model based on the GPS, while underwater acoustic surveys are usually referenced to the mean sea level at the time of survey, which is referenced to a local or regional tidal gauge that is itself referenced to a local datum. Calls for a consistent and unified vertical datum have been made but this issue is still unresolved (Hogrefe et al., 2008; Quadros et al., 2008). Finally, data quality and uncertainty may complicate the fusion of the different data sets. For instance, the inability of bathymetric lidar systems to collect reliable data in turbid or cloudy waters and in breaking wave conditions, in addition to their difficulties to distinguish the seafloor from the water surface in waters shallower than $30 \mathrm{~cm}$ (Quadros et al., 2008) may create a smaller littoral gap called the "dead zone" (Nayegandhi et al., 2009) and prevent proper fusion. Bernstein et al. (2011) recommend a customized survey design to minimize the challenges associated with creating a seamless DTM.

Regular problems of data fusion, for instance related to merging multi-resolution data sets or to software and format compatibility/interoperability, also apply to the development of DTMs for broader-scale coastal geomorphometry. Terrestrial terrain models may have a digital elevation model (.dem) format, bathymetric lidar data can be recorded with a laser file (.las) format, and acoustic data can be saved in a Bathymetric Attributed Grid (.bag) format; all these file formats have different structure and characteristics. Impediments to the fusion of multisensor data to build seamless elevation and depth surfaces include, but are not limited to, inconsistent spatial and temporal scales, incompatible formats, and differences in levels of reliability, uncertainty and completeness. Despite these impediments, data fusion has been identified as a promising technique for geomorphometry (Bishop et al., 2012).

Some authors (e.g. Quadros et al., 2008) argue that the different types of data sets cannot be readily integrated, but the main challenges will likely be addressed with improvements in data fusion techniques and ease of implementation of these techniques for non-expert users (Zhang, 2010) for geomorphometry. Current work includes detection and correction of differences in geoid models, consideration of uncertainties, and improvement in edge matching algorithms (Quadros et al., 2008; Dong et al., 2009; Stoker et al., 2009). Recently, Leitão et al. (2016) proposed a new method to merge different DTMs developed specifically for geomorphometry. Future developments in data fusion will likely allow for better integration of different data to create seamless coverage for complete geomorphometric analysis and identification of broadscale overlapping landforms between the different realms. This will be useful for a wide range of coastal applications. For instance, observations of underwater and terrestrial landforms have shed light on how glaciers retreated in Atlantic Canada during the last deglaciation (Shaw et al., 2006); the investigation of landforms that overlap both realms could help refine this type of analysis. Other potential applications include the investigation of coastal morphodynamics and land-sea exchange modelling, dredging, the identification of hazards due to sea-level rise and severe storms, the assessment of consequences of such storm events, monitoring and shore protection, coastal archaeology, resource management and marine spatial planning, anthropogenic sensitivity and environmental status assessment, and other scientific research.

\subsubsection{Underwater archaeology}

In the last 25 years, terrestrial archaeology has largely benefitted from remote sensing tools and methods (McCoy and Ladefoged, 2009). Radar and lidar data have helped reveal archaeological features of interest in many areas of the world (e.g. Meylemans et al., 2015), or detect anomalies that could be linked to sites of interests that cannot be seen from the ground (e.g. Lin et al., 2011). Geomorphometry has been used on radar and lidar data to identify such patterns (Kvamme, 1999) or to describe particular areas (Turrero et al., 2013). Similarly to what happens in marine geomorphometry, its use is often not being recognized as geomorphometry or terrain analysis.

The remote sensing techniques described in Sect. 2 have also been used in underwater archaeology to collect bathymetric and backscatter data that were used, for instance, in initial investigations of wreck site locations and extent before divers or ROVs further investigate the sites (e.g. Jones et al., 2005; Masetti and Calder, 2012). Similarly to terrestrial archaeology, these types of data enable both the direct identification of the features on the seafloor or anomalies that may indicate potentially buried artefacts (Papatheodorou et al., 2005). Geomorphometry has yet to gain traction in underwater archaeology, but is not completely absent. Using MBES data, Stieglitz (2012) documented an area of seafloor off Australia that had a conspicuous arrangement of over 1200 shallow holes, and wide (up to $10 \mathrm{~m}$ ) and deep (up to $1.5 \mathrm{~m}$ ) holes. They classified these holes using local slope measurements, and found that the systematic distribution of these seafloor features was related to their distance from a shipwreck and likely caused by bioturbation. In another ap- 
plication, Passaro et al. (2013) extracted archaeological features related to Italian sunken cities using curvatures and the r.param.scale command from GRASS GIS (cf. Sect. 5.1). Slopes values were used by Solsten and Aitken (2006) to assess the risk of disturbance of archaeological sites by mass movement and marine flooding in Nunavut, Canada. The application of techniques from geomorphometry to underwater archaeology is likely to increase in the future, and we note the potential of seismic geomorphometry to assist in the investigation of buried artefacts.

\section{The future of marine geomorphometry}

\subsection{Current and future trends in marine geomorphometry}

Current developments in the marine geomorphometry literature are primarily focused on the data acquisition end of the workflow. Technology and equipment for surveying the seafloor are improving in quality, accuracy, and cost effectiveness, which will allow for an increase in data availability and quality. In coastal environments, ongoing research is focused on improving the extraction of depth information in the littoral gap in order to create seamless DTMs from the seafloor to land, and developments in data fusion should soon enable broadscale geomorphometric analyses of coastal environments. As the pressure on coastal environments increases, such information will become crucial for many applications. From an ecosystem point of view, coastal environments are also very rich in biodiversity. Studies of the topographic structure that can be identified from CTMs using geomorphometric techniques are likely to facilitate a better scientific understanding of these ecosystems. In the deep sea, extensive use of AUV- and ROV-based MBES and other technologies means we are now able to collect high-resolution bathymetric data of environments never explored before at such level of detail. The knowledge that has been gained from using these data in combination with different techniques, including geomorphometry, has revolutionized scientific understanding of many marine environments. It was initially thought that the deep sea was mostly flat, muddy and lifeless, but the last 20 years of research have proven otherwise. Nevertheless, exploration is far from complete; there are still wide gaps in the scientific knowledge of deep-sea patterns, processes, and ecosystems. High quality bathymetric data are fundamental to the success of revealing this knowledge and its limited availability is currently a barrier to effective protection and management of vulnerable species (Vierod et al., 2014; Ross et al., 2015).

As the marine geomorphometry community moves forward, it will rapidly need to start addressing issues other than those associated with data acquisition. The availability of tools that streamline the workflow from data collection to analysis will be key in making a more complete science of marine geomorphometry accessible to marine scientists with a wide range of background and experience. Repositories of comprehensive and freely available data sets and tools, such as Digital Coast that provide free coastal and marine bathymetric data and analytical tools (NOAA, 2016), are the way forward to improve accessibility to the wider scientific community, and this may well mean that bathymetric data gain the attention of those currently engaged in developing geomorphometric methods for terrestrial data. We also acknowledge that easily accessible GIS tools and readily available data can also bring hidden dangers from non-critical use by users with limited appreciation of data collection and processing methods, which to the expert clearly reflect the limitations in the utility of particular bathymetric data sets. To prevent this danger of inappropriate use, tools and data sets need to be accompanied by complete metadata that include information on data provenance, survey, scale, error, and uncertainty quantification, and any other information relevant to further use of the tools and data sets. Metadata are crucial to create a "quality-aware" community (Devillers et al., 2007; Lecours et al., 2015b). The use of the CUBE algorithm to create BASE surfaces is one way to carry over a measure of quantified uncertainty of the data, but such information is not readily available for the majority of publicly available data sets. This type of information needs to become more accessible to marine scientists with a broad range of scientific backgrounds.

It is becoming critical to raise awareness of geomorphometry in the marine science community. Methods from specific geomorphometry demonstrate a lot of potential for marine applications and should be used more extensively. At the same time, it is opportune to improve practices by setting standards and protocols for the application of geomorphometry. Methods and interpretations need to be standardized, particularly in view of issues specific to the marine environment, or where data and analyses behave differently underwater than on land. Amongst these, the influence of scale and data resolution on the results, and the consideration of spatial uncertainty should be prioritized. End users should be explicit about which algorithms or methods they use and at which scale in order to enable proper comparison among studies. Since geomorphometric analyses are more and more performed within GIS environments, devising a GIS-based standard methodology and symbology for marine geomorphological mapping using geomorphometry would be a very useful goal for the marine geomorphometry community. Ultimately, the type of standards and protocols a marine geomorphometry community could develop should encourage wider applications of bathymetric data and allow marine scientists optimize the use of their expensive data sets.

\subsection{Uniting efforts in geomorphometry}

This manuscript has discussed the current practices in marine geomorphometry, from data collection to the applications. Through all aspects of this discussion it is apparent 
that the use of modern geomorphometric techniques in the marine realm is relatively nascent, having begun only over a decade ago in application areas outside of marine geomorphology. The dramatic increase in DBM availability, combined with the increasingly accessible and user-friendly GIS tools, is currently fuelling the amount and diversity of applications of marine geomorphometry. However, this availability can become a double-edge sword. As noted by Dolan and Lucieer (2014), "Although a [DBM] is a model of the seabed surface, it is often not treated as a model but rather is accepted as a true representation of the seabed". Furthermore, as highlighted in Fig. 2, the end users of geomorphometric techniques are not always aware that they are actually "doing" geomorphometry, but rather think of the steps they are performing as simply using GIS tools for data analysis. As the number of applications increases, some of the fundamental issues associated with marine geomorphometry are not being addressed quickly or broadly enough. This can increase the risk of unsuspecting end users misusing data or techniques, and to the misinterpretation of results. For instance, due to a lack of awareness of the impact of artefacts in DBMs and their propagation to terrain attributes, artefacts are often disregarded, or assumed to be obvious. In habitat mapping, the consequences of artefacts are often apparent to geomorphometry-aware users in the final maps (e.g. Zieger et al., 2009; Lucieer et al., 2012), but this can become problematic if the maps are being used in conservation and management decision making if the effect of the artefacts is not appreciated by the end user. It is thus crucial for end users, planners, managers, and decision makers to become aware and understand the properties of their data that result from each of the five steps of geomorphometry, and how these properties influence their particular application.

In addition to end users not being aware of geomorphometry as a science, scientists engaged in more terrestrial and extra-terrestrial geomorphometry are rarely aware of marine geomorphometry, its differences, and its similarities with their field of expertise. For example, at the turn of the millennium, Pike (2000) identified the study of seafloor abyssal hills as a prospect topic for the application of geomorphometry. However, many examples can be found of marine geophysics and geomorphology studies dating from the 1980s1990s that have used geomorphometry in abyssal hills (e.g. Malinverno and Gilbert, 1989; Goff, 1991, 1992; Malinverno and Cowie, 1993; Shaw and Lin, 1993). A decade later, Pike et al. (2009) tried to suggest using digital depth models (DDM) to characterize surface models of the seafloor, despite the wide acceptance of DBM as an appropriate term in the marine geomorphometry literature.

We recognize a critical need for a dedicated scientific effort in marine geomorphometry that will address, and raise awareness of the fundamental issues related to marine geomorphometry. This effort does not necessarily have to come solely from the marine science community, indeed it may well benefit from the expertise of many of those scientists already engaged in terrestrial geomorphometry. The main objectives of this effort would be to learn from the lessons of terrestrial geomorphometry, ensure that studies of geomorphometry become more widespread in the marine literature, and respond to the challenges and opportunities for a wider adoption of marine geomorphometry as a key tool in marine sciences, whilst improving and upholding scientific standards. Since sub-fields of geomorphometry dealing with different types of environments are ultimately parts of the same science and share more similarities than have differences, these standards should become common to all these sub-fields. For example, geomorphometry is a field recognized for its ambiguous terminology, particularly in terms of terrain attributes (Bishop et al., 2012). The field of geomorphometry should move towards a more uniting terminology and vocabulary across environments that would reduce some of that ambiguity. For instance, the use of the terms DEM, DBM, CTM, and DDM should be abandoned in favour of the more neutral, all-encompassing term DTM. Moving towards a joint terminology is just an example of how we can reunite all sub-fields of geomorphometry together, with common goals and approaches. For instance, many of the issues and future challenges mentioned in this overview (e.g. uncertainty and error propagation and modelling, scale, change detection) have been discussed in recent reviews about terrestrial high-resolution topographic data and Earth surface processes (Tarolli, 2014; Passalacqua et al., 2015), highlighting the similarities in challenges and opportunities that marine and terrestrial geomorphometry are facing. Uniting efforts in geomorphometry will likely result in more effective research and development and facilitate the coupling with other disciplines, including different fields of marine sciences.

\section{Conclusions}

Relative to the "young" and "still forming" modern terrestrial geomorphometry (Evans and Minár, 2011, p. 105), the use of geomorphometry in the marine realm is still in its infancy. Ever since the first coarse-scale DBMs were generated, marine geomorphometry has helped improve scientific understanding of the oceans, from the relatively thin border where land meets sea to the deepest waters. This paper is timely because it provides an overview of the state of the art in the field and discusses standards for the applications of marine geomorphometry. By following the five main steps of geomorphometry by Pike et al. (2009), we have reviewed marine geomorphometry in a way that can easily be compared with terrestrial geomorphometry. We have provided an overview of the different methods to sample the depth of the seafloor, the interpolation methods and issues of spatial scale associated with the generation of a DBM, as well as discussing the different errors and artefacts that are characteristic of DBMs but different from those common in DEMs. Further, we have discussed how general and specific geomorphometry are applied underwater, provided applications 
of marine geomorphometry, and outlined future trends in the field. Clearly there is room in the literature for more detailed reviews of each of these five steps and relating to many of the sub-disciplines; however, we hope that this review will serve as a solid foundation for further, more detailed reviews on these sub-topics.

Based on this review, we provide the following recommendations that should help establish more productive practices in marine geomorphometry: (1) errors and spatial uncertainty should be quantified so that they are able to be considered in the geomorphometric analyses and in the interpretation of results; (2) metadata should consistently be associated with data sets to explicitly indicate data provenance, quality (i.e. quantification of uncertainty), and the spatial scale at which the data set was intended to be used; (3) data, metadata and tools should be made available for a wider applications of bathymetric data; (4) standardization of methods and interpretations for each field of application should be documented, particularly in view of the influence of algorithms, scale and data resolution on the results; and (5) a GIS-based standard symbology for marine geomorphological mapping based on geomorphometry should be devised.

Through raised awareness of each other's disciplines, we hope that both marine scientists and geomorphometry practitioners will be better placed to work together in addressing the fundamental issues of marine geomorphometry, whilst upholding scientific standards in marine spatial analysis. Building a dedicated effort in marine geomorphometry that can draw on lessons learned in terrestrial geomorphometry will not only encourage marine applications and continued scientific development, but will ensure that the science of geomorphometry is used to its full potential for studying the topography of the whole planet. 


\section{Appendix A: Details on the theories behind bathymetric data collection techniques}

\section{A1 Satellite radar altimetry}

Radar altimeters emit microwaves that bounce on the sea surface and return to the receiver, giving the altitude of the satellite over the sea surface. The topography of the surface can then be deduced and used to derive ocean circulation patterns (Fu, 1983) or geoid models (e.g. Fernandes et al., 2000). The geoid represents the gravitational equipotential surface of the Earth; gravity varies in space, and the anomalies in its distribution were found to be correlated with bathymetry (McKenzie and Bowin, 1976; Watts 1979). Despite initial reports stating that it was impossible to derive reliable bathymetry from satellite altimeter (Keating et al., 1984; Watts and Ribe, 1984), Dixon et al. (1983) were the first to demonstrate its feasibility using real data. Several algorithms and methods to estimate and predict bathymetry from the gravitational field have since been developed (reviewed in Calmant and Beaudry, 1996 and Sandwell and Smith, 2001). However, it remains a complex process (Calmant and Beaudry, 1996) that still requires acoustic data for calibration (Smith and Sandwell, 1997). Altimetry-derived bathymetric data only provide low resolution estimates of the bathymetry; ocean waves create a lot of noise that prevents the collection of fine-resolution data (Smith, 1998), and rough seafloor geology affects finer-scale data accuracy (Smith and Sandwell, 1994).

\section{A2 Optical remote sensing}

The ability to derive depth estimates from imagery comes from the optical Beer-Lambert law of light absorbance, which describes light absorption in uniformly attenuating water (Serway and Beichner, 1983). In water, light gets absorbed exponentially as depth increases (Lyzenga, 1978). The Beer-Lambert law allows the mathematical derivation of depth estimates from the brightness values of pixels in an image, when the absorption characteristics of an area are known (Mobley et al., 2005; Carbonneau et al., 2006). Since the absorption rate of an area is dependent on water turbidity and the characteristics of the incoming energy (e.g. the intensity, angle and wavelength of sunlight), calibration with ground-truth data (i.e. measurements of local light absorption characteristics) is a key step in the application of this method. However, calibration is made difficult by temporal variations in the illumination characteristics of an area (Carbonneau et al., 2006); the calibration data would ideally need to be collected at the same time as the remotely sensed data to ensure identical environmental conditions. Since reliable calibration data are particularly challenging to obtain in marine waters (Lafon et al., 2002; Dekker et al., 2011), some methods have been proposed to estimate bathymetry without ground-truth data (e.g. Fonstad and Marcus, 2005), however these are not yet widely adopted (Feurer et al., 2008). Rather than using the level of absorbed energy to derive bathymetry from imagery, some authors, e.g. Maritorena et al. (1994), have used bottom reflectance, which is the level of reflected energy. Many types of imagery have been used to derive marine bathymetry: hyperspectral (e.g. Ma et al., 2014), multispectral (e.g. Lyzenga et al., 2006; Pacheco et al., 2015), broadband colour (e.g. Westaway et al., 2003) and grayscale images (e.g. Winterbottom and Gilvear, 1997). Multispectral images enable refined depth estimates by extracting information on the bottom types from non-visible spectral bands; accounting for bottom reflectance allows better distinguishing the spectral response from which depth estimates are derived (Winterbottom and Gilvear, 1997). The red band of the electromagnetic spectrum is particularly successful in detecting depth variations (Legleiter et al., 2004).

\section{A3 Acoustic remote sensing}

Acoustic waves are the most practical vehicle of information in the submarine environment; since water is denser than air, acoustic vibrations propagate through water four to five times quicker (Lurton, 2010). Sound also travels greater distances underwater as there is less attenuation in the water compared to air (Lurton, 2010). Sidescan sonars (SSS) developed for military applications in the 1940s - , singlebeam echosounders (SBES), and multibeam echosounders (MBES) are all active sonars that transmit a characteristic and controlled signal in direction of the seafloor. When knowing the speed of sound in water, the two-way travel time - the time taken for acoustic waves to travel between the source and the seafloor and back to the source again can be measured to estimate the range between the target and the sonar, thus enabling deduction of depth. The intensity of this return (i.e. backscatter) can also be measured to provide information on the properties of the seafloor (e.g. sediment composition). Despite their ability to provide information on the topographic roughness and hardness of the seafloor, SSS cannot reliably measure seafloor relief directly, except when two receiving antennas are combined and principles of interferometry are applied to create bathymetric estimates. Synthetic aperture sonars differ from traditional SSS by utilising data from several consecutive pings to synthesize a longer sonar array capable of measuring at higher resolution. Many modifications of SBES were suggested through time to increase their performance. For instance, the splitbeam echosounder uses interferometry to improve the accuracy of the data and was used to determine slope directly (Fosså et al., 2005). The dual-beam echosounder uses two beams of different aperture oriented in the same direction to locate targets more accurately. Finally, the sweep sounder is a combination of several SBES mounted on a horizontal support to increase the number of soundings. 


\section{A4 Bathymetric lidar}

Lidar systems are active sensors that generate laser beams; by knowing the speed of light and measuring the time between when a beam was sent and when its corresponding returns came back to the sensor, it is possible to derive the distance between the sensor and the different targets (e.g. land, water surface, seabed) encountered by the laser beams (Irish and Lillycrop, 1999). Principles and the geometry of bathymetric lidar systems are reviewed in Kashani et al. (2015). 
Acknowledgements. V. Lecours thanks Emma LeClerc for her valuable comments on sections of this manuscript, Rodolphe Devillers for the insightful discussions about marine geomorphometry, and the Natural Sciences and Engineering Research Council (NSERC) of Canada for providing funding. A. Micallef is funded by a Marie Curie Career Integration Grant PCIG13-GA-2013-618149. We also acknowledge Memorial University Libraries for financial support, and the three referees and the editor for their comments.

Edited by: H. Mitasova

Reviewed by: N. Mitchell and two anonymous referees

\section{References}

Adams, E. W. and Schlager, W.: Basic types of submarine slope curvature, J. Sediment. Res., 70, 814-828, 2000.

Anderson, M. G. and Ferree, C. E.: Conserving the stage: climate change and the geophysical underpinnings of species diversity, PLOS One, 5, e11554, doi:10.1371/journal.pone.0011554, 2010.

Arifin, R. R. and Kennedy, A. B.: The evolution of large scale crescentic bars on the northern Gulf of Mexico coast, Mar. Geol., 285, 46-58, 2011.

Bakran-Petricioli, T., Antonić, O., Bukovec, D., Petricioli, D., Janeković, I., Križan, J., Kušan, V., and Dujmović, S.: Modelling spatial distribution of the Croatian marine benthic habitats, Ecol. Model., 191, 96-105, 2006.

Becker, J. J., Sandwell, D. T., Smith, W. H. F., Braud, J., Binder, B., Depner, J., Fabre, D., Factor, J., Ingalls, S., Kim, S.-H., Ladner, R., Marks, K., Nelson, S., Pharaoh, A., Trimmer, R., Von Rosenberg, J., Wallace, G., and Weatherall, P.: Global bathymetry and elevation data at 30 arc seconds resolution: SRTM30_PLUS, Mar. Geod., 32, 355-371, 2009.

Benz, U. C., Hofmann, P., Willhauck, G., Lingenfelder, I., and Heynen, M.: Multi-resolution, object-oriented fuzzy analysis of remote sensing data for GIS-ready information, ISPRS J. Photogramm., 58, 239-258, 2004.

Berkson, J. M. and Matthews, J. E.: Statistical properties of seafloor roughness, in: Acoustics in the Sea-bed, Bath University Press, Bath, UK, 215-223, 1984.

Bernstein, D. J., Sumners, B. J., Freeman, C. W., and Mitasova, H.: Modern techniques for improved topo/bathy elevation modelling of tidal inlets, U.S. Hydro 2011, 1-11, 2011.

Bishop, M. P., James, L. A., Shroder Jr., J. F., and Walsh, S. J.: Geospatial technologies and digital geomorphological mapping: concepts, issues and research, Geomorphology, 137, 5-26, 2012.

Blaschke, T., Hay, G. J., Kelly, M., Lang, S., Hofmann, P., Addink, E., Queiroz Feitosa, R., van der Meer, F., van der Werff, H., van Coillie, F., and Tiede, D.: Geographic object-based image analysis - towards a new paradigm, ISPRS J. Photogramm., 87, 180191,2014

Blaszczynski, J. S.: Landform characterization with geographic information systems, Photogramm. Eng. Rem. S., 63, 183-191, 1997.

Blondel, P. and Murton, B. J.: Interpretation of sidescan sonar imagery, John Wiley, Chichester, UK, 1997.

Blondel, P., Parson, L. M., and Robigou, V.: TexAn: Textural analysis of sidescan sonar imagery and generic seafloor characterisation, Oceans-IEEE, 419-423, 1998.
Booth, J. S. and O'Leary, D. W.: A statistical overview of mass movement characteristics on the North American Atlantic Outer Continental Margin, Mar. Geotechnol., 10, 1-18, 1991.

Brock, J. C. and Purkis, S. J.: The emerging role of LiDAR remote sensing in coastal research and resource management, J. Coastal Res., 53, 1-5, 2009.

Brown, C. J., Smith, J. A., Lawton, P., and Anderson, J. T.: Benthic habitat mapping: a review of progress towards improved understanding of the spatial ecology of the seafloor using acoustic techniques, Estuar. Coast. Shelf S., 92, 502-520, 2011.

Brown, C. J., Sameoto, J. A., and Smith, S. J.: Multiple methods, maps, and management applications: purpose made seafloor maps in support of ocean management, J. Sea Res., 72, 1-13, 2012.

Bøe, R., Skarðhamar, J., Rise, L., Dolan, M. F., Bellec, V. K., Winsborrow, M., Skagseth, Ø., Knies, J., King, E. L., Walderhaug, O., and Chand, S.: Sandwaves and sand transport on the Barents Sea continental slope offshore northern Norway, Mar. Petrol. Geol., 60, 34-53, 2015.

Burrough, P. A.: Principles of Geographic Information Systems for Land Resource Assessment, Monographs on Soil Resources Survey 12, Oxford Science Publications, New York, USA, 193 pp., 1986.

Burrows, M. T., Robb, L., Nickell, L. A., and Hughes, D. J.: Topography as a determinant of search paths of fishes and mobile macrocrustacea on the sediment surface, J. Exp. Mar. Biol. Ecol., 285-286, 235-249, 2003.

Buscarnera, G. and Di Prisco, C.: Soil stability and flow slides in unsaturated shallow slopes: can saturation events trigger liquefaction processes?, Geotechnique, 63, 801-817, 2013.

Calder, B.: Automatic statistical processing of multibeam echosounder data, Int. Hydrogr. Rev., 4, 53-68, 2003.

Calder, B. and Mayer, L. A.: Automatic processing of high-rate, high-density multibeam echosounder data, Geochem. Geophy. Geosy., 4, 1048-1070, 2003.

Calmant, S. and Baudry, N.: Modelling bathymetry by inverting satellite altimetry data: a review, Mar. Geophys, Res., 18, 123134, 1996.

Calvert, J., Strong, J. A., Service, M., McGonigle, C., and Quinn, R.: An evaluation of supervised and unsupervised classification techniques for marine benthic habitat mapping using multibeam echosounder data, ICES J. Mar. Sci., 72, 1498-1513, 2015.

Cameron, M. J., Lucieer, V., Barrett, N. S., Johnson, C. R., and Edgar, G. J.: Understanding community-habitat associations of temperate reef fishes using fine-resolution bathymetric measures of physical structure, Mar. Ecol.-Prog. Ser., 506, 213-229, 2014.

Carbonneau, P. E., Lane, S. N., and Bergeron, N.: Feature based image processing methods applied to bathymetric measurements from airborne remote sensing in fluvial environments, Earth Surf. Proc. Land., 31, 1413-1423, 2006.

Carmichael, D. R., Linnett, L. M., Clarke, S. J., and Calder, B. R.: Seabed classification through multifractal analysis of sidescan sonar imagery, IEE P-Radar Son. Nav., 143, 140-148, 1996.

Carrara, A., Bitelli, G., and Carla, R.: Comparison of techniques for generating digital terrain models from contour lines, Int. J. Geogr. Inf. Sci., 11, 451-473, 1997.

Carron, M. J., Vogt, P. R., and Jung, W.-Y.: A proposed international long-term project to systematically map the world's ocean 
floors from beach to trench: GOMaP (Global Ocean Mapping Program), Int. Hydrogr. Rev., 2, 49-55, 2001.

Carson, M. A. and Kirby, M. J.: Hillslope form and process, Cambridge University Press, Cambridge, UK, 475 pp., 1972.

Carter, D. C.: Channel and sandstone body geometry from 3-D seismic and well control in Widuri Field, Offshore SE Sumatra, Indonesia, AAPG Bull., 87, 909-934, 2003.

Casalbore, D., Romagnoli, C., Bosman, A., and Chiocci, F.: Potential tsunamigenic landslides at Stromboli Volcano (Italy): Insight from marine DEM analysis, Geomorphology, 126, 42-50, 2011.

Chakraborty, B., Schenke, H. W., Kodagali, V., and Hagen, R.: Analysis of multibeam-Hydrosweep echo peaks for seabed characterisation, Geo-Mar. Lett., 20, 174-181, 2001.

Chorley, R. J., Malm, D. E. C., and Pogorzelski, H. A.: A new standard for measuring drainage basin shape, Am. J. Sci., 255, 138$141,1957$.

Chust, G., Grande, M., Galparsoro, I., Uriarte, A., and Borja, Á.: Capabilities of the bathymetric Hawk Eye LiDAR for coastal habitat mapping: a case study within a Basque estuary, Estuar. Coast. Shelf S., 89, 200-213, 2010.

Coggan, R. A. and Diesing, M.: Rock ridges in the central English Channel, in: Seafloor geomorphology as benthic habitat: Geo$\mathrm{Hab}$ atlas of seafloor geomorphic features and benthic habitats, Elsevier, Amsterdam, the Netherlands, 471-480, 2012.

Collet, C., Provost, J.-N., Rostaing, P. Perez, P., and Bouthemy, P.: SPOT satellite data analysis for bathymetric mapping, IEEE Image Proc., 3, 464-467, 2000.

Collier, J. S. and Humber, S. R.: Fringing reefs of the Seychelles inner granitic islands, western Indian Ocean, in: Seafloor geomorphology as benthic habitat: GeoHab atlas of seafloor geomorphic features and benthic habitats, Elsevier, Amsterdam, the Netherlands, 340-347, 2012.

Collin, A., Long, B., and Archambault, P.: Merging land-marine realms: spatial patterns of seamless coastal habitats using a multispectral LiDAR, Remote Sens. Environ., 123, 390-399, 2012.

Copeland, A., Edinger, E., Devillers, R., Bell, T., LeBLanc, P., and Wroblewski, J.: Marine habitat mapping in support of Marine Protected Area management in a subarctic fjord: Gilbert Bay, Labrador, Canada, J. Coast. Conserv., 17, 225-237, 2013.

Costa, B. M. and Battista, T. A.: The semi-automated classification of acoustic imagery for characterizing coral reef ecosystems, Int. J. Remote Sens., 34, 6389-6422, 2013.

Costa, B. M., Battista, T. A., and Pittman, S. J.: Comparative evaluation of airborne LiDAR and ship-based multibeam SoNAR bathymetry and intensity for mapping coral reef ecosystems, Remote Sens. Environ., 113, 1082-1100, 2009.

Cushman-Roisin, B. and Beckers, J.-M.: Introduction to geophysical fluid dynamics, 2nd edition, Academic Press, MA, USA, 875 pp., 2011.

Czarnecki, M. F. and Bergin, J. M.: Characteristics of the twodimensional spectrum of roughness on a seamount. Naval Research Laboratory, Washington, D.C., USA, NRL Report 9022, 26 pp., 1986.

Dartnell, P. and Gardner, J. V.: Predicting seafloor facies from multibeam bathymetry and backscatter data, Photogramm. Eng. Rem. S., 70, 1081-1091, 2004.

Davies, A. J., Wisshak, M., Orr, J. C., and Roberts, J. M.: Predicting suitable habitat for the cold-water coral Lophelia pertusa (Scleractinia), Deep-Sea Res. Pt I, 55, 1048-1062, 2008.
Dekker, A. G., Phinn, S. R., Anstee, J., Bissett, P., Brando, V. E., Casey, B., Fearns, P., Hedley, J., Klonowski, W., Lee, Z. P., Lynch, M., Lyons, M., Mobley, C., and Roelfsema, C.: Intercomparison of shallow water bathymetry, hydro-optics, and benthos mapping techniques in Australian and Caribbean coastal environments, Limnol. Oceanogr.-Meth., 9, 396-425, 2011.

De Moustier, C.: State of the art in swath bathymetry survey systems, Int. Hydrogr. Rev., 65, 25-54, 1988.

De Moustier, C. and Matsumoto, H.: Seafloor acoustic remote sensing with multibeam echo-sounders and bathymetric sidescan sonar system, Mar. Geophys. Res., 15, 27-42, 1993.

Devillers, R., Bédard, Y., Gervais, M., Jeansoulin, R., Pinet, F., Schneider, M., Bejaoui, L., Lévesque, M.-A., Salehi, M., and Zargar, A.: How to improve geospatial data usability: from metadata to quality-aware GIS community, in: Spatial data usability, an AGILE pre-conference workshop, Proceedings of the 10th AGILE International Conference on Geographic Information Science, Aalborg, Denmark, AGILE (Association of Geographic Information Laboratories in Europe), 1-8, 2007.

Diesing, M., Green, S. L., Stephens, D., Lark, R. M., Stewart, H. A., and Dove, D.: Mapping seabed sediments: comparison of manual, geostatistical, object-based image analysis and machine learning approaches, Cont. Shelf Res., 84, 107-119, 2014.

Dimri, A. P., Yasunari, T., Wiltshire, A., Kumar, P., Mathison, C., Ridley, J., and Jacob, D.: Application of regional climate models to the Indian winter monsoon over the western Himalayas, Sci. Total Environ., 468-469, S36-S47, 2013.

Dixon, T. H., Naraghi, M., McNutt, M. K., and Smith, S. M.: Bathymetric prediction from SEASAT altimeter data, J. Geophys, Res., 88, 1563-1571, 1983.

Dolan, M. F., Grehan, A. J., Guinan, J. C., and Brown, C.: Modelling the local distribution of cold-water corals in relation to bathymetric variables: Adding spatial context to deep-sea video data, Deep Sea Res. Pt I, 55, 1564-1579, 2008.

Dolan, M. F. J. and Lucieer, V. L.: Variation and uncertainty in bathymetric slope calculations using geographic information systems, Mar. Geod., 37, 187-219, 2014.

Dolan, M. F. J., Thorsnes, T., Leth, J., Al-Hamdani, Z., Guinan, J., and Van Lancker, V.: Terrain characterization from bathymetry data at various resolutions in European waters - experiences and recommendations, NGU Report 2012.045, Geological Survey of Norway, Trondheim, Norway, 2012.

Dong, J., Zhuang, D., Huang Y., and Fu, J.: Advance in multi-sensor data fusion: algorithms and applications, Sensors, 9, 7771-7784, 2009.

Douglas, B. C., McAdoo, D. C., and Cheney, R. E.: Oceanographic and geophysical applications of satellite altimetry, Rev. Geophys., 25, 875-880, 1987.

Dowling, D. R. and Sabra, K. G.: Acoustic remote sensing, Annu. Rev. Fluid Mech., 47, 221-243, 2015.

Drăguţ, L. and Blaschke, T.: Automated classification of landform elements using object-based image analysis, Geomorphology, 81, 330-344, 2006.

Drăguţ, L. and Eisank, C.: Object representations at multiple scales from digital elevation models, Geomorphology, 129, 183-189, 2011.

Drăgut,, L., Eisank, C., and Strasser, T.: Local variance for multiscale analysis in geomorphometry, Geomorphology, 130, 162172, 2011. 
Duffy, G. P. and Hughes-Clarke, J. E.: Application of spatial cross correlation to detection of migration of submarine sand dunes, $\mathrm{J}$. Geophys. Res.-Earth, 110, 1-11, 2005.

Dunkin, L. M. and McCormick, J.: Monitoring shore protection projects along the Florida panhandle using three-dimensional spatial data. Coastal Engineering Practice - Proceedings of the 2011 Conference on Coastal Engineering Practice, 742-752, 2011.

Dunkin, L. M., Wozencraft, J. M., and McCormick, J.: Changes to geomorphic and bathymetric features due to extreme storm events near East Pass inlet, Florida, Solutions to Coastal Disasters 2011, 176-187, 2011

Dunn, D. C. and Halpin, P. N.: Rugosity-based regional modeling of hard-bottom habitat, Mar. Ecol. Prog. Ser, 377, 1-11, 2009.

Du Preez, C.: A new arc-chord ratio (ACR) rugosity index for quantifying three-dimensional landscape structural complexity, Landscape Ecol., 30, 181-192, 2015.

Eisank, C., Smith, M., and Hillier, J.: Assessment of multiresolution segmentation for delimiting drumlins in digital elevation models, Geomorphology, 214, 452-464, 2014.

Elvenes, S.: Landscape mapping in MAREANO, NGU report 2013.035, Geological Survey of Norway, Trondheim, Norway, 2013.

Elvenes, S., Dolan, M. F., Buhl-Mortensen, P., and Bellec, V. K.: An evaluation of compiled single-beam bathymetry data as a basis for regional sediment and biotope mapping, ICES J. Mar. Sci., 71, 867-881, 2014.

EMODnet: European Marine Observation and Data Network (EMODnet) bathymetry portal, available at: http://www. emodnet-hydrography.eu/ (last access: 3 August 2016), 2015.

Erikstad, L., Bakkestuen, V., Bekkby, T., and Halvorsen, R.: Impact of scale and quality of digital terrain models on predictability of seabed terrain types, Mar. Geod., 36, 2-21, 2013.

Eugenio, F., Marcello, J., and Martin, J.: High-resolution maps of bathymetry and benthic habitats in shallow-water environments using multispectral remote sensing imagery, IEEE T. Geosci. Remote, 53, 3539-3549, 2015.

Evans, I. S.: General geomorphometry, derivatives of altitude, and descriptive statistics, in Spatial Analysis in Geomorphology, Methuen, London, UK, 17-90, 1972.

Evans, I. S.: An integrated system of terrain analysis and slope mapping, Z Geomorphol. Supp., 36, 274-295, 1980.

Evans, I. S.: General geomorphometry, in: Geomorphological techniques, 2nd Edn., Taylor and Francis, New York, USA, 49-62, 2003.

Evans, I. S.: Land surface derivatives: history, calculation and further development, in: Geomorphometry 2013, Nanjing, China, K3-1-K3-4, 2013.

Evans, I. S. and Minár, J.: A classification of geomorphometric variables, in Geomorphometry 2011, Redlands, USA, 105-108, 2011.

Ezhova, E., Dorokhov, D., Sivkov, V., Zhamoida, V., Ryabchuk, D., and Kocheshkova, O.: Benthic habitats and benthic communities in Southeastern Baltic Sea, Russian sector, in: Seafloor geomorphology as benthic habitat: GeoHab atlas of seafloor geomorphic features and benthic habitats, Elsevier, Amsterdam, the Netherlands, 613-621, 2012.
Fachmi, M. and Wood, L.: Quantitative seismic geomorphology of Belanak and Gabus fields, West Natuna Basin, Indonesia, AAPG Ann. Meet., 51-52, 2003.

Fernandes, M. J., Bastos, L., and Catalão, J.: The role of multimission ERS altimetry in the determination of the marine geoid in the Azores, Mar. Geod., 23, 1-16, 2000.

Feurer, D., Bailly, J.-S., Puech, C., Le Coarer, Y., and Viau, A. A.: Very-high-resolution mapping of river-immersed topography by remote sensing, Prog. Phys. Geog., 32, 403-419, 2008.

Fisher, P. F. and Tate, N. J.: Causes and consequences of error in digital elevation models, Prog. Phys. Geog., 30, 467-489, 2006.

Florinsky, I. V.: Accuracy of local topographic variables derived from digital elevation models, Int. J. Geogr. Inf. Sci., 12, 47-61, 1998.

Florinsky, I. V.: Digital terrain analysis in soil science and geology. Elsevier/Academic Press, the Netherlands, 379 pp., 2012.

Fonstad, M. A. and Marcus, W. A.: Remote sensing of stream depths with hydraulically assisted bathymetry (HAB) models, Geomorphology, 72, 320-339, 2005.

Fosså, J. H., Lindberg, B., Christensen, O., Lundälv, T., Svellingen, I., Mortensen, P. B.., and Alvsvag, J.: Mapping of Lophelia reefs in Norway: experiences and survey methods, in: Coldwater corals and ecosytems, Springer-Verlag, Berlin, Germany, 35900391, 2005.

Foster, G., Walker, B. K., and Riegl, B. M.: Interpretation of singlebeam acoustic backscatter using LiDAR-derived topographic complexity and benthic habitat classifications in a coral reef environment, J. Coastal Res., 53, 16-26, 2009.

Fox, C. G.: Objective classification of oceanic ridge-crest terrains using two-dimensional spectral models of bathymetry: Application to the Juan de Fuca Ridge, Mar. Geophys. Res., 18, 707-728, 1996.

Fox, C. G. and Hayes, D. E.: Quantitative methods for analyzing the roughness of the seafloor, Rev. Geophys., 23, 1-48, 1985.

Fu, L.-L.: Recent progress in the application of satellite altimetry to observing the mesoscale variability and the general circulation of the oceans, Rev. Geophys. Space Phys., 21, 1657-1666, 1983.

Friedman, A., Pizarro, O., Williams, S. B., and Johnson-Roberson, M.: Multi-scale measures of rugosity, slope and aspect from benthic stereo image reconstructions, PLOS One, 7, e50440, doi:10.1371/journal.pone.0050440, 2012.

Gafeira, J., Long, D., and Diaz-Doce, D.: Semi-automated characterisation of seabed pockmarks in the central North Sea, Near. Surf. Geophys., 10, 303-314, 2012.

Galparsoro, I., Borja, Á., Bald, J., Liria, P., and Chust, G.: Predicting suitable habitat for the European lobster (Homarus gammarus), on the Basque continental shelf (Bay of Biscay), using Ecological-Niche Factor Analysis, Ecol. Model., 220, 556-567, 2009.

GEBCO: General bathymetric chart of the oceans 30 arc-second global grid of elevations 2014, available at: www.gebco.net (last access: 3 August 2016), 2014

Gee, M. J. R., Watts, A. B., Masson, D. G., and Mitchell, N. C.: Landslides and the evolution of El Hierro in the Canary Islands, Mar. Geol., 177, 271-293, 2001.

Gessler, P., Pike, R., MacMillan, R. A., Hengl, T., and Reuter, H. I.: The future of geomorphometry, in: Geomorphometry: concepts, software, applications, Elsevier, Amsterdam, the Netherlands, 637-652, 2009. 
Giannoulaki, M., Machias, A., Koutsikopoulos, C., and Somarakis, S.: The effect of coastal topography on the spatial structure of anchovy and sardine, ICES J. Mar. Sci., 63, 650-662, 2006.

Gilbert, L. E. and Malinverno, A.: A characterization of the spectral density of residual ocean floor topography, Geophys. Res. Lett., 15, 1401-1404, 1988.

Gille, S. T., Metzger, E. J., and Tokmakian, R.: Seafloor topography and ocean circulation, Oceanography, 17, 47-54, 2004.

Gjerde, K. M.: Ecosystems and biodiversity in deep waters and high seas. UNEP Regional Seas Reports and Studies 178, UNEP/IUCN, Gland, Switzerland, 2006.

Goff, J. A.: A global and regional stochastic analysis of near-ridge abyssal hill morphology, J. Geophys. Res., 96, 21713-21737, 1991.

Goff, J. A.: Quantitative characteristics of abyssal hill morphology along flow line in the Atlantic Ocean, J. Geophys. Res., 97, 9183-9202, 1992.

Goff, J. A.: Quantiative classification of canyon systems on continental slopes and a possible relationship to slope curvature, Geophys. Res. Lett., 28, 4359-4362, 2001.

Goff, J. A. and Jordan, T. H.: Stochastic modelling of seafloor morphology: Inversion of Sea Beam data for second-order statistics, J. Geophys. Res., 93, 13589-13608, 1988.

Goff, J. A. and Tucholke, B. E.: Multiscale spectral analysis of bathymetry on the flank of the Mid-Atlantic Ridge: Modification of the seafloor by mass wasting and sedimentation, J. Geophys. Res., 102, 15447-15462, 1997.

Goff, J. A., Smith, W. H. F., and Marks, K. M.: The contributions of abyssal hill morphology and noise to altimetric gravity fabric, Oceanography, 17, 24-37, 2004.

Graham, D., Chen, A., and Ermisch, D.: NOAA shoreline data explorer application. Coastal GeoTools 2015, March 30-April 2, Charleston, North Carolina, USA, 2015.

Green, A. and Uken, R.: Submarine landsliding and canyon evolution on the northern KwaZuluNatal continental shelf, South Africa, Mar. Geol., 254, 152-170, 2008.

Greene, H. G., Yoklavich, M. M., Starr, R. M., O'Connell, V. M., Wakefield, W. W., Sullivan, D. E., McRea Jr., J. E., and Cailliet, G. M.: A classification scheme for deep seafloor habitats, Oceanol. Acta, 22, 663-678, 1999.

Grohmann, C. H.: Morphometric analysis in geographic information systems: applications of free software GRASS and R, Comput. Geosci., 30, 1055-1067, 2004.

Grohmann, C. H.: Effects of spatial resolution on slope and aspect derivation for regional-scale analysis, Comput. Geosci., 77, 111$117,2015$.

Guenther, G. C., Lillycrop, W. J., and Banic, J. R.: Future advancements in airborne hydrography, Int. Hydrogr. Rev., 3, 67-90, 2002.

Guinan, J., Brown, C., Dolan, M. F. J., and Grehan, A. J.: Ecological niche modelling of the distribution of cold-water coral habitat using underwater remote sensing data, Ecol. Inform., 4, 83-92, 2009.

Haflidason, H., Lien, R., Sejrup, H. P., Forsberg, C. F., and Bryn, P.: The dating and morphometry of the Storegga Slide, Mar. Petrol. Geol., 22, 123-136, 2005.

Hamylton, S. M., Hedley, J. D., and Beaman, R. J.: Derivation of high-resolution bathymetry from multispectral satellite imagery: a comparison of empirical and optimisation methods through geographical error analysis, Remote Sens., 7, 16257-16273, 2015.

Hardin, E., Mitasova, H., Tateosian, L., and Overton, M.: GIS-based analysis of coastal Lidar time-series. Springer Briefs in Computer Science, Springer, New York, USA, 84 pp., 2014.

Harris, P. T. and Baker, E. K.: Seafloor geomorphology as benthic habitat: GeoHab atlas of seafloor geomorphic features and benthic habitats, Elsevier, the Netherlands, 900 pp., 2012 a.

Harris, P. T. and Baker, E. K.: Synthesis and lessons learned, in: Seafloor geomorphology as benthic habitat: GeoHab atlas of seafloor geomorphic features and benthic habitats, Elsevier, Amsterdam, the Netherlands, 871-887, 2012b.

Harris, P. T. and Baker, E. K.: Why map benthic habitats?, in: Seafloor geomorphology as benthic habitat: GeoHab atlas of seafloor geomorphic features and benthic habitats, Elsevier, Amsterdam, the Netherlands, 3-22, 2012c.

Harris, P. T., Macmillan-Lawler, M., Rupp, J., and Baker, E. K.: Geomorphology of the oceans, Mar. Geol., 352, 4-24, 2014.

Harrison, J. W., Ferrie, F. P., Hefford, S. W., Samson, C., Kusevic, K., Mrstik, P., and Iles, P. J. W.: Finding anomalies in highdensity LiDAR point clouds, Geomatica, 63, 397-405, 2009.

Harrison, R., Bellec, V. K., Mann, D., and Wang, W.: A new approach to the automated mapping of pockmarks in multi-beam bathymetry. IEEE Image Proc., 18, 2777-2780, 2011.

Hasan, R. C., Ierodiaconou, D., and Laurenson, L.: Combining angular response classification and backscatter imagery segmentation for benthic biological habitat mapping, Estuar. Coast. Shelf S., 97, 1-9, 2012.

Hedley, J. D., Harborne, A. R., and Mumby, P. J.: Simple and robust removal of sun glint for mapping shallow-water benthos, Int. J. Remote Sens., 26, 2107-2112, 2005.

Hengl, T. and Evans, I. S.: Mathematical and digital models of the land surface, in: Geomorphometry: concepts, software, applications, Elsevier, Amsterdam, the Netherlands, 31-63, 2009.

Hengl, T. and MacMillan, R. A.: Geomorphometry - a key to landscape mapping and modelling, in: Geomorphometry: concepts, software, applications, Elsevier, Amsterdam, the Netherlands, 433-460, 2009.

Herzfeld, U. C.: Geostatistical methods for evaluation of seabeam bathymetric surveys: Case studies of Wegener Canyon, Antarctica, Mar. Geol., 88, 83-95, 1989.

Herzfeld, U. C: A method for seafloor classification using directional variograms, demonstrated for data from the western flank of the Mid-Atlantic Ridge, Math. Geol., 25, 901-924, 1993.

Herzfeld, U. C. and Higginson, C. A.: Automated geostatistical seafloor classification - principles, parameters, feature vectors and discrimination criteria, Comput. Geosci., 22, 35-52, 1996.

Heyman, W. D. and Kobara, S.: Geomorphology of reef fish spawning aggregrations in Belize and the Cayman Islands (Caribbean), in: Seafloor geomorphology as benthic habitat: GeoHab atlas of seafloor geomorphic features and benthic habitats, Elsevier, Amsterdam, the Netherlands, 387-396, 2012.

Hill, N. A., Lucieer, V., Barrett, N. S., Anderson, T. J., and Williams, S. B.: Filling the gaps: predicting the distribution of temperate reef biota using high resolution biological and acoustic data, Estuar. Coast. Shelf S., 147, 137-147, 2014.

Hillman, J. I. T., Gorman, A. R., and Pecher, I. A.: Geostatistical analysis of seafloor depressions on the southeast margin of New Zealand's South Island - investigating the impact of dynamic 
near seafloor processes on geomorphology, Mar. Geol., 360, 7083, 2015.

Hogrefe, K. R., Wright, D. J., and Hochberg, E. J.: Derivation and integration of shallow-water bathymetry: implications for coastal terrain modelling and subsequent analyses, Mar. Geod., 31, 299317,2008

Holman, R. and Haller, M. C.: Remote sensing of the nearshore, Annu. Rev. Marine Sci., 5, 95-113, 2013.

Horn, B. K. P.: Hill shading and the reflectance map, P. IEEE, 69, 14-47, 1981.

Hughes-Clarke, J. E.: The effects of fine-scale seabed morphology and texture on the fidelity of swath bathymetric sounding data, Canadian Hydrographic Conference, Victoria, Canada, 114, 1998.

Hughes-Clarke, J. E.: Dynamic motion residuals in swath sonar data: ironing out the creases, Int. Hydrogr. Rev., 4, 6-23, $2003 \mathrm{a}$.

Hughes-Clarke, J. E.: A reassessment of vessel coordinate systems: what is it that we are really aligning?, US Hydrographic Conference 2003, Biloxi, MS, USA, 1-12, 2003b.

Hughes-Clarke, J. E., Mayer, L. A., and Wells, D. E.: Shallow-water imaging multibeam sonars: a new tool for investigating seafloor processes in the coastal zone and on the continental shelf, Mar. Geophys. Res., 18, 607-629, 1996.

Hühnerbach, V., Masson, D. G., and Partners of the COSTAProject: Landslides in the North Atlantic and its adjacent seas: an analysis of their morphology, setting and behaviour, Mar. Geol., 213, 343-362, 2004.

Huvenne, V. A. I., Blondel, P., and Henriet, J. P.: Textural analyses of sidescan sonar imagery from two mound provinces in the Porcupine Seabight, Mar. Geol., 189, 323-341, 2002.

Huvenne, V. A. I., Beyer, A., de Haas, H., Dekindt, K., Henriet, J.-P., Kozachenko, M., Olu-Le Roy, K., Wheeler, A. J., and the TOBI/Pelagia 197 and CARACOLE cruise participants: The seabed appearance of different coral bank provinces in the Porcupine Seabight, NE Atlantic: results from sidescan sonar and ROV seabed mapping, in: Cold-water corals and ecosytems, SpringerVerlag, Berlin, Germany, 535-569, 2005.

IHO (International Hydrographic Organisation): IHO Standards for Hydrographic Surveys, Special publication No. 44. 5th Edition, February 2008, International Hydrographic Bureau, Monaco, 2008.

Imhof, E.: Cartographic relief presentation, Walter de Gruyter, Berlin, Germany, 389 pp., 1982.

Iordanishvili, I. K.: The peculiarities of hydrological processes in mountain reservoirs, Water Resour., 27, 617-624, 2000.

Irish, J. L. and Lillycrop, W. J.: Scanning laser mapping of the coastal zone: the SHOALS system, ISPRS J. Photogramm., 54, 123-129, 1999.

Ismail, K., Huvenne, V. A. I., and Masson, D. G.: Objective automated classification technique for marine landscape mapping in submarine canyons, Mar. Geol., 362, 17-32, 2015.

Issler, D., De Blasio, F. V., Elverhøi, A., Bryn, P., and Lien, R.: Scaling behaviour of clay-rich submarine debris flows, Mar. Petrol. Geol., 22, 187-194, 2005.

Jakobsson, M., Mayer, L., Coakley, B., Dowdeswell, J. A., Forbes, S., Fridman, B., Hodnesdal, H., Noormets, R., Pederson, R., Rebesco, M., Schenke, H. W., Zarayskaya, Y., Accettella, D., Armstrong, A., Anderson, R. M., Bienhoff, P., Camerlenghi, A., Church, I., Edwards, M., Gardner, J. V., Hall, J. K., Hell, B.,
Hestvik, O., Kristoffersen, Y., Marcussen, C., Mohammad, R., Mosher, D., Nghiem, S. V., Pedrosa, M. T., Travaglini, P. G., and Weatherall, P.: The International Bathymetric Chart of the Arctic Ocean (IBCAO) version 3.0., Geophys. Res. Lett., 39, L12609, doi:10.1029/2012GL052219/, 2012.

Jalali, M. A., Ierodiaconou, D., Monk, J., Gorfine, H., and Rattray, A.: Predictive mapping of abalone fishing grounds using remotely-sensed LiDAR and commercial catch data, Fish. Res., 169, 26-36, 2015.

James, J. W. C., Pearce, B., Coggan, R. A., and Morando, A.: Open shelf valley system, northern palaeovalley, English Channel, UK, in: Seafloor geomorphology as benthic habitat: GeoHab atlas of seafloor geomorphic features and benthic habitats, Elsevier, Amsterdam, the Netherlands, 587-596, 2012.

Jarvis, R. S. and Clifford, N. J.: Specific geomorphometry, in: Geomorphological techniques, second edition.,Taylor and Francis, New York, USA, 70-78, 2003.

Jayne, S. R., St. Laurent, L. C., and Gille, S. T.: Connections between ocean bottom topography and Earth's climate, Oceanography, 17, 65-74, 2004.

Jawak, S. D., Vadlamani, S. S., and Luis, A. J.: A synoptic review on deriving bathymetry information using remote sensing technologies: models, methods and comparisons, Adv. Remote Sens., 4, 147-162, 2015.

Jenness, J. S.: Calculating landscape surface area from digital elevation models, Wildlife Soc. B., 32, 829-839, 2004.

Jiang, M., Stewart, W., and Marra, M.: Segmentation of seafloor sidescan imagery using Markov random fields and neural networks, Oceans-IEEE, 456-461, 1993.

Johnson-Roberson, M., Pizarro, O., Williams, S. B., and Mahon, I.: Generation and visualization of large-scale three-dimensional reconstructions from underwater robotic surveys, J. Field Robot., 27, 21-51, 2010.

Jones, G. E., Cumming, R. E., and Hunt, P. R.: The use of remote sensing techniques for the location and investigation of heritage wreck sites, Adv. Arc. Ser., 19, 185-194, 2005.

Jones, K. H.: A comparison of algorithms used to compute hill slope as a property of the DEM, Comput. Geosci., 24, 315-323, 1998.

Kashani, A. G., Olsen, M. J., Parrish, C. E., and Wilson, N.: A review of LIDAR radiometric processing: from Ad Hoc intensity correction to rigorous radiometric calibration, Sensors, 15 , 28099-28128, 2015.

Kay, S., Hedley, J., and Lavender, S.: Sun glint correction of high and low spatial resolution images of aquatic scenes: a review of methods for visible and near-infrared wavelengths, Remote Sens., 1, 697-730, 2009.

Keating, B., Cherkis, N. Z., Fell, P. W., Handschmacher, D., Hey, R. N., Lazarewicz, A., Naar, D. F., Perry, R. K., Sandwell, D., Schwank, D. C., Vogt, P. R., and Zondek, B.: Field tests of SEASAT bathymetric detections, Mar. Geophys. Res., 7, 69-71, 1984.

Kennedy, D. M., Ierodiaconou, D., and Schimel, A.: Granitic coastal geomorphology: applying integrated terrestrial and bathymetric LiDAR with multibeam sonar to examine coastal landscape evolution, Earth Surf. Proc. Land., 39, 1663-1674, 2014.

Kenny, A. J., Cato, I., Desprez, G., Fader, T., Schüttenhelm, R. T. E., and Side, J.: An overview of seabed-mapping technologies in the context of marine habitat classification, ICES J. Mar. Sci., 60, 411-418, 2003. 
Klemas, V.: Remote sensing techniques for studying coastal ecosystems: an overview, J. Coastal Res., 27, 2-17, 2011a.

Klemas, V.: Beach profiling and LIDAR bathymetry: an overview with case studies, J. Coastal Res., 27, 1019-1028, 2011 b.

Klemas, V.: Airborne remote sensing of coastal features and processes: an overview, J. Coastal Res., 29, 239-255, 2013.

Knudby, A., LeDrew, E., and Brenning, A.: Predictive mapping of reef fish species richness, diversity and biomass in Zanzibar using IKONOS imagery and machine-learning techniques, Remote Sens. Environ., 114, 1230-1241, 2010.

Knudby, A., Kenchington, E., and Murillo, F. J.: Modeling the distribution of Geodia sponges and sponge grounds in the Northwest Atlantic, PLOS One, 8, e82306, doi:10.1371/journal.pone.0082306, 2013.

Konsberg Maritime: HISAS 1030 High resolution interferometric synthetic aperture sonar, available at: https://www.km.kongsberg.com/ks/web/nokbg0397.nsf/ AllWeb/86E9FFB43569CDEEC12576B9006D75C7/\$file/ HISAS_1030_brochure_v1_lowres_v2.pdf?OpenElement, last access: 3 December 2015.

Kostylev, V. E., Erlandsson, J., Ming, M. Y., and Williams, G. A.: The relative importance of habitat complexity and surface area in assessing biodiversity: fractal application on rocky shores, Ecol. Complex., 2, 272-286, 2005.

Krause, D. C. and Menard, H. W.: Depth distribution and bathymetric classification of some seafloor profiles, Mar. Geol., 3, 169193, 1965.

Krcho, J.: Morphometric analysis of relief on the basis of geometric aspect of field theory, Acta Geographica Universitatis Comenianae, Geographico-Physica, 1, 7-233, 1973.

Kukowski, N., Hampel, A., Hoth, S., and Bialas, J.: Morphotectonic and morphometric analysis of the Nazca plate and the adjacent offshore Peruvian continental slope - Implications for submarine landscape evolution, Mar. Geol., 254, 107-120, 2008.

Kunze, E. and Llewellyn Smith, S. G.: The role of small-scale topography in turbulent mixing of the global ocean, Oceanography, 17, 55-64, 2004.

Kvamme, K. L.: Recent directions and developments in geographical information systems, J. Archaeol. Res., 7, 153-201, 1999.

Kwasnitschka, T., Hansteen, T. H., Devey, C. W., and Kutterolf, S.: Doing fieldwork on the seafloor: photogrammetric techniques to yield 3-D visual models from ROV video, Comput. Geosci., 52, 218-226, 2013.

Lafon, V., Froidefond, J. M., Lahet, F., and Castaing, P.: SPOT shallow water bathymetry of a moderately turbid tidal inlet based on field measurements, Remote Sens. Environ., 81, 136-148, 2002.

Lanier, A., Romsos, C., and Goldfinger, C.: Seafloor habitat mapping on the Oregon continental margin: A spatially nested GIS approach to mapping scale, mapping methods, and accuracy quantification, Mar. Geod., 30, 51-76, 2007.

Lawrence, E., Hayes, K. R., Lucieer, V. L., Nichol, S. L., Dambacher, J. M., Hill, N. A., Barrett, N., Kool, J., and Siwabessy, J.: Mapping habitats and developing baselines in offshore marine reserves with little prior knowledge: a critical evaluation of a new approach, PloS One, 10, e0141051, doi:10.1371/journal.pone.0141051, 2015.

Lecours, V.: Terrain Attribute Selection for Spatial Ecology (TASSE), v.1.0, available at: www.marinegis.com (last access: 3 August 2016), 2015.
Lecours, V. and Devillers, R.: Assessing the spatial data quality paradox in the deep-sea, in Proceedings of spatial knowledge and information Canada 2015, 1-8, 2015.

Lecours, V., Miles, L. L., Devillers, R., and Edinger, E. N.: Data analysis towards the multiscale characterization of cold-water coral and sponge habitats in Canadian waters. Tech. Rep. REQ. No. F6160-120010, Department of Fisheries and Oceans Canada, Newfoundland and Labrador Region, St. John's, 2013.

Lecours, V., Lucieer, V. L., Dolan, M. F. J., and Micallef, A.: An ocean of possibilities: applications and challenges of marine geomorphometry, in: Geomorphometry for geosciences, International Society for Geomorphometry, Poznań, Poland, 23-26, 2015a.

Lecours, V., Devillers, R., Schneider, D. C., Lucieer, V. L., Brown, C. J., and Edinger, E. N.: Spatial scale and geographic context in benthic habitat mapping: review and future directions, Mar. Ecol. Prog. Ser., 535, 259-284, 2015 b.

Legleiter, C. J., Roberts, D. A., Marcus, W. A., and Fonstad, M. A.: Passive optical remote sensing of river channel morphology and in-stream habitat: physical basis and feasibility, Remote Sens. Environ., 93, 493-510, 2004.

Leon, J. X., Phinn, S. R., Hamylton, S., and Saunders, M. I.: Filling the "white ribbon" - a multisource seamless digital elevation model for Lizard Island, northern Great Barrier Reef, Int. J. Remote Sens., 34, 6337-6354, 2013.

Leitão, J. P., Prodanović, D., and Maksimović, Č.: Improving merge methods for grid-based digital elevation models, Comput. Geosci., 88, 115-131, 2016.

Li, F. K. and Goldstein, R. M.: Studies of multibaseline spaceborne interferometric synthetic aperture radars, IEEE T. Geosci. Remote, 28, 88-97, 1990.

$\mathrm{Li}, \mathrm{H}$. and $\mathrm{Wu}, \mathrm{J} .:$ Uncertainty analysis in ecological studies: an overview, in Scaling and uncertainty analysis in ecology: methods and applications, Springer, Dordrecht, the Netherlands, 4566, 2006.

Li, J. and Heap, A. D.: A review of comparative studies of spatial interpolation methods in environmental sciences: performance and impact factors, Ecol. Inform., 6, 228-241, 2011.

Li, K., Chen, J., Tarolli, P., Sofia, G., Feng, Z., and Li, J.: Geomorphometric multi-scale analysis for the automatic detection of linear structures on the lunar surface, Earth Sci. Front., 21, 212222, 2014.

Li, Z., Zhu, Q., and Gold, C.: Digital terrain modeling: principles and methodology. CRC Press, USA, 319 pp., 2005.

Liceaga-Correa, M. A. and Euan-Avila, J. I.: Assessment of coral reef bathymetric mapping using visible Landsat Thematic Mapper data, Int. J. Remote Sens., 23, 3-14, 2002.

Lin, A. Y.-M., Novo, A., Har-Noy, S., Ricklin, N. D., and Stamatiou, K.: Combining GeoEye-1 satellite remote sensing, UAV aerial imaging, and geophysical surveys in anomaly detection applied to archaeology, IEEE J. Sel. Top. Appl., 4, 870-876, 2011.

Louchard, E. M., Reid, R. P., Stephens, F. C., Davis, C. O., Leathers, R. A., and Downes, T. V.: Optical remote sensing of benthic habitats and bathymetry in coastal environments at Lee Stocking Island, Bahamas: a comparative spectral classification approach, Limnol. Oceanogr., 48, 511-521, 2003.

Lucieer, V. and Lamarche, G.: Unsupervised fuzzy classification and object-based image analysis of multibeam data to map deep 
water substrates, Cook Strait, New Zealand, Cont. Shelf Res., 31, 1236-1247, 2011.

Lucieer, V., Barrett, N., Hill, N., and Nichol, S. L.: Characterization of shallow inshore coastal reefs on the Tasman Peninsula, Southeastern Tasmania, Australia, in: Seafloor geomorphology as benthic habitat: GeoHab atlas of seafloor geomorphic features and benthic habitats, Elsevier, Amsterdam, the Netherlands, 481492, 2012.

Lucieer, V., Hill, N. A., Barrett, N. S., and Nichol, S.: Do marine substrate "look" and "sound" the same? Supervised classification of multibeam acoustic data using autonomous underwater vehicle images, Estuar. Coast. Shelf S., 117, 94-106, 2013.

Lucieer, V. L.: Object-oriented classification of sidescan sonar data for mapping benthic marine habitats, Int. J. Remote Sens., 29, 905-921, 2008

Ludvigsen, M., Johnsen, G., Sørensen, A. J., Lagstad, P. A., and Odegard, O.: Scientific operations combining ROV and AUV in the Trondheim Fjord, Mar. Technol. J., 48, 59-71, 2014.

Lundblad, E., Wright, D. J., Miller, J., Larkin, E. M., Rinehart, R., Naar, D. F., Donahue, B. T., Anderson, S. M., and Battista, T.: A Benthic Terrain Classification Scheme for American Samoa, Mar. Geod., 29, 89-111, 2006.

Lurton, X.: An introduction to underwater acoustics: principles and applications, 2nd edition, Springer/Praxis Publishing, Berlin, Germany, 704 pp., 2010.

Lyzenga, D. R.: Passive remote sensing techniques for mapping water depth and bottom features, Appl. Optics, 17, 379-383, 1978.

Lyzenga, D. R., Malinas, N. P., and Tanis, F. J.: Multispectral bathymetry using a simple physically based algorithm, IEEE T. Geosci. Remote, 44, 2251-2259, 2006.

Ma, S., Tao, Z., Yang, X., Yu, Y., Zhou, X., and Li, Z.: Bathymetry retrieval from hyperspectral remote sensing data in opticalshallow water, IEEE T. Geosci. Remote, 52, 1205-1212, 2014.

Mackenzie, D.: Ocean floor is laid bare by new satellite data, Science, 277, 1921, doi:10.1126/science.277.5334.1921, 1997.

Macon, C., Wozencraft, J., Park, J. Y., and Tuell, G.: Seafloor and land cover classification through airborne lidar and hyperspectral data fusion, Int. Geosci. Remote Se., II-77-II-80, 2008.

Malinverno, A.: A quantitative study of the axial topography of the Mid-Atlantic Ridge, J. Geophys. Res., 95, 2645-2660, 1990.

Malinverno, A. and Cowie, P. A.: Normal faulting and the topographic roughness of mid-ocean ridge flanks, J. Geophys. Res., 98, 17921-17939, 1993.

Malinverno, A. and Gilbert, L. E.: A stochastic model for the creation of ocean floor topography at a slow spreading center, J. Geophys. Res., 94, 1665-1675, 1989.

Mark, D. M.: Geomorphometric parameters: a review and evaluation, Geogr. Ann. A, 57, 165-177, 1975.

Marsh, I. and Brown, C.: Neural network classification of multibeam backscatter and bathymetry data from Stanton Bank (Area IV), Appl. Acoust., 70, 1269-1276, 2009.

Maritorena, S., Morel, A., and Gentili, B.: Diffuse-reflectance of oceanic shallow waters - influence of water depth and bottom albedo, Limnol. Oceanogr., 39, 1689-1703, 1994.

Martorelli, E., D’Angelo, S., Fiorentino, A., and Chiocci, F. L.: Nontropical carbonate shelf sedimentation: the archipelago Pontino (central Italy) case history, in: Seafloor geomorphology as benthic habitat: GeoHab atlas of seafloor geomorphic features and benthic habitats, Elsevier, Amsterdam, the Netherlands, 449456, 2012.

Masetti, G. and Calder, B.: Remote identification of a shipwreck site from MBES backscatter, J. Environ. Manage., 111, 44-52, 2012.

McAdoo, B. G., Pratson, L. F., and Orange, D. L.: Submarine landslide geomorphology, US continental slope, Mar. Geol., 169, 103-136, 2000.

McArthur, M. A., Brooke, B. P., Przeslawski, R., Ryan, D. A., Lucieer, V. L., Nichol, S., McCallum, A. W., Mellin, C., Cresswell, I. D., and Radke, L. C.: On the use of abiotic surrogates to describe marine benthic biodiversity, Estuar. Coast. Shelf S., 88, 21-32, 2010.

McCoy, M. D. and Ladefoged, T. N.: New developments in the use of spatial technology in archaeology, J. Archaeol. Res., 17, 263295, 2009.

McKenzie, D. and Bowin, C.: The relationship between bathymetry and gravity in the Atlantic Ocean, J. Geophys. Res., 81, 19031915, 1976.

McNutt, M.: The hunt for MH370, Science, 344, 947, doi:10.1126/science.1255963, 2014.

Metzger, E. G. and Hurlburt, H. E.: The importance of high horizontal resolution and accurate coastline geometry in modeling South China Sea Inflow, Geophys. Res. Lett., 28, 1059-1062, 2001.

Meylemans, E., Creemers, G., De Bie, M., and Paesen, J.: Revealing extensive protohistoric field systems through high resolution LIDAR data in the northern part of Belgium, Archaol. Korresponden., 45, 197-213, 2015.

Miall, A.: Architecture and sequence stratigraphy in Pleistocene fluvial systems in the Malay Basin, based on seismic time-slice analysis, AAPG Bull., 86, 1201-1216, 2003.

Micallef, A. and Mountjoy, J. J.: A topographic signature of a hydrodynamic origin for submarine gullies, Geology, 39, 115-118, 2011.

Micallef, A., Berndt, C., Masson, D. G., and Stow, D. A. V.: A technique for the morphological characterization of submarine landscapes as exemplified by debris flows of the Storegga Slide, J. Geophys. Res., 112, F02001, doi:10.1029/2006JF000505, 2007a.

Micallef, A., Masson, D. G., Berndt, C., and Stow, D. A. V.: Morphology and mechanics of submarine spreading: A case study from the Storegga Slide, J. Geophys. Res., 112, F03023, doi:10.1029/2006JF000739, 2007b.

Micallef, A., Berndt, C., Masson, D. G., and Stow, D. A. V.: Scale invariant characteristics of the Storegga Slide and implications for large-scale submarine mass movements, Mar. Geol., 247, 46$60,2008$.

Micallef, A., Masson, D. G., Berndt, C., and Stow, D. A. V.: Development and mass movement processes of the north-eastern Storegga Slide, Quaternary Sci. Rev., 28, 433-448, 2009.

Micallef, A., Le Bas, T. P., Huvenne, V. A. I., Blondel, P., Hühnerbach, V., and Deidun, A.: A multi-method approach for benthic habitat mapping of shallow coastal areas with high resolution multibeam data, Cont. Shelf Res., 39-40, 14-26, 2012a.

Micallef, A., Mountjoy, J. J., Canals, M., and Lastras, G.: Deepseated bedrock landslides and submarine canyon evolution in an active tectonic margin: Cook Strait, New Zealand., in: Submarine Mass Movements and Their Consequences, Springer, London, UK, 201-212, 2012b. 
Micallef, A., Mountjoy, J., Barnes, P. M., Canals, M., and Lastras, G.: Geomorphic response of submarine canyons to tectonic activity: Insights from the Cook Strait canyon system, New Zealand, Geosphere, 10, 905-929, 2014a.

Micallef, A., Ribó, M., Canals, M., Puig, P., Lastras, G., and Tubau, X.: Space-for-time substitution and the evolution of a submarine canyon-channel system in a passive progradational margin, Geomorphology, 221, 34-50, 2014b.

Minár, J. and Evans, I. S.: Elementary forms for land surface segmentation: the theoretical basis of terrain analysis and geomorphological mapping, Geomorphology, 95, 236-259, 2008.

Minár, J., Jenčo, M., Evans, I. S., Minár Jr., J., Kadlec, M., Krcho, J., Pacina, J., Burian, L., and Benová, A.: Third-order geomorphometric variables (derivatives): definition, computation and utilization of changes of curvatures, Int. J. Geogr. Inf. Sci., 27, 1381-1402, 2013.

Mitchell, N. C.: Susceptibility of mid-ocean ridge volcanic islands and seamounts to large-scale landsliding, J. Geophys. Res., 108, 2397, doi:10.1029/2002JB001997, 2003.

Mitchell, N. C.: Form of submarine erosion from confluences in Atlantic USA continental slope canyons, Am. J. Sci., 304, 590$611,2004$.

Mitchell, N. C.: Interpreting long-profiles of canyons in the USA Atlantic continental slope, Mar. Geol., 214, 75-99, 2005.

Mitchell, N. C. and Clarke, J. E. H.: Classification of seafloor geology using multibeam sonar data from the Scotian Shelf, Mar. Geol., 121, 143-160, 1994.

Mitchell, N. C. and Searle, R. C.: Fault scarp statistics at the Galapagos spreading centre from Deep Tow data, Mar. Geophys. Res., 20, 183-193, 1998.

Mitchell, N. C. and Somers, M. L.: Quantitative backscatter measurements with a long-range side-scan, IEEE J. Oceanic Eng., 14, 368-374, 1989.

Mitchell, N. C., Tivey, M. A., and Gente, P.: Seafloor slopes at midocean ridges from submersible observations and implications for interpreting geology from seafloor topography, Earth Planet. Sc. Lett., 183, 543-555, 2000.

Mitchell, N. C., Masson, D. G., Watts, A. B., Gee, M. J. R., and Urgeles, R.: The morphology of the submarine flanks of volcanic ocean islands: A comparative study of the Canary and Hawaiian hotspot islands, J. Volcanol. Geoth. Res., 115, 83-107, 2002.

Mitchell, N. C., Dade, W. B., and Masson, D. G.: Erosion of the submarine flanks of the Canary Islands, J. Geophys. Res., 108, 6002, doi:10.1029/2002JF000003, 2003.

Mobley, C. D., Sundman, L. K., Davis, C. O., Bowles, J. H., Downes, T. V., Leathers, R. A., Montes, M. J., Bissett, W. P., Kohler, D. D. R., Reid, R. P., Louchard, E. M., and Gleason, A.: Interpretation of hyperspectral remote-sensing imagery by spectrum matching and look-up tables, Appl. Optics, 44, 3576-3592, 2005.

Moernaut, J. and De Batist, M.: Frontal emplacement and mobility of sublacustrine landslides: Results from morphometric and seismostratigraphic analysis, Mar. Geol., 285, 29-45, 2011.

Mofield, H. O., Massell Symons, C., Londsdale, P., Gonzales, F. I., and Titov, V. V.: Tsunami scattering and earthquake faults in the deep Pacific Ocean, Oceanography, 17, 38-46, 2004.

Mohammadi, H., Rajabifard, A., and Williamson, I. P.: Enabling spatial data sharing through multi-source spatial data integration.
Global Spatial Data Infrastructure Conference, Rotterdam, the Netherlands, 1-19, 2011.

Mohn, C., Rengstorf, A., White, M., Duineveld, G., Mienis, F., Soetaert, K., and Grehan, A.: Linking benthic hydrodynamics and cold-water coral occurrences: a high-resolution model study at three cold-water coral provinces in the NE Atlantic, Prog. Oceanogr., 122, 92-104, 2014.

Monk, J., Ierodiaconou, D., Versace, V. L., Bellgrove, A., Harvey, E., Rattray, A., Laurenson, L., and Quinn, G. P.: Habitat suitability for marine fishes using presence-only modelling and multibeam sonar. Mar. Ecol. Prog. Ser., 420, 157-174, 2010.

Monk, J., Ierodiaconou, D., Bellgrove, A., Harvey, E., and Laurenson, L.: Remotely sensed hydroacoustics and observation data for predicting fish habitat suitability, Cont. Shelf Res., 31, S17S27, 2011.

Moskalik, M., Błaszczyk, M., and Jania, J.: Statistical analysis of Brepollen bathymetry as a key to determine average depths on a glacier foreland, Geomorphology, 206, 262-270, 2014a.

Moskalik, M., Tegowski, J., Grabowiecki, P., and Zulichowska, M.: Principal Component and Cluster Analysis for determining diversification of bottom morphology based on bathymetric profiles from Brepollen (Hornsund, Spitsbergen), Oceanologia, 56, 59-84, 2014b.

Mountjoy, J. J., McKean, J., Barnes, P. M., and Pettinga, J. R.: Terrestrial-style slow-moving earthflow kinematics in a submarine landslide complex, Mar. Geol., 267, 114-127, 2009.

Nayegandhi, M., Brock, J., and Wright, C.: Small-footprint, waveform-resolving lidar estimation of submerged and subcanopy topography in coastal environments, Int. J. Remote Sens., 30, 861-878, 2009.

Neidell, N. S.: Spectral studies of marine geophysical profiles, Geophysics, 31, 122-134, 1966.

NOAA (National Oceanic and Atmospheric Administration): Digital Coast, Office for Coastal Management, available at: https: //coast.noaa.gov/digitalcoast/, last access: 24 February 2016.

Normile, D.: Lost at sea, Science, 344, 963-965, 2014.

Oksanen, J. and Sarjakoski, T.: Error propagation of DEM-based surface derivatives, Comput. Geosci., 31, 1015-1027, 2005.

Palomino, D., Vázquez, J.-T., Ercilla, G., Alonso, B., LópezGonzález, N., and Díaz-del-Río, V.: Interaction between seabed morphology and water masses around the seamounts on the Motril Marginal Plateau (Alboran Sea, Western Mediterranean), Geo-Mar. Lett., 31, 465-479, 2011.

Pacheco, A., Horta, J., Loureiro, C., and Ferreira, Ó.: Retrieval of nearshore bathymetry from Landsat 8 images: a tool for coastal monitoring in shallow waters, Remote Sens. Environ., 159, 102116, 2015.

Papatheodorou, G., Geraga, M., and Ferentinos, G.: The Navarino Naval Battle Site, Greece - an integrated remote-sensing survey and a rational management approach, Int. J. Naut. Archaeol., 34, 95-109, 2005.

Parsons, B. and Sclater, J. G.: An analysis of the variation of ocean floor bathymetry and heat flow with age, J. Geophys. Res., 82, 803-827, 1977.

Passalacqua, P., Belmont, P., Staley, D. M., Simley, J. D., Arrowsmith, J. R., Bode, C. A., Crosby, C., DeLong, S. B., Glenn, N. F., Kelly, S. A., Lague, D., Sangireddy, H., Schaffrath, K., Tarboton, D. G., Wasklewicz, T., and Wheaton, J. M.: Analyzing high resolution topography for advancing the understanding of 
mass and energy transfer through landscapes: a review, EarthSci. Rev., 148, 174-193, 2015.

Passaro, S., Milano, G., D'Istanto, C., Ruggieri, S., Tonielli, R., Bruno, P. P., Sprovieri, M., and Marsella, E.: DTM-based morphometry of the Palinuro seamount (Eastern Tyrrhenian Sea): Geomorphological and volcanological implications, Geomorphology, 115, 129-140, 2010.

Passaro, S., Ferranti, L., and De Alteris, G.: The use of highresolution elevation histograms for mapping submerged terraces: Tests from the Eastern Tyrrhenian Sea and the Eastern Atlantic Ocean, Quatern. Int., 232, 238-249, 2011.

Passaro, S., Barra, M., Saggiomo, R., Di Giacomo, S., Leotta, A., Uhlen, H., and Mazzola, S.: Multi-resolution morphobathymetric survey results at the Pozzuoli-Baia underwater archaeological site (Naples, Italy), J. Archaeol. Sci., 40, 12681278,2013

Peuchen, J.: Site characterization in nearshore and offshore geotechnical projects, in: Geotechnical and geophysical site characterization 4, Taylor and Francis, London, UK, 83-112, 2013.

Peyton, L. and Boettcher, R.: Interpretation of incised valleys using new 3-D seismic techniques: A case history using spectral decomposition and coherency, The Leading Edge, 17, 1294-1296, 1998.

Pike, R. J.: The geometric signature: quantifying landslide-terrain types from Digital Elevation Models, Math. Geol., 20, 491-511, 1988.

Pike, R. J.: Goemorphometry - diversity in quantitative surface analysis, Prog. Phys. Geog., 24, 1-20, 2000.

Pike, R. J., Evans, I. S., and Hengl, T.: Geomorphometry: a brief guide, in: Geomorphometry: concepts, software, applications, Elsevier, Amsterdam, the Netherlands, 3-30, 2009.

Pirtle, J. L., Weber, T. C., Wilson, C. D., and Rooper, C. N.: Assessment of trawlable and untrawlable seafloor using multibeamderived metrics, Methods Oceanogr., 12, 18-35, 2015.

Pittman, S. J., Costa, B. M., and Battista, T. A.: Using lidar bathymetry and boosted regression trees to predict the diversity and abundance of fish and corals, J. Coastal Res., 53, 27-38, 2009

Podobnikar, T., and Székely, B.: Towards the automated geomorphometric extraction of talus slopes in Martian landscapes, Planet. Space Sci., 105, 148-158, 2015.

Pohl, C. and van Genderen, J. L.: Multisensor image fusion in remote sensing: concepts, methods and applications, Int. J. Remote Sens., 19, 823-854, 1998.

Posamentier, H. W.: Depositional elements associated with a basin floor channel-levee system: Case study from the Gulf of Mexico, Mar. Petrol. Geol., 20, 677-690, 2003.

Posamentier, H. W. and Kolla, V.: Seismic geomorphology and stratigraphy of depositional elements in deep-water settings, J. Sediment. Res., 73, 367-388, 2003.

Posamentier, H. W., Dorn, G. A., Cole, M. J., Beierle, C. W., and Ross, S. P.: Imaging elements of depositional systems with 3D seismic data: a case study, SEPM, Gulf Coast Section, 17th Annual Research Conference, 213-228, 1996.

Posamentier, H. W., Meizarwin, P. S., and Wisman, T.: Deep water depositional systems - ultra-deep Makassar Strait, Indonesia, in: Deep-water reservoirs of the world, SEPM, Gulf Coast Section, 20th Annual Research Conference, 806-816, 2000.
Pratson, L. F. and Ryan, W. B. F.: Automated drainage extraction in mapping the Monterey submarine drainage system, California margin, Mar. Geophys. Res., 18, 757-777, 1996.

Preston, J. M., Christney, A. C., Bloomer, S. F., and Beaudet, I. L.: Seabed classification of multibeam sonar images, Oceans-IEEE, 2616-2623, 2001.

Purkis, S. J., Graham, N. A. J., and Riegl, B. M.: Predictability of reef fish abundance using remote sensing data in Diego Garcia (Chagos Archipelago), Coral Reefs, 27, 167-178, 2008.

Qin, C.-Z., Bao, L.-L., Zhu, A.-X., Hu, X.-M., and Qin, B.: Artificial surfaces simulating complex terrain types for evaluating grid-based flow algorithms, Int. J. Geogr. Inf. Sci., 27, 10551072, 2013.

Quadros, N. D., Collier, P. A., and Fraser, C. S.: Integration of bathymetric and topographic lidar: a preliminary investigation. Int. Arch. Photogrammetry, Remote Sens. Spat. Inf. Sci., 37, 315-320, 2008.

Ramillien, G. and Cazenave, A.: Global bathymetry derived from altimeter data of the ERS-1 geodetic mission, J. Geodyn., 23, 129-149, 1997.

Rattray, A., Ierodiaconnu, D., Monk, J., Versace, V. L., and Laurenson, L. J. B.: Detecting patterns of change in benthic habitats by acoustic remote sensing, Mar. Ecol. Prog. Ser., 477, 1-13, 2013.

Rattray, A., Ierodiaconou, D., Monk, J., Laurenson, L. J. B., and Kennedy, P.: Quantification of spatial and thematic uncertainty in the application of underwater video for benthic habitat mapping, Mar. Geod., 37, 315-336, 2014.

Rengstorf, A. M., Grehan, A. J., Yesson, C., and Brown, C.: Towards high-resolution habitat suitability modelling of vulnerable marine ecosystems in the deep-sea: resolving terrain attribute dependencies, Mar. Geod., 35, 343-361, 2012.

Rengstorf, A. M., Yesson, C., Brown, C., and Grehan, A. J.: Highresolution habitat suitability modelling can improve conservation of vulnerable marine ecosystems in the deep sea, J. Biogeogr., 40, 1702-1714, 2013.

Rengstorf, A. M., Mohn, C., Brown, C., Wisz, M. S., and Grehan, A. J.: Predicting the distribution of deep-sea vulnerable marine ecosystems using high-resolution data: considerations and novel approaches, Deep Sea Res. Pt I, 93, 72-82, 2014

Reuter, H. I., Hengl, T., Gessler, P., and Soille, P.: Preparation of DEMs for geomorphometric analysis, in: Geomorphometry: concepts, software, applications, Elsevier, Amsterdam, the Netherlands, 87-120, 2009.

Rigol-Sanchez, J. P., Stuart, N., and Pulido-Bosch, A.: ArcGeomorphometry: a toolbox for geomorphometric characterisation of DEMs in the ArcGIS environment, Comput. Geosci., 85, 155$163,2015$.

Robinson, L. M., Elith, J., Hobday, A. J., Pearson, R. G., Kendall, B. E., Possingham, H. P., and Richardson, A. J.: Pushing the limits in marine species distribution modelling: lessons from the land present challenges and opportunities, Global Ecol. Biogeogr., 20, 211-226, 2011.

Roman, C. and Singh, H.: Consistency based error evaluation for deep sea bathymetric mapping with robotic vehicles, in: Proceedings of the 2006 IEEE international conference on robotics and automation, Orlando, FL, USA, 3568-3574, 2006.

Ross, L. K., Ross, R. E., Stewart, H. A., and Howell, K. L.: The influence of data resolution on predicted distribution and estimates of extent of current protection of three "listed" deep-sea habitats, 
PloS One, 10, e0140061, doi:10.1371/journal.pone.0140061, 2015.

Ross, R. E. and Howell, K. L.: Use of predictive habitat modelling to assess the distribution and extent of the current protection of "listed" deep-sea habitats, Divers. Distrib., 19, 433-445, 2013.

Rovere, M., Gamberi, F., Mercorella, A., and Leidi, E.: Geomorphometry of a submarine mass-transport complex and relationships with active faults in a rapidly uplifting margin (Gioia Basin, NE Sicily margin), Mar. Geol., 356, 31-43, 2014.

Roy, S., Hovland, M., Noormets, R., and Olaussen, S.: Seepage in Isfjorden and its tributary fjords, West Spitsbergen, Mar. Geol., 363, 146-159, 2015.

Samadzadeghan, F.: Data integration related to sensors, data and models, Int. Soc. Photogramm., Istanbul, Turkey, 2004.

Sandwell, D. T. and Smith, W. H. F.: Bathymetric estimation, in: Satellite altimetry and Earth Sciences: a handbook of techniques and applications, Academic Press, San Diego, USA, 441-458, 2001.

Sandwell, D. T., Gille, S. T., and Smith, W. H. F.: Bathymetry from space: oceanography, geophysics, and climate. Geoscience Profesional Services, Bethesda, Maryland, USA, 2002.

Sappington, J. M., Longshore, K. M., and Thomson, D. B.: Quantifiying Landscape Ruggedness for Animal Habitat Anaysis: A case Study Using Bighorn Sheep in the Mojave Desert, J. Wildlife Manage., 71, 1419-1426, 2007.

Schabber, G. G., Pike, R. J., and Berlin, G. L.: Terrain-analysis procedures for modelling radar back-scatter, Open-file report 791088, U.S. Geological Survey, 61 pp., 1979.

Schimel, A. C. G., Healy, T. R., Johnson, D., and Immenga, D.: Quantitative experimental comparison of single-beam, sidescan, and multibeam benthic habitat maps, ICES J. Mar. Sci., 67, 1766-1779, 2010a.

Schimel, A. C. G., Healy, T. R., McComb, P., and Immenga, D.: Comparison of a self-processed EM3000 multibeam echosounder dataset with a QTC View habitat mapping and a sidescan sonar imagey, Tamaki Strait, New Zealand, J. Coastal Res., 26, 714-725, 2010b.

Serway, R. A. and Beichner, R. J.: Physics for scientists and engineers (Saunders golden sunburst series), 2nd edition, Saunders College Publishing, Philadelphia, USA, 1072 pp., 1983.

Schimel, A. C., Ierodiaconou, D., Hulands, L., and Kennedy, D. M.: Accounting for uncertainty in volumes of seabed change measured with repeat multibeam sonar surveys, Cont. Shelf Res., 111, 52-68, 2015.

Shary, P. A., Sharaya, L. S., and Mitusov, A. V.: The problem of scale-specific and scale-free approaches in geomorphometry, Geogr. Fis. Din. Quat., 28, 81-101, 2005.

Shaw, J., Piper, D. J. W., Fader, G. B. J., King, E. L., Todd, B. J., Bell, T., Batterson, M. J., and Liverman, D. G. E.: A conceptual model of the deglaciation of Atlantic Canada, Quaternary Sci. Rev., 25, 2059-2081, 2006.

Shaw, P. R.: Ridge segmentation, faulting and crustal thickness in the Atlantic Ocean, Nature, 358, 490-493, 1992.

Shaw, P. R. and Lin, J.: Causes and consequences of variations in faulting style at a Mid-Atlantic Ridge. J. Geophys. Res., 98, 21839-21851, 1993.

Shaw, P. R. and Smith, D. K.: Statistical methods for describing seafloor topography, Geophys. Res. Lett., 14, 1061-1064, 1987.
Shaw, P. R. and Smith, D. K.: Robust description of statistically heterogeneous seafloor topography through its slope distribution, J. Geophys. Res., 95, 8705-8722, 1990.

Shih, P. T.-Y., Chen, Y.-H., and Chen, J.-C.: Historic shipwreck study in Dongsha Atoll with bathymetric LiDAR, Archaeol. Prospect., 21, 139-146, 2014.

Sieglitz, T. C.: The Yongala's "Halo of Holes" - systematic bioturbation close to a shipwreck, in: Seafloor geomorphology as benthic habitat: GeoHab atlas of seafloor geomorphic features and benthic habitats, Elsevier, Amsterdam, the Netherlands, 277 287, 2012.

Smith, D. K. and Shaw, P. R.: Using topographic slope distributions to infer seafloor patterns, IEEE J. Oceanic Eng., 14, 338-347, 1989.

Smith, D. P., Kvitek, R.., Iampietro, P. J., and Wong, K.: Twentynine months of geomorphic change in upper Monterey Canyon (2002-2005), Mar. Geol., 236, 79-94, 2007.

Smith, M. J., Paron, P., and Griffiths, J. S.: Geomorphological mapping: methods and applications. Developments in Earth Surface Processes Vol. 15, Elsevier Science, the Netherlands, 610 pp., 2011.

Smith, T. A. and McConnaughey, R. A.: The applicability of sonars for habitat mapping: a bibliography, US Dep. Commer., NOAA Tech. Memo. NMFS-AFSC-317, 129 pp., 2016.

Smith, W. H. F.: On the accuracy of digital bathymetric data, J. Geophys. Res., 98, 9591-9603, 1993.

Smith, W. H. F.: Introduction to this special issue on bathymetry from space, Oceanography, 17, 6-7, 2004.

Smith, W. H. F.: Seafloor tectonic fabric from satellite altimetry, Annu. Rev. Earth Planet. Sci., 26, 697-738, 1998.

Smith, W. H. F. and Sandwell, D. T.: Bathymetry prediction from dense satellite altimetry and sparse shipboard bathymetry, J. Geophys. Res., 99, 12803-21824, 1994.

Smith, W. H. F. and Sandwell, D. T.: Global sea floor topography from satellite altimetry and ship depth soundings, Science, 277, 1956-1962, 1997.

Smith, W. H. F. and Marks, K. M.: Seafloor in the Malaysia Airlines flight MH370 search area, EOS. T. Am. Geophys. Un., 95, 173180, 2014.

Smith, W. H. F. and Sandwell, D. T.: Bathymetry prediction from dense satellite altimetry and sparse shipboard bathymetry, J. Geophys. Res., 99, 12803-21824, 1994.

Smith, W. H. F. and Wessel, P.: Gridding with continuous curvature spline in tension, Geophysics, 55, 293-305, 1990.

Sofia, G., Pirotti, F., and Tarolli, P.: Variations in multiscale curvature distribution and signatures of LiDAR DTM errors, Earth Surf. Proc. Land., 38, 1116-1134, 2013.

Solan, M., Germano, J. D., Rhoads, D. C., Smith, C., Michaud, E., Parry, D., Wenzhöfer, F., Kennedy, B., Henriques, C., Battle, E., Carey, D., Iocco, L., Valente, R., Watson, J., and Rosenberg, R.: Towards a greater understanding of pattern, scale and process in marine benthic systems: a picture is worth a thousand worms, J. Exp. Mar. Biol. Ecol., 285-286, 313-338, 2003.

Solsten, B. L. and Aitken, A. E.: An application of GIS techniques to assess the risk of disturbance of archaeological sites by mass movement and marine flooding in Auyuittuq National Park Reserve, Nunavut., Geogr. Phys. Quatern., 60, 81-92, 2006. 
Speight, J. G.: A parametric approach to landform regions, in: Progress in geomorphology: papers in honour of David L. Linton, Alden Press, London, UK, 239-250, 1974.

Speight, M. and Henderson, P.: Marine ecology, concepts and applications, Wiley-Blackwell, Chichester, UK, 2010.

Stojic, M., Chandler, J., Ashmore, P., and Luce, J.: The assessment of sediment transport rates by automated digital photogrammetry, Photogramm. Eng. Rem. S., 64, 387-395, 1998.

Stoker, J. M., Tyler, D. J., Turnipseed, D. P., Van Wilson Jr., K., and Oimoen, M. J.: Integrating disparate lidar datasets for a regional storm tide inundation analysis of hurricane Katrina, J. Coastal Res., 53, 66-72, 2009.

Storlazzi, C. D., Fregoso, T. A., Figurski, J. D., Freiwald, J., Lonhart, S. I., and Finlayson, D. P.: Burial and exhumation of temperate bedrock reefs as elucidated by repetitive high-resolution sea floor sonar surveys: spatial patterns and impacts to species' richness and diversity, Cont. Shelf Res., 55, 40-51, 2013.

Stow, D. A. V., Hernandez-Molina, F. J., Llave, E., Sayago-Gil, M., Diaz del Rio, V., and Branson, A.: Bedform-velocity matrix: The estimation of bottom current velocity from bedform observations, Geology, 37, 327-330, 2009.

Stretch, R. C., Mitchell, N. C., and Portaro, R. A.: A morphometric analysis of the submarine volcanic ridge south-east of Pico Island, Azores, J. Volcanol. Geoth. Res., 156, 35-54, 2006.

Stumpf, R. P., Holderied, K., and Sinclair, M.: Determination of water depth with high-resolution satellite imagery over variable bottom types, Limnol. Oceanogr., 48, 547-556, 2003.

Su, H., Liu, H., Wang, L., Filippi, A. M., Heyman, W. D., and Beck, R. A.: Geographically adaptive inversion model for improving bathymetric retrieval from satellite multispectral imagery, IEEE T. Geosci. Remote, 52, 465-476, 2014.

Tang, G., Liu, X., Fang, L., and Luo, M.: A review on the scale issue in DEMs and digital terrain analysis.,Geomatics and Information Science of Wuhan University, 31, 1059-1066, 2006.

Teide Group: Morphometric interpretation of the northwest and southeast slopes of Tenerife, Canary Islands, J. Geophys. Res., 102, 20325-20342, 1997.

Temme, A. J. A. M., Heuvelink, G. B. M., Schoorl, J. M., and Claessens, L.: Geostatistical simulation and error propagation in geomorphometry, in: Geomorphometry: concepts, software, applications, Elsevier, Amsterdam, the Netherlands, 121-140, 2009

Tempera, F., Giacomello, E., Mitchell, N. C., Campos, A. S., Braga Henriques, A., Bashmachnikov, I., Martins, A., Mendonça, A., Morato, T., Colaço, A., Porteiro, F. M., Catarino, D., Gonçalves, J., Pinho, M. R., Isidro, E. J., Santos, R. S., and Menezes, G.: Mapping the Condor seamount seafloor environment and associated biological assemblages (Azores, NE Atlantic), in: Seafloor geomorphology as benthic habitat: GeoHab atlas of seafloor geomorphic features and benthic habitats, Elsevier, Amsterdam, the Netherlands, 807-818, 2012.

Thiers, L., Louzao, M., Ridoux, V., Corre, M. L., Jaquemet, S., and Weimerskirch, H.: Combining methods to describe important marine habitats for top predators: applications to identify biological hotspots in tropical waters, PLoS ONE, 9, e115057, doi:10.1371/journal.pone.0115057, 2014

Tong, R., Purser, A., Guinan, J., and Unnithan, V.: Modeling the habitat suitability of deep-water gorgonian corals based on terrain variables, Ecol. Inform., 13, 123-132, 2013.
Turrero, P., Domínguez-Cuesta, M.-J., Jiménez-Sánchez, M., and García-Vázquez, E.: The spatial distribution of Palaeolithic human settlements and its influence on palaeoecological studies: a case from Northern Iberia, J. Archaeol. Sci., 40, 4127-4138, 2013.

Usery, E. L., Finn, M. P., and Starbuck, M.: Integrating data layers to support the national map of the United States, Int. Cartogr. Conf., Corua, Spain, 2005.

Vachtman, D., Mitchell, N. C., and Gawthorpe, B.: Morphologic signatures in submarine canyons and gullies, central USA Atlantic continental margins, Mar. Petrol. Geol., 41, 250-263, 2013.

van Lancker, V., Moerkerke, G., Du Four, I., Verfaillie, E., Rabaut, M., and Degraer, S.: Fine-scale geomorphological mapping of sandbank environments for the prediction of macrobenthic occurrences, Belgian part of the North Sea, in: Seafloor geomorphology as benthic habitat: GeoHab atlas of seafloor geomorphic features and benthic habitats, Elsevier, Amsterdam, the Netherlands, 251-260, 2012.

Van Rein, H. B., Brown, C. J., Quinn, R., and Breen, J.: A review of sublittoral monitoring methods in temperate waters: a focus on spatial scale, Underwater Technol., 28, 99-113, 2009.

Vierod, A. D. T., Guinotte, J. M., and Davies, A. J.: Predicting the distribution of vulnerable marine ecosystems in the deep sea using presence-background models, Deep-Sea Res. II, 99, 6-18, 2014.

Wang, C. K. and Philpot, W. D.: Using airborne bathymetric LiDAR to detect bottom type variation in shallow waters, Remote Sens. Environ., 106, 123-135, 2007.

Watts, A. B.: On geoid heights derived from the GEOS 3 altimeter data along the Hawaiian-Emperor seamount chain, J. Geophys. Res., 84, 3817-3826, 1979.

Watts, A. B. and Ribe, N. M.: On geoid heights and flexure of the lithosphere at seamounts, J. Geophys. Res., 89, 11152-11170, 1984.

Wedding, L. M., Friedlander, A. M., McGranaghan, M., Yost, R. S., and Monaco, M. E.: Using bathymetric LiDAR to define nearshore benthic habitat complexity: implications for management of reef fish assemblages in Hawaii, Remote Sens. Environ. 112, 4159-4165, 2008.

Weiss, A. D.: Topographic Position and Landform Analysis (poster), ESRI User Conference, San Diego, USA, 2001.

Wessel, P. and Chandler, M. T.: The spatial and temporal distribution of marine geophysical surveys, Acta Geophys., 59, 55-71, 2011.

Westaway, S. J., Lane, S. N., and Hicks, D. M.: Remote survey of large-scale braided rivers using digital photogrammetry and image analysis, Int. J. Remote Sens., 24, 795-816, 2003.

White, M., Mohn, C., and Orren, M. J.: Physical processes and seamount productivity, in: Seamounts: ecology, fisheries and conservation, Blackwell Publishing, UK, 65-84, 2007.

Whittingham, M. J., Percival, S. M., and Brown, A. F.: Nest-site selection by golden plover: why do shorebirds avoid nesting on slopes?, J. Avian Biol., 33, 184-190, 2002.

Wilson, M. F. J.: Deep sea habitat mapping using a Remotely Operated Vehicle: mapping and modelling seabed terrain and benthic habitat at multiple scales in the Porcupine Seabight, SW Ireland, PhD Thesis, National University of Ireland, Galway, Ireland, 2006. 
Wilson, M. F. J., O'Connell, B., Brown, C., Guinan, J. C., and Grehan, A. J.: Multiscale Terrain Analysis of Multibeam Bathymetry Data for Habitat Mapping on the Continental Slope, Mar. Geod., 30, 3-35, 2007.

Winterbottom, S. J. and Gilvear, D. J.: Quantification of channel bed morphology in gravel-bed rivers using airborne multispectral imagery and aerial photography, Regul. River., 13, 489-499, 1997.

Wise, S. M.: The effect of GIS interpolation errors on the use of digital elevation models in geomorphology, in: Landform monitoring, modelling and analysis, Wiley, Chichester, UK, 139-164, 1998.

Wood, J.: The Geomorphological Characterisation of Digital Elevation Models, PhD Thesis, University of Leicester, UK, 1996.

Wood, J.: Landserf Version 2.3, available at: www.landserf.org (last access: 3 August 2016), 2009.

Wood, L. J.: Quantitative seismic geomorphology and reservoir architecture of clastic depositional systems: the future of uncertainty analysis in exploration and production, AAPG Ann. Meet., 182-183, 2003.

Wood, L. J. and Dragicevic, S.: GIS-based multicriteria evaluation and fuzzy sets to identify priority sites for marine protection, Biodivers. Conserv., 16, 2539-2558, 2007.

Wright, D. J., Pendleton, M., Boulware, J., Walbridge, S., Gerlt, B., Eslinger, D., Sampson, D., and Huntley, E.: ArcGIS Benthic Terrain Modeler (BTM), v. 3.0, Environmental Systems Research Institute, NOAA Coastal Services Center, Massachusetts Office of Coastal Zone Management, 2012.
Yang, F., Li, J., Wu, Z., Jin, X., Chu, F., and Kang, Z.: A postprocessing method for the removal of refraction artifacts in multibeam bathymetry data, Mar. Geod., 30, 235-247, 2007.

Zavalas, R., Ierodiaconou, D., Ryan, D., Rattray, A., and Monk, J.: Habitat classification of temperate marine macroalgal communities using bathymetric LiDAR, Remote Sens., 6, 2154-2175, 2014.

Zeng, H. L. and Hentz, T. F.: High-frequency sequence stratigraphy from seismic sedimentology applied to Miocene, Vermilion Block 50, Tiger Shoal area, offshore Louisiana, AAPG Bull., 88, 153-174, 2004.

Zevenbergen, L. W. and Thorne, C.: Quantitative analysis of land surface topography, Earth Surf. Proc. Land., 12, 47-56, 1987.

Zhang, J.: Multi-source remote sensing data fusion: status and trends, Int. J. Image Data Fusion, 1, 5-24, 2010.

Zhang, J., Atkinson, P. M., and Goodchild, M. F.: Scale in spatial information and analysis, CRC Press, Boca Raton, FL, USA, 2014.

Zhou, Q. and Liu, X.: Analysis of errors of derived slope and aspect related to DEM data properties, Comput. Geosci., 30, 369-378, 2004.

Zieger, S., Stieglitz, T., and Kininmonth, S.: Mapping reef features from multibeam sonar data using multiscale morphometric analysis, Mar. Geol., 264, 209-217, 2009. 